\title{
CAIO CIPRIANO BARBOSA
}

Estudo da carburação de ferro esponja simultânea à reforma catalítica de metano para redução direta 



\title{
CAIO CIPRIANO BARBOSA
}

\section{Estudo da carburação de ferro esponja simultânea à reforma catalítica de metano para redução direta}

\section{Versão corrigida}

\author{
Dissertação apresentada à

Escola Politécnica da \\ Universidade de São Paulo para \\ obtenção do título de Mestre em \\ Ciências.
}

Orientador: Prof. Dr. Marcelo Breda Mourão 
Autorizo a reprodução e divulgação total ou parcial deste trabalho, por qualquer meio convencional ou eletrônico, para fins de estudo e pesquisa, desde que citada a fonte.

Este exemplar foi revisado e alterado em relação à versão original, sob responsabilidade única do autor e com a anuência de seu orientador.

São Paulo, 18 de novembro de 2020.

Assinatura do autor

Assinatura do orientador

Catalogação-na-publicação

Barbosa, Caio

Estudo da carburação de ferro esponja simultânea à reforma catalítica de metano para redução direta / C. Barbosa - versão corr. -- São Paulo, 2020.

$107 \mathrm{p}$.

Dissertação (Mestrado) - Escola Politécnica da Universidade de São Paulo. Departamento de Engenharia Metalúrgica e de Materiais.

1.Redução direta 2.Carburação 3.Pirometalurgia 4.Metalurgia extrativa ferrosa 5.Catálise I.Universidade de São Paulo. Escola Politécnica. Departamento de Engenharia Metalúrgica e de Materiais II.t. 
Nome: Caio Cipriano Barbosa

Título: Estudo da carburação de ferro esponja simultânea à reforma catalítica de metano para redução direta

Dissertação apresentada à Escola Politécnica da Universidade de São Paulo para obtenção do título de Mestre em Ciências.

Área de concentração: Engenharia Metalúrgica e de Materiais

Aprovado em:

\section{Banca Examinadora}

Prof. Dr. Marcelo Breda Mourão

Instituição: Escola Politécnica da USP

Julgamento:

Prof. Dr. Alberto Eloy Anduze Nogueira

Instituição: Instituto Federal de São Paulo - Itaquaquecetuba

Julgamento:

Dr. João Batista Ferreira Neto

Instituição: Companhia Brasileira de Metalurgia e Mineração - CBMM

Julgamento: 


\section{Agradecimentos}

Primeiramente, agradeço a Deus, à Natureza e ao Universo por todas as benções, todas as oportunidades e todos os caminhos que me permitiram chegar até aqui.

Agradeço à minha esposa, Malu, pelo companheirismo, pela paciência e pela maravilhosa relação que construímos e construiremos juntos. Te amo!

Agradeço aos meus pais por todo amor, carinho e oportunidades. Agradeço aos meus ancestrais por todo esforço que fizeram para que nossa família colhesse os frutos do amor e do sucesso.

Um muito obrigado ao Tiago Ramos Ribeiro pela motivação, orientação e conversas a respeito deste trabalho.

Agradeço ao Prof. Marcelo Breda Mourão pela orientação e pela paciência ao longo do mestrado.

Agradeço ao Instituto de Pesquisas Tecnológicas e à Universidade de São Paulo pelos ambientes ricos e construtivos que permitiram 0 desenvolvimento deste e de tantos outros projetos.

Agradeço à Fundação de Apoio aos Institutos de Pesquisas Tecnológicas (FIPT) e à CAPES pelo apoio e financiamento.

Um obrigado especial ao Omar Ogusuku Alexandrino, ao Gilmar Vieira Avancini, ao Valter Joaquim de Oliveira, ao Akira Mizoguchi e ao saudoso José Carlos Luiz por toda operação, montagem e desenvolvimento da estrutura experimental. Vocês são demais!!

Obrigado ao Gilmar Alves de Almeida, Karina Torre da Fonseca, Alzira Vicente Correa, Maciel Santos Luz, Sérgio Soares de Lima e todos aqueles não nomeados que colaboraram com as análises do projeto. 


\section{Resumo}

O processo Energiron é uma tecnologia de produção de ferro esponja ou DRI (Direct Reduced Iron) no qual os gases redutores ( $\mathrm{CO}$ e $\left.\mathrm{H}_{2}\right)$, responsáveis pela redução das pelotas de minério de ferro, são produzidos no mesmo reator onde ocorre a redução. A produção destes gases ocorre pela reforma de metano, utilizando a superfície do DRI recém-produzido como catalisador. Neste cenário, é possível que o ferro esponja seja carburado.

É encontrada na literatura uma vasta gama de trabalhos que estudem a reforma de metano e também a carburação de ferro. Entretanto, não há trabalhos que tratem da reforma do metano e da carburação do DRI simultaneamente. Desta forma, o objetivo do presente trabalho é promover um estudo da carburação do ferro esponja simultânea à reforma do metano, com foco na análise cinética da carburação do DRI.

Foi desenvolvida uma metodologia de estudo baseada em experimentos de carburação utilizando uma retorta metálica, na qual o DRI foi exposto a misturas gasosas com diferentes composições. Alteraram-se a temperatura e o tempo dos ensaios, além da relação $\mathrm{CH}_{4} / \mathrm{H}_{2} \mathrm{O}$ das misturas gasosas, com o intuito de avaliar os diversos níveis de carburação do DRI.

Os resultados mostraram que os teores finais de carbono do DRI foram maiores conforme o incremento do tempo e da temperatura dos ensaios e do valor da relação $\mathrm{CH}_{4} / \mathrm{H}_{2} \mathrm{O}$ nas misturas gasosas. A conversão do metano através da reforma é maior com a temperatura e independe do tempo. A análise cinética dos resultados apontou que o controle da carburação em temperaturas entre $900^{\circ} \mathrm{C}$ e $1000^{\circ} \mathrm{C}$ se dá por reação química. O carbono incorporado ao ferro, quando superior ao limite de saturação, se precipita preferencialmente na forma de cementita. 


\begin{abstract}
The Energiron process is a direct reduction technology whose main product is the direct reduced iron (DRI). The DRI is produced by the passage of reducing gases $\left(\mathrm{CO}\right.$ and $\left.\mathrm{H}_{2}\right)$ through a bed of iron ore pellets. These gases are produced by methane reforming using the newly produced DRI's surface as a catalyst, in the same reactor where the reduction occurs. In this scenario, it is possible that sponge iron is carburized.

A wide range of studies regarding the methane reforming as well as iron carburization are found in the literature. However, there are no papers that deal with methane reforming and DRI carburization simultaneously. Thus, the objective of the present work is to promote a study of sponge iron pellets carburization simultaneously with methane reforming, focusing on the kinetics analysis of DRI carburization.

A methodology based on carburization experiments was developed using a metal reactor, in which DRI was exposed to gas mixtures with different compositions. The temperature and time of the tests were changed, as well as the $\mathrm{CH}_{4} / \mathrm{H}_{2} \mathrm{O}$ ratio of the gas mixtures, in order to evaluate the different carburization levels of the DRI.

The results showed that at higher temperatures and tests duration, as well as higher $\mathrm{CH}_{4} / \mathrm{H}_{2} \mathrm{O}$ ratios in the gas mixtures, the final carbon content of DRI was higher. The conversion of methane through reforming, which is independent of time, was higher at higher temperatures. The kinetic analysis of the results indicated that chemical reaction is the rate controlling of DRI carburization at temperatures between 900 and $1000{ }^{\circ} \mathrm{C}$. Carbon incorporated into iron, above saturation level, precipitates preferentially in the form of cementite.
\end{abstract}




\section{Lista de Figuras}

Figura 1 - Diagrama simplificado do processo Midrex. 4

Figura 2 - Diagrama simplificado do processo HyL/Energiron-ZR. 5

Figura 3 - Gráficos de estabilidade de fases e composições gasosas de equilíbrio para diversas reações de redução de minérios de ferro com $\mathrm{CO}$ e $\mathrm{H}_{2}$. 7

Figura 4 - Composições gasosas, consumo ou deposição de carbono e predominância de fases para o equilíbrio termodinâmico da reação 12 em função da temperatura.

Figura 5 - Padrão de difração de raios-x de diferentes amostras de minério de ferro expostas à mistura de reação $\left(35 \% \mathrm{CH}_{4}-55 \% \mathrm{H}_{2}-10 \% \mathrm{Ar}\right)$, em diferentes tempos de ensaio.

Figura 6 - A) Fração de cementita em função da temperatura e do tempo para reações de minério de ferro com misturas $35 \% \mathrm{CH}_{4}-55 \% \mathrm{H}_{2}-10 \%$ Ar. B) Taxa de formação de cementita em função da temperatura, considerando apenas os intervalos em que havia crescimento da fração de cementita.

Figura 7 - A) Fração de cementita em função do tempo para reação de decomposição da cementita em atmosfera de argônio para diferentes temperaturas. B) Taxa de decomposição da cementita em função da temperatura. 13

Figura 8 - Diagrama de equilíbrio metaestável Fe-C 14

Figura 9 - Porcentagem mássica de carbono em função do tempo a $1000^{\circ} \mathrm{C} .15$ Figura 10 - Taxa global, taxa de carburação e taxa de descarburação, em função da porcentagem de carbono a $1000^{\circ} \mathrm{C}$.

Figura 11 - Taxa de descarburação em função da atividade de carbono a 1000 ${ }^{\circ} \mathrm{C}$.

Figura 12 - Efeito de hidrogênio na carburação por monóxido de carbono. 21

Figura 13 - Conversão teórica do metano em função da temperatura e da pressão. 
Figura 14 - Dados experimentais para velocidade de consumo de metano ( $r$ ) utilizando ferro como catalisador: A) Resultados para relação $\mathrm{pH}_{2} \mathrm{O} / \mathrm{pH}_{2}$ constante e diferentes temperaturas; B) Resultados para temperatura constante e diferentes relações $\mathrm{pH}_{2} \mathrm{O} / \mathrm{pH}_{2}$.

Figura 15 - Dados experimentais da velocidade de consumo de metano ( $r$ ) utilizando ferro como catalisador, em função da temperatura e da relação $\mathrm{pH}_{2} \mathrm{O} / \mathrm{pH}_{2}$.

Figura 16 - Dados experimentais de conversão do metano em função da relação W/FCH40para diferentes temperaturas e composições gasosas.

Figura 17 - Aplicação do modelo de controle por reação química (Equação (37)) aos dados obtidos nos experimentos de reforma catalítica de metano para composição 1 e conversão de metano até 0,5 e composição 2

Figura 18 - Representação esquemática da estrutura experimental. 35

Figura 19 - Desenho esquemático da retorta de aço inoxidável utilizada nos experimentos de carburação e reforma de metano. 36

Figura 20 - Estrutura geral do aparato experimental mostrando a retorta metálica inserida dentro do forno de resistências elétricas, além do sistema de produção de vapor composto pelo reservatório de $\mathrm{H}_{2} \mathrm{O}$, a bomba peristáltica e $\mathrm{O}$ evaporador.

Figura 21 - Estrutura experimental mostrando a retorta metálica inserida no forno, a entrada e a saída dos gases do reator e o termopar inserido no poço pirométrico. 38

Figura 22 - Perfil de temperatura do leito de pelotas de minério de ferro durante o décimo segundo ensaio de redução direta.

Figura 23 - Porcentagem final de carbono do DRI em função da relação $\mathrm{CH}_{4} / \mathrm{H}_{2} \mathrm{O}$ nos ensaios de carburação simultânea à reforma de metano a $1050{ }^{\circ} \mathrm{C}$ por 90 minutos.

Figura 24 - Temperatura das pelotas e concentração de espécies gasosas ao longo do ensaio de carburação simultânea à reforma utilizando a mistura $3 . . .47$ 
Figura 25 - Teor final de carbono do DRI, em mols/g $g_{D R}$, em função do tempo e da temperatura dos ensaios de carburação simultânea à reforma de metano, utilizando a mistura 3.

Figura 26 - Fração de carburação obtida experimentalmente em função do tempo.

Figura 27 - Fração de carburação em função do tempo reduzido para os dados experimentais e diferentes modelos cinéticos obtidos da literatura. ${ }^{42,43}$ 54

Figura 28 - Gráfico de Arrhenius obtido a partir das constantes cinéticas apresentadas na Tabela 13 58

Figura 29 - Gráfico de Arrhenius obtido a partir das constantes cinéticas reportadas na Tabela 15 .

Figura 30 - Perfil de difração de raios-x obtido do DRI resultante do ensaio de carburação simultânea à reforma de metano a $1000{ }^{\circ} \mathrm{C}$ e 60 min de duração. $\% \mathrm{C}_{\mathrm{DRI}}=1,88$.

Figura 31 - Micrografia da seção transversal do DRI ensaiado a $900{ }^{\circ} \mathrm{C}$ por 30 minutos. Aumento de 500x. $\% \mathrm{C}_{\mathrm{DRI}}=0,20$. Ataque: nital.

Figura 32 - Micrografia da seção transversal do DRI ensaiado a $1000{ }^{\circ} \mathrm{C}$ por 60 minutos. Aumento de 500x. \% $C_{D R I}=1,88$. Ataque: nital.

Figura 33 - Micrografia da seção transversal do DRI ensaiado a $900{ }^{\circ} \mathrm{C}$ por 30 minutos. Aumento de $1000 x . \% C_{D R I}=0,20$. Ataque: nital.

Figura 34 - A) Microestrutura da seção transversal de ferro esponja após ensaios de carburação simultânea à reforma de metano a $950{ }^{\circ} \mathrm{C}$ e 60 minutos de duração. Aumento de 5000 vezes. Ataque: nital. B) Perfil EDS do ponto 1. C)

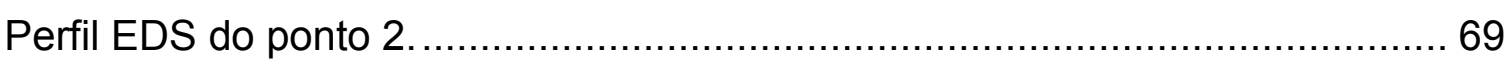

Figura 35 - Perfil de difração de raios-x obtido do DRI resultante do ensaio de carburação simultânea à reforma de metano a $1050{ }^{\circ} \mathrm{C}$ e 90 min de duração. $\% \mathrm{C}_{\mathrm{DRI}}=3,67$. 70

Figura 36 - Micrografia da seção transversal do DRI ensaiado a $1050{ }^{\circ} \mathrm{C}$ por 90 minutos. Aumento de $1000 x . \% C_{D R I}=3,67$. Ataque: nital. 71 


\section{Lista de Tabelas}

Tabela 1 - Energia livre de Gibbs padrão para diversas reações de redução de óxidos de ferro no sistema e seus intervalos de validade.

Tabela 2 - Tipos de controle cinético e seus respectivos modelos matemáticos, em função da temperatura, granulometria e grau de redução, para redução de minério de ferro por $\mathrm{H}_{2}$. $\alpha$ representa a fração de reação, isto é, o grau de conversão do minério em metal.

Tabela 3 - Principais reações de carburação, suas energias livres de Gibbs padrão e faixas de validade em função da temperatura.

Tabela 4 - Principais reações de reforma do metano, suas energias livres de Gibbs padrão e faixas de validade em função da temperatura.

Tabela 5 - Parâmetros dos ensaios de reforma catalítica de metano de Ribeiro et al.

Tabela 6 - Composição química das pelotas de minério de ferro Vale para redução direta. Valores em \% em massa.

Tabela 7 - Composições das misturas padrão utilizadas para calibração do cromatógrafo gasoso. 36

Tabela 8 - Parâmetros dos testes de carburação simultânea à reforma de metano com variação da composição gasosa. A atividade de carbono sólido na mistura gasosa foi calculada através do software Fact Sage 6.4, pacote FactPS.

Tabela 9 - Massa inicial e final das pelotas durante os ensaios de redução gasosa de minério de ferro, e o grau de redução estimado.

Tabela 10 - Conversões de metano por reforma gasosa, por carburação e total em função do tempo e da temperatura dos ensaios.

Tabela 11 - Modelos cinéticos de reações gás/sólido e suas respectivas funções da fração de reação $(\alpha)$.

Tabela 12 - Modelos cinéticos ${ }^{42,43}$, funções que os descrevem e o coeficiente de determinação $\left(R^{2}\right)$ calculado para cada modelo a partir dos valores de $\alpha_{c}$ 
apresentados na Figura 27. Em destaque, os maiores valores de $\mathrm{R}^{2}$ para cada temperatura e para média dos quatro valores. 56

Tabela 13 - Constantes cinéticas calculadas a partir dos dados experimentais pelo modelo de reação química em partículas esféricas.

Tabela 14 - Somatório dos Quadrados das Diferenças entre os valores de mols de carbono calculados pelos modelos analíticos de cada etapa intermediária da reação de decomposição do metano e dos valores de mols de C obtidos experimentalmente, em função da temperatura. 61

Tabela 15 - Valores das constantes cinéticas, k, calculadas a partir do modelo cinético da etapa de dissociação do radical $\mathrm{CH}_{3}$, representada pela reação (21).

Tabela 16 - Porosidade média do DRI após os ensaios de carburação simultânea à reforma de metano, calculada através da técnica de porosimetria de imagens. 


\section{Sumário}

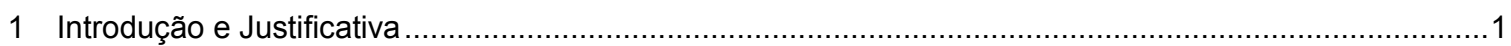

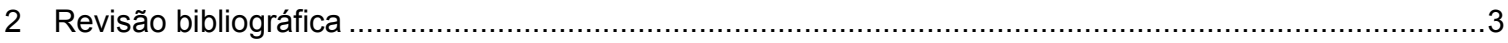

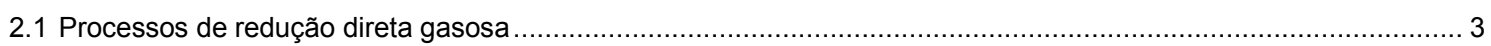

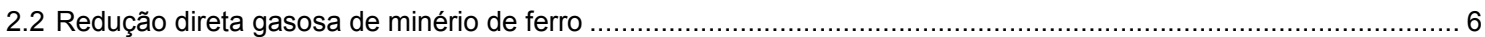

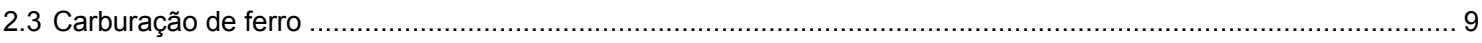

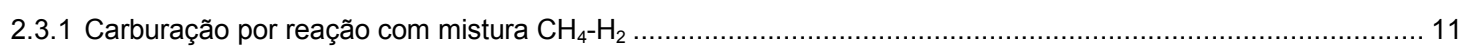

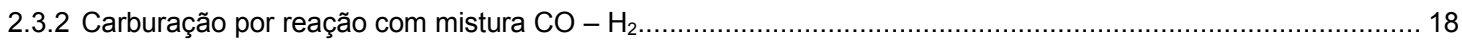

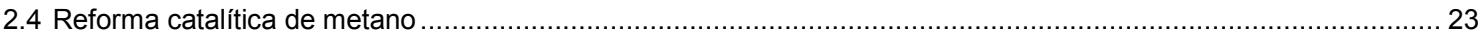

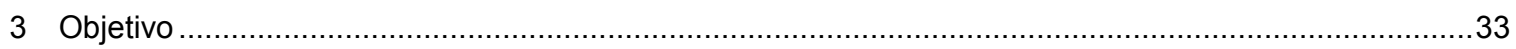

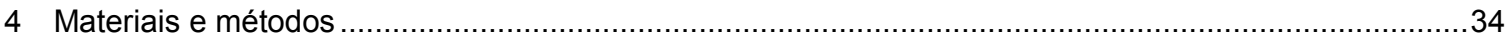

4.1 Sistema experimental de redução de pelotas e carburação de DRI ............................................................. 34

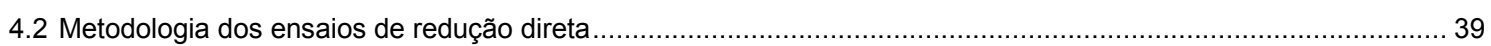

4.3 Metodologia dos ensaios de carburação simultânea à reforma catalítica de metano ................................... 40

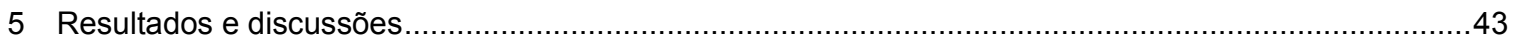

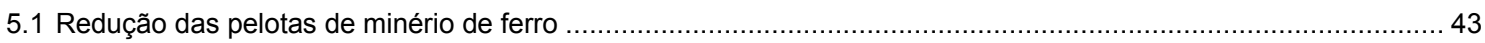

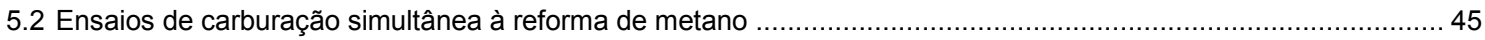

5.2.1 Avaliação do efeito da relação $\mathrm{CH}_{4} / \mathrm{H}_{2} \mathrm{O}$ no gás de entrada sobre a carburação ...........................................45

5.2.2 Ensaios interrompidos de carburação simultânea à reforma de metano ...................................................48

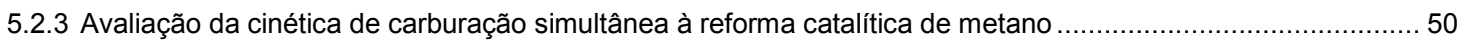

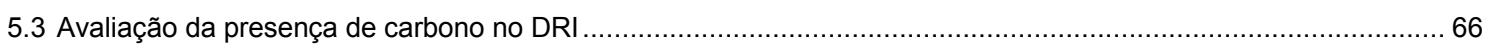

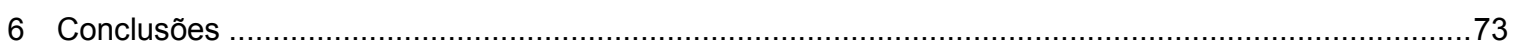

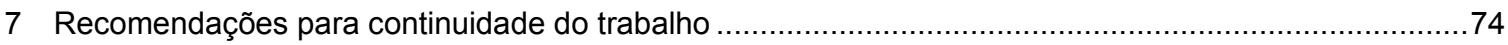

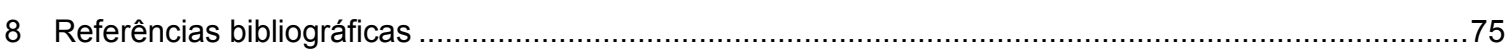

ANEXO A - RESULTADOS DOS ENSAIOS DE CARBURAÇÃO SIMULTÂNEA À REFORMA DE METANO 


\section{Introdução e Justificativa}

O Brasil foi o terceiro maior produtor de minério de ferro ao longo dos três últimos anos. Parte desse minério é exportada na forma pelotas que, dentre outros destinos, são utilizadas em processos de redução direta (RD). A produção nacional de pelotas de minério de ferro em 2018 atingiu números da ordem de 55,3 milhões de toneladas, sendo que, aproximadamente, $46 \%$ desta produção foram destinadas a processos de RD. Esta quantidade representou cerca de 3,1 bilhões de dólares ${ }^{1,2}$. Neste cenário, é necessário ressaltar que a precificação e desenvolvimento de novos tipos de pelotas estão diretamente relacionados com o conhecimento dos processos de RD.

Desta maneira, as novas tecnologias de redução direta carecem constantemente de estudos mais aprofundados com intuito de se encontrar alternativas que viabilizem máxima eficiência em conjunto com mínimo dano ambiental. ${ }^{3,4} \mathrm{O}$ processo de redução direta gasosa envolve diversas etapas e, consequentemente, diferentes tipos de reações químicas ao longo da transformação do minério em ferro esponja ou DRI (do inglês, direct reduced iron). De forma generalizada, o processo RD pode ser divido entre três etapas: a reforma do gás natural, a redução do minério e carburação do ferro reduzido.

A reforma do gás natural, que é composto majoritariamente por metano $\left(\mathrm{CH}_{4}\right)$, pode ser expressa através das reações (1) e (2). Já a redução do minério é caracterizada pelas reações globais (3) e (4): ${ }^{5-8}$

$$
\begin{gathered}
\mathrm{CH}_{4(g)}+\mathrm{H}_{2} \mathrm{O}_{(g)}=\mathrm{CO}_{(g)}+3 \mathrm{H}_{2(g)} \\
\mathrm{CH}_{4(g)}+\mathrm{CO}_{2(g)}=2 \mathrm{CO}_{(g)}+2 \mathrm{H}_{2(g)} \\
\mathrm{Fe}_{2} \mathrm{O}_{3}+3 \mathrm{CO}=2 \mathrm{Fe}+3 \mathrm{CO}_{2} \\
\mathrm{Fe}_{2} \mathrm{O}_{3}+3 \mathrm{H}_{2}=2 \mathrm{Fe}+3 \mathrm{H}_{2} \mathrm{O}
\end{gathered}
$$


O ferro metálico pode atuar como catalisador das reações (1) e (2) e, em contato com metano, pode sofrer carburação, como apresentado de maneira simplificada na reação (5): 9,10

$$
3 \mathrm{Fe}_{(s)}+\mathrm{CH}_{4(g)}=\mathrm{Fe}_{3} \mathrm{C}_{(s)}+2 \mathrm{H}_{2(g)}
$$

O fenômeno da carburação de ferro foi amplamente estudado nos últimos 40 anos. Entretanto, não foram encontrados estudos utilizando o DRI, ou ainda em simultaneidade com outros fenômenos como a reforma do gás natural e a redução do minério de ferro.

A necessidade de estudos fundamentais de carburação, no contexto dos processos de redução direta, associada ao papel do Brasil como produtor mundial de pelotas para RD são as motivações para realização do presente trabalho. 


\section{Revisão bibliográfica}

\subsection{Processos de redução direta gasosa}

Das 100,5 milhões de toneladas de DRI produzidas mundialmente em 2018, aproximadamente $80 \%$ teve origem em processos de redução direta em fornos de cuba, cujas principais tecnologias aplicadas são a Midrex e a HyL/Energiron. ${ }^{7,11}$

O processo Midrex foi desenvolvido nos anos de 1960 e é constituído de quatro principais componentes: o forno de redução, o reformador de gases naturais, um depurador de gases e um trocador de calor. A Figura 1 exibe de forma esquemática um fluxograma do processo Midrex. Gás natural é alimentado a um trocador de calor e aquecido até temperaturas entre 250 e $400^{\circ} \mathrm{C}$. Em sequência, o gás é alimentado a um reformador com catalisadores de níquel suportados em alumina, onde ocorre a reforma através das reações (1) e (2).

Em sequência, a mistura é injetada à meia-altura do forno de redução, fluindo em contracorrente ao leito de pelotas de minério de ferro (que são alimentadas na parte superior do forno) e produzindo o ferro esponja através das reações (3) e (4). O processo de redução ocorre em temperaturas entre $800^{\circ} \mathrm{C}$ e $1000^{\circ} \mathrm{C}$ e pressões entre 1,5 a 2,0 bar. A mistura gasosa de saída do reator é conduzida ao depurador (do inglês scrubber) para remoção de partículas e redução do teor de vapor de água. Posteriormente, esse fluxo gasoso é reaproveitado no reformador de gás natural como fonte de $\mathrm{CO}_{2}$ ou como combustível no trocador de calor. [12] Atualmente, o processo Midrex é responsável por $64 \%$ da produção mundial de DRI. ${ }^{11,13-15}$ 
Figura 1 - Diagrama simplificado do processo Midrex.

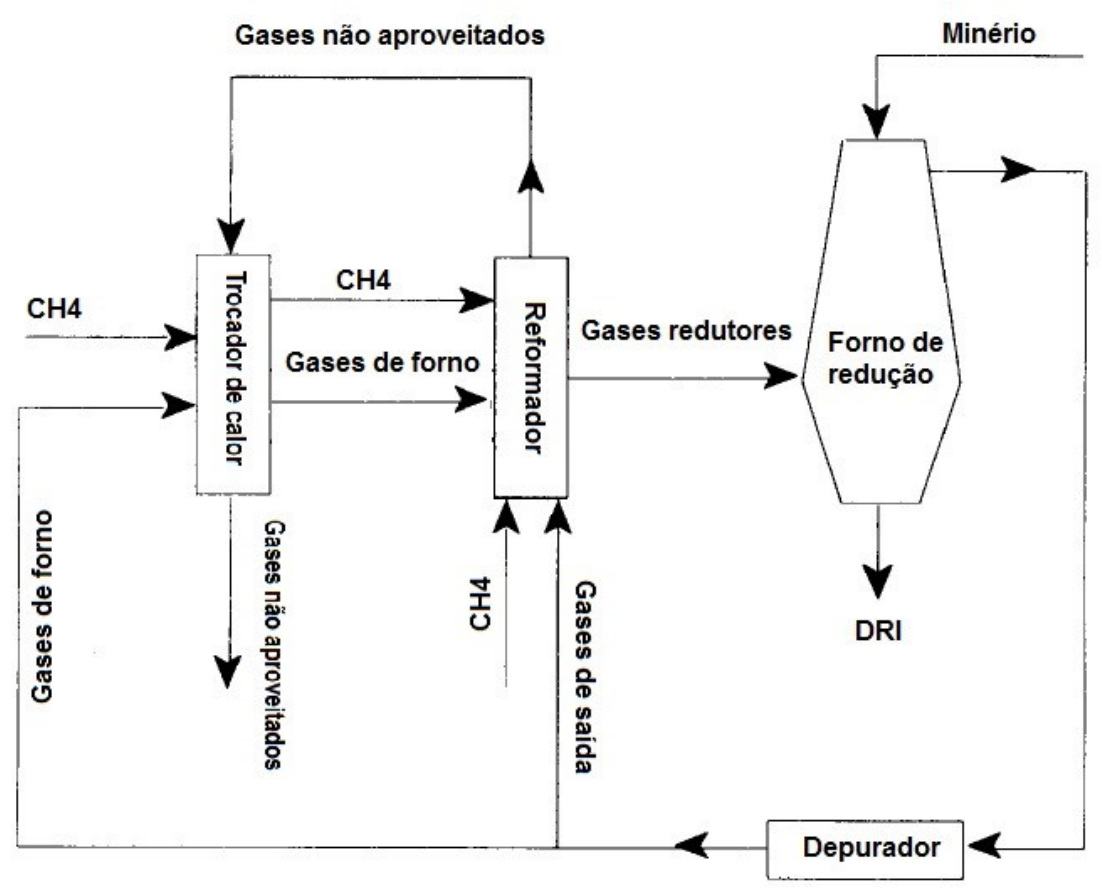

Fonte: Zervas, McMullan e Williams. ${ }^{12}$

Os processos HyL são responsáveis por $16 \%$ da produção mundial de DRI. ${ }^{11}$ A estrutura industrial do HyL-III é semelhante ao processo Midrex. Entretanto, no processo HyL-III, o gás natural é reformado com excesso de vapor de água para que se produza mais $\mathrm{H}_{2}$ em relação a $\mathrm{CO}$ e é injetado no forno vertical em temperaturas entre $900^{\circ} \mathrm{C}$ e $1000^{\circ} \mathrm{C}$. ${ }^{16}$ As pressões de operação no forno vertical vão até 8 bar na zona de injeção do gás redutor. ${ }^{17-19}$

$\mathrm{Na}$ década de 1990, foi desenvolvido o processo HyL-ZR (do inglês, zero reformer), posteriormente denominado Energiron-ZR ${ }^{20}$, que exclui o reformador pois introduz metano diretamente no forno de redução, para que o ferro reduzido atue como catalisador da reforma in situ de $\mathrm{CH}_{4}$. A Figura 2 apresenta um diagrama simplificado do processo HyL/Energiron-ZR. As principais diferenças para o processo HyL/Energiron-III são a exclusão do reformador externo e a temperatura em que os gases são injetados no reator, que são entre $1050^{\circ} \mathrm{C} \mathrm{e}$ $1080^{\circ} \mathrm{C}$.

O aumento de temperatura dos gases é feito para compensar o caráter endotérmico das reações de reforma. Para tanto, ocorre a combustão parcial do 
gás natural, que além de aquecer a mistura, promove a formação de $\mathrm{CO}_{2}$ e $\mathrm{H}_{2} \mathrm{O}$, reagentes do processo de reforma de $\mathrm{CH}_{4} \cdot{ }^{17,}{ }^{21-23} \mathrm{E}$ no contexto do processo HyL/Energiron-ZR que o presente trabalho dá o seu enfoque, i.e no estudo dos fenômenos de carburação do DRI e da reforma catalítica de metano em condições de simultaneidade.

Figura 2 - Diagrama simplificado do processo HyL/Energiron-ZR.

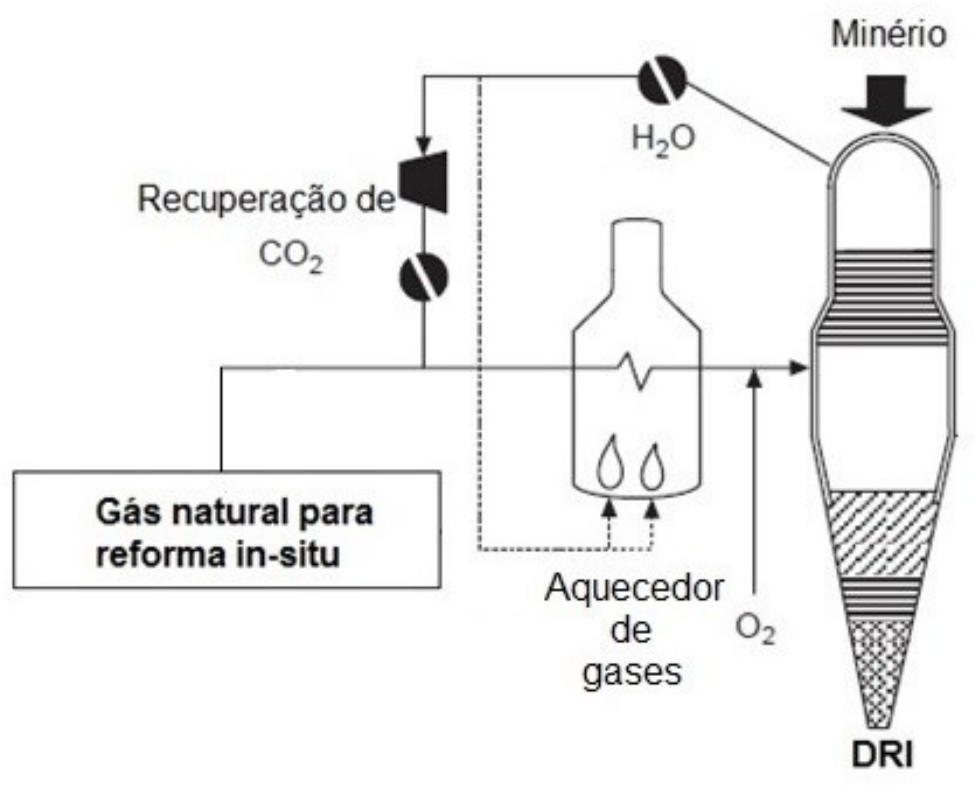

Fonte: Feinman. ${ }^{17}$ 


\subsection{Redução direta gasosa de minério de ferro}

A Tabela 1 apresenta os valores das energias livres de Gibbs padrão para as principais reações de redução dos óxidos de ferro.

Tabela 1 - Energia livre de Gibbs padrão para diversas reações de redução de óxidos de ferro no sistema e seus intervalos de validade.

\begin{tabular}{cccc}
\hline Fórmula da reação & Eq & $\Delta G_{\boldsymbol{T}}^{\mathbf{0}}(\mathbf{k J})$ & $\begin{array}{c}\text { Faixa de } \\
\text { validade (K) }\end{array}$ \\
\hline $3 \mathrm{Fe}_{2} \mathrm{O}_{3}+\mathrm{CO}=2 \mathrm{Fe}_{3} \mathrm{O}_{4}+\mathrm{CO}_{2}$ & $(6)$ & $-52,7-49,0.10^{-3} \mathrm{~T}$ & 298 a 1473 \\
\hline $\mathrm{Fe}_{3} \mathrm{O}_{4}+\mathrm{CO}=3 \mathrm{FeO}+\mathrm{CO}_{2}$ & $(7)$ & $+40,4-40,8.10^{-3} \mathrm{~T}$ & 298 a 1473 \\
\hline $\mathrm{FeO}+\mathrm{CO}=\mathrm{Fe}+\mathrm{CO}_{2}$ & $(8)$ & $-18,6+15,7.10^{-3} \mathrm{~T}$ & 298 a 1473 \\
\hline $3 \mathrm{Fe}_{2} \mathrm{O}_{3}+\mathrm{H}_{2}=2 \mathrm{Fe}_{3} \mathrm{O}_{4}+\mathrm{H}_{2} \mathrm{O}$ & $(9)$ & $-11,3-91,2.10^{-3} \mathrm{~T}$ & 473 a 1473 \\
\hline $\mathrm{Fe}_{3} \mathrm{O}_{4}+\mathrm{H}_{2}=3 \mathrm{FeO}+\mathrm{H}_{2} \mathrm{O}$ & $(10)$ & $+81,6-83,3.10^{-3} \mathrm{~T}$ & 473 a 1473 \\
\hline $\mathrm{FeO}+\mathrm{H}_{2}=\mathrm{Fe}+\mathrm{H}_{2} \mathrm{O}$ & $(11)$ & $+22,6-626.10^{-3} \mathrm{~T}$ & 473 a 1473 \\
\hline
\end{tabular}

Fonte: construída com os dados de Rosenqvist ${ }^{24}$, Kubaschewki ${ }^{25}$ e Vignes ${ }^{26}$.

A partir das constantes de equilíbrio obtidas dos valores das energias livres de Gibbs padrão e proporções estequiométricas entre produtos e reagentes, considerando a atividade das fases sólidas unitárias, obtêm-se os gráficos de estabilidade, em função das concentrações gasosas de equilíbrio, para as reduções dos óxidos de ferro por $\mathrm{CO}$ e $\mathrm{H}_{2}$, como apresentados na Figura 3.

Do ponto de vista termodinâmico, o CO tende a diminuir sua eficiência como redutor da wustita com o incremento da temperatura, em consequência do caráter exotérmico dessa reação. Em contraposição, o $\mathrm{H}_{2}$ tem sua eficiência como redutor da wustita aumentada com o incremento da temperatura, em razão do caráter endotérmico dessa transformação. 
Figura 3 - Gráficos de estabilidade de fases e composições gasosas de equilíbrio para diversas reações de redução de minérios de ferro com $\mathrm{CO}$ e $\mathrm{H}_{2}$.
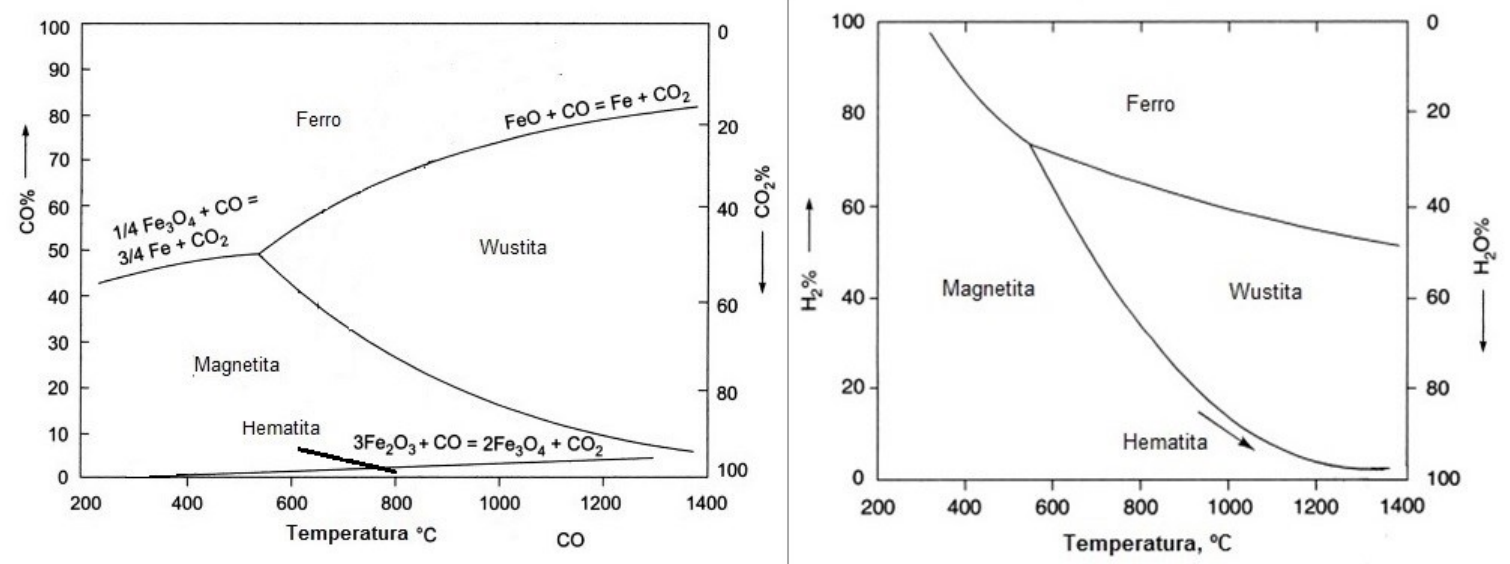

Fonte: Zervas, McMullan e Williams. ${ }^{12}$

Turkdogan e Vinters ${ }^{27}$ estudaram a redução de minério de ferro por hidrogênio, em partículas de minério não aglomeradas com granulometria entre $0,35 \mathrm{~mm}$ e $15 \mathrm{~mm}$, temperaturas entre $400^{\circ} \mathrm{C}$ e $1000^{\circ} \mathrm{C}$ e pressão atmosférica. Os autores identificaram três possíveis mecanismos cinéticos que controlassem a redução dos óxidos de ferro: controle cinético por reação química uniforme; controle misto i.e., em que há uma parcela controlada pela difusão dos reagentes/produtos gasosos pelos poros das partículas e outra parcela controlada pela reação na interface óxido-metal; e controle por difusão das espécies gasosas através das camadas porosas de ferro. A Tabela 2 apresenta as equações de controle cinético e as condições em que são válidas, para redução de minério de ferro por hidrogênio. ${ }^{27}$ 
Tabela 2 - Tipos de controle cinético e seus respectivos modelos matemáticos, em função da temperatura, granulometria e grau de redução, para redução de minério de ferro por $\mathrm{H}_{2} . \alpha$ representa a fração de reação, isto é, o grau de conversão do minério em metal.

\begin{tabular}{ccccc}
\hline $\begin{array}{c}\text { Tipo de } \\
\text { controle }\end{array}$ & $\begin{array}{c}\text { Modelo } \\
\text { cinético }\end{array}$ & $\begin{array}{c}\text { Temperatura } \\
\left({ }^{\circ} \mathbf{C}\right)\end{array}$ & $\begin{array}{c}\text { Granulometria } \\
(\mathbf{m m})\end{array}$ & $\begin{array}{c}\text { Grau de } \\
\text { redução } \\
(\%)\end{array}$ \\
\hline $\begin{array}{c}\text { Reação química } \\
\text { uniforme }\end{array}$ & $-\ln (1-\alpha)$ & $\leq 600$ & $\leq 4$ & - \\
\hline Controle misto $^{1}$ & $1-(1-\alpha)^{\frac{1}{3}}$ & Todas & Entre 4 e 7 & $\leq 50$ \\
\hline $\begin{array}{c}\text { Difusão em } \\
\text { camada porosa }\end{array}$ & $\frac{1}{2}-\frac{\alpha}{3}-\frac{(1-\alpha)^{2 / 3}}{2}$ & $\geq 800$ & $\geq 7$ & $>50$ \\
\hline
\end{tabular}

Fonte: construída com os dados obtidos de Turkdogan e Vinter. ${ }^{27}$

Towhidi e Szekely ${ }^{28}$ promoveram estudos de redução de minério de ferro em misturas de $\mathrm{CO}-\mathrm{H}_{2}$. Os testes foram conduzidos com partículas de minério que apresentavam granulometria entre $6 \mathrm{~mm}$ e $16 \mathrm{~mm}$, temperaturas entre $600{ }^{\circ} \mathrm{C}$ e $1234^{\circ} \mathrm{C}$ e pressão atmosférica. Os autores concluíram que o aumento de $\mathrm{H}_{2}$ na mistura aumenta a velocidade de conversão dos óxidos em ferro metálico, uma vez que o hidrogênio consegue se difundir mais facilmente que o $\mathrm{CO}$, devido ao seu tamanho ser menor. E, como discutido anteriormente, a redução por $\mathrm{H}_{2}$ é termodinamicamente favorecida conforme o aumento da temperatura, enquanto a redução por $\mathrm{CO}$ é desfavorecida.

Os autores também concluíram que havia dois tipos de controle cinético predominantes: controle misto, em graus de redução de até $50 \%$; e controle por difusão na camada porosa de ferro, para graus de redução entre 50 e 90 \%. As conclusões sobre os controles cinéticos são semelhantes às encontradas nos estudos de Turkdogan e Vinters. ${ }^{27}$ Os autores afirmaram que o limite entre os controles, bem como o controle cinético predominante acima de $90 \%$ de conversão, não pode ser definido com clareza. ${ }^{28}$

${ }^{1}$ Nomenclatura utilizada pelos autores. Normalmente, a equação que representa esse modelo é utilizada para descrever o controle cinético por reação química. 


\subsection{Carburação de ferro}

A Tabela 3 apresenta as principais reações químicas envolvidas no fenômeno de carburação. As reações de carburação que utilizam monóxido de carbono como reagente apresentam um caráter exotérmico, enquanto as reações que utilizam o metano como elemento carburante apresentam um caráter endotérmico. Assim, pelo ponto de vista termodinâmico, é de se esperar que o aumento de temperatura favoreça a carburação pela reação com metano e desfavoreça a carburação pela reação com CO.

Tabela 3 - Principais reações de carburação, suas energias livres de Gibbs padrão e faixas de validade em função da temperatura.

\begin{tabular}{cccc}
\hline Fórmula da reação & Equação & $\Delta \boldsymbol{G}_{\boldsymbol{T}}^{\mathbf{0}}(\mathbf{k J})$ & $\begin{array}{c}\text { Faixa de } \\
\text { validade (K) }\end{array}$ \\
\hline $\mathrm{CO}+\mathrm{H}_{2}=\mathrm{C}+\mathrm{H}_{2} \mathrm{O}$ & $(12)$ & $-96,4+0,143 . \mathrm{T}$ & 473 a 1473 \\
\hline $2 \mathrm{CO}=\mathrm{C}+\mathrm{CO}_{2}$ & $(13)$ & $-124+0,176 . \mathrm{T}$ & 298 a 1473 \\
\hline $\mathrm{CH}_{4}=\mathrm{C}+2 \mathrm{H}_{2}$ & $(14)$ & $+56,7-0,106 . \mathrm{T}$ & 298 a 1473 \\
\hline $3 \mathrm{Fe}_{(\alpha)}+\mathrm{CH}_{4}=\mathrm{Fe}_{3} \mathrm{C}+2 \mathrm{H}_{2}$ & $(5)$ & $+120-0,139 . \mathrm{T}$ & 298 a 1000 \\
\hline $3 \mathrm{Fe}_{(\gamma)}+\mathrm{CH}_{4}=\mathrm{Fe}_{3} \mathrm{C}+2 \mathrm{H}_{2}$ & $(5)$ & $+102-0,122 . \mathrm{T}$ & 1000 a 1667 \\
\hline $3 \mathrm{Fe}_{(\alpha)}+2 \mathrm{CO}=\mathrm{Fe}_{3} \mathrm{C}+\mathrm{CO}_{2}$ & $(15)$ & $-102+0,150 . \mathrm{T}$ & 298 a 1184 \\
\hline $3 \mathrm{Fe}_{(\gamma)}+2 \mathrm{CO}=\mathrm{Fe}_{3} \mathrm{C}+\mathrm{CO}_{2}$ & $(16)$ & $-112-0,161 . \mathrm{T}$ & 1184 a 1473 \\
\hline
\end{tabular}

Fonte: construída com os dados obtidos de Gaskell ${ }^{29}$, Turkdogan ${ }^{30}$ e através do software FACTSAGE 6.4, pacote FACT-PS.

A Figura 4 apresenta gráficos com as composições gasosas esperadas para os equilíbrios das reações apresentadas na Tabela 3. Os gráficos foram construídos a partir das constantes de equilíbrio das reações supracitadas e proporções estequiométricas entre produtos e reagentes. Além disso, assumiuse que a atividade das fases sólidas é igual à unidade. A Figura 4-A apresenta os equilíbrios das reações (5) e (14), a Figura 4-B os equilíbrios das reações 
(13), (15) e (16), enquanto a Figura 4-C exibe o equilíbrio para reação (12). Estão mostradas as áreas onde a composição do gás levaria à deposição de carbono (atividade termodinâmica superior a um) ou, opostamente, ao consumo de carbono (atividade inferior a um).

O aumento da pressão total desloca o equilíbrio das reações no sentido de consumo de gases, i.e., para o lado da reação onde há menor quantidade molar de espécies gasosas.

Figura 4 - Composições gasosas, consumo ou deposição de carbono e predominância de fases para o equilíbrio termodinâmico da reação 12 em função da temperatura.
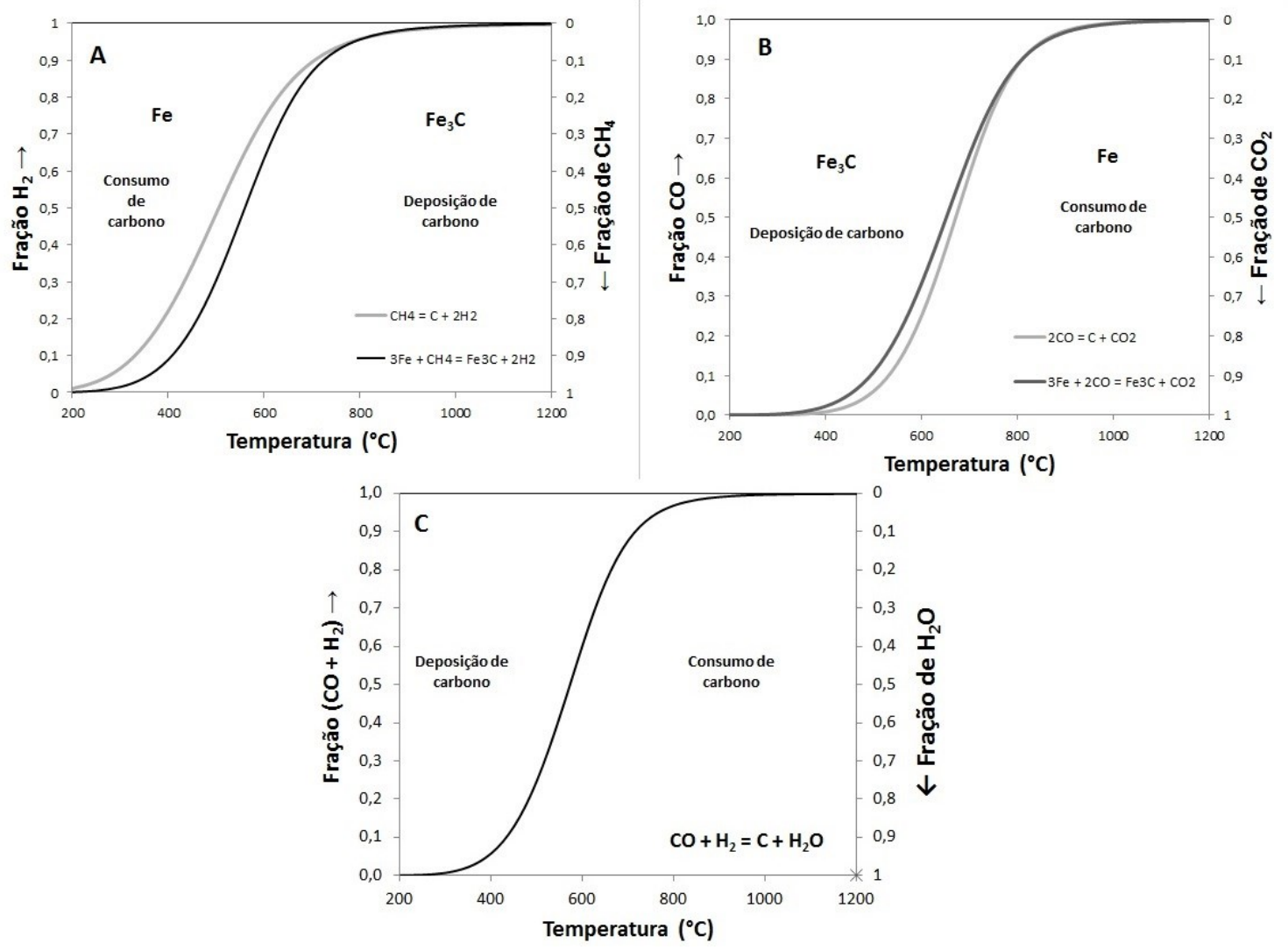

Fonte: o autor. 


\subsubsection{Carburação por reação com mistura $\mathrm{CH}_{4}-\mathrm{H}_{2}$}

Zhang e Ostrovski $^{31}$ estudaram a carburação sobre partículas não aglomeradas de minério de ferro por reação com mistura $\mathrm{CH}_{4}-\mathrm{H}_{2}$, em temperaturas entre $600^{\circ} \mathrm{C}$ e $925^{\circ} \mathrm{C}$ e pressão atmosférica, em um sistema termogravimétrico. Ao serem expostas às misturas de reação, as amostras de minério foram reduzidas até ferro metálico e sequencialmente convertidas em cementita. Essas transformações foram acompanhadas pela perda (redução do minério) ou ganho (formação de cementita) de massa do sistema e comprovadas através da difração de raios-x de amostras utilizadas em ensaios interrompidos, conforme apresentado na Figura 5.

Figura 5 - Padrão de difração de raios-x de diferentes amostras de minério de ferro expostas à mistura de reação (35 \% $\mathrm{CH}_{4}-55 \% \mathrm{H}_{2}-10 \% \mathrm{Ar}$ ), em diferentes tempos de ensaio.

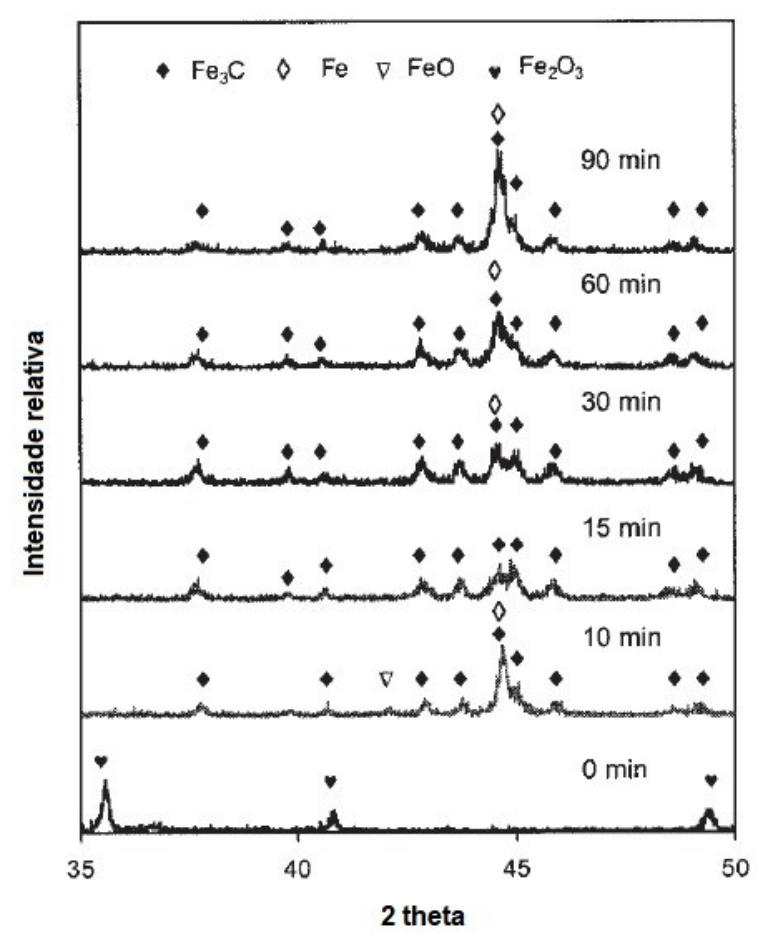

Fonte: Zhang e Ostrovski. ${ }^{[31}$

Os autores observaram que mantendo a amostra aquecida, a cementita formada passava por um processo de decomposição em ferro e grafite, 
diminuindo a fração de cementita das amostras, conforme observado na Figura 6-A após os pontos de máxima fração de cementita em cada curva apresentada.

A partir dos dados experimentais fornecidos pelos autores foi possível calcular a taxa de formação de cementita, $r_{\mathrm{Fe}_{3} \mathrm{C}}$, em função da temperatura, conforme a Equação (17), considerando-se apenas os intervalos em que havia aumento da fração de cementita. Os resultados são exibidos na Figura 6-B. Nota-se que o aumento da temperatura aumentou a taxa de formação da cementita.

$$
r_{F e_{3} C}=\frac{\theta_{\text {máx }}-\theta_{0}}{t_{\text {máx }}-t_{0}}
$$

Onde,

$\theta_{\text {máx }}$ e $t_{\text {máx }}$ representam a máxima fração de cementita de cada curva e o tempo em que essa fração é observada, respectivamente

$\theta_{0}$ e $t_{0}$ representam a fração inicial de cementita em cada curva e o tempo em que essa fração é observada, respectivamente.

Figura 6 - A) Fração de cementita em função da temperatura e do tempo para reações de minério de ferro com misturas $35 \% \mathrm{CH}_{4}-55 \% \mathrm{H}_{2}-10 \% \mathrm{Ar}$. B) Taxa de formação de cementita em função da temperatura, considerando apenas os intervalos em que havia crescimento da fração de cementita.
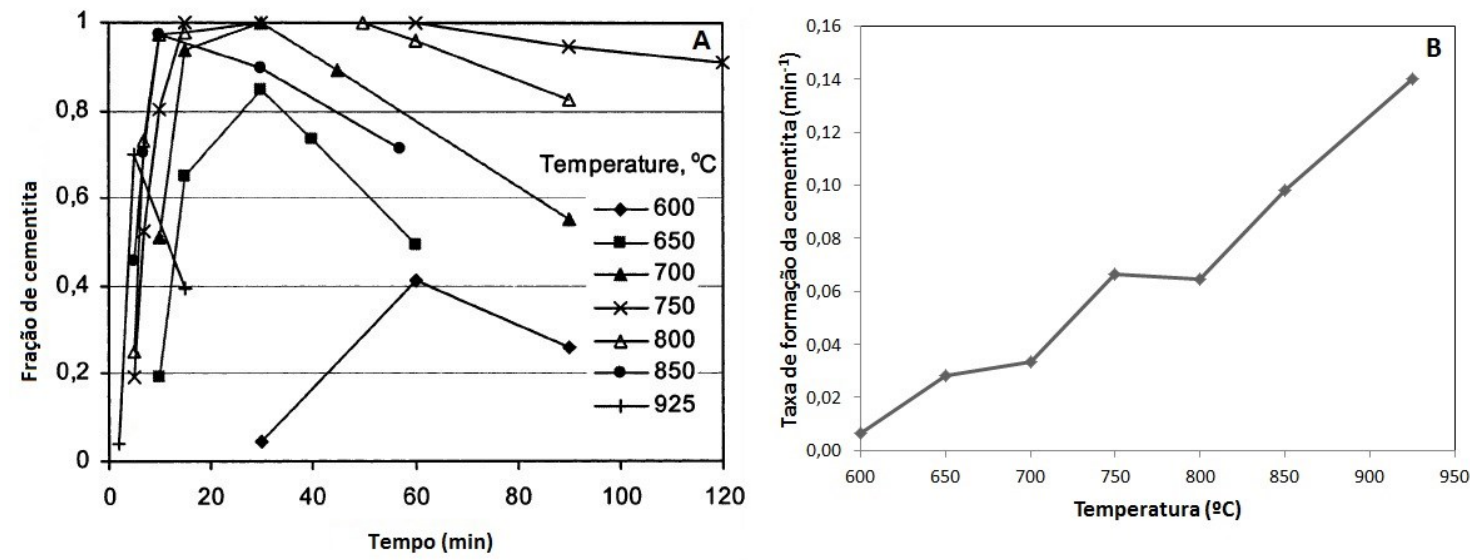

Fonte: A - Zhang e Ostrovski ${ }^{31}$; B - o autor. 
No estudo, os autores concluíram que a formação da cementita é relacionada às reações de adsorção e decomposição do metano sobre a superfície do ferro metálico.

Para avaliar a decomposição da cementita, os autores promoveram a reação de minério de ferro com a mistura $35 \% \mathrm{CH}_{4}-55 \% \mathrm{H}_{2}-10 \% \mathrm{Ar}$ a $750^{\circ} \mathrm{C}$ por $15 \mathrm{~min}$. Em seguida, alteraram a atmosfera para argônio puro e variaram a temperatura do sistema para os patamares desejados. A Figura 7-A apresenta os resultados destes experimentos.

A partir dos dados obtidos experimentalmente foi possível calcular a taxa de decomposição da cementita, considerando a diferença entre a primeira e a última fração de $\mathrm{Fe}_{3} \mathrm{C}$ registrada em cada curva, em função da temperatura. Essas curvas são exibidas na Figura 7-B. Entre 500 e $650^{\circ} \mathrm{C}$ e após $750^{\circ} \mathrm{C}$, o aumento da temperatura aumentou a taxa de decomposição da cementita e, entre 650 e $750^{\circ} \mathrm{C}$, o aumento da temperatura desacelerou a decomposição do $\mathrm{Fe}_{3} \mathrm{C}$.

Figura 7 - A) Fração de cementita em função do tempo para reação de decomposição da cementita em atmosfera de argônio para diferentes temperaturas. B) Taxa de decomposição da cementita em função da temperatura.
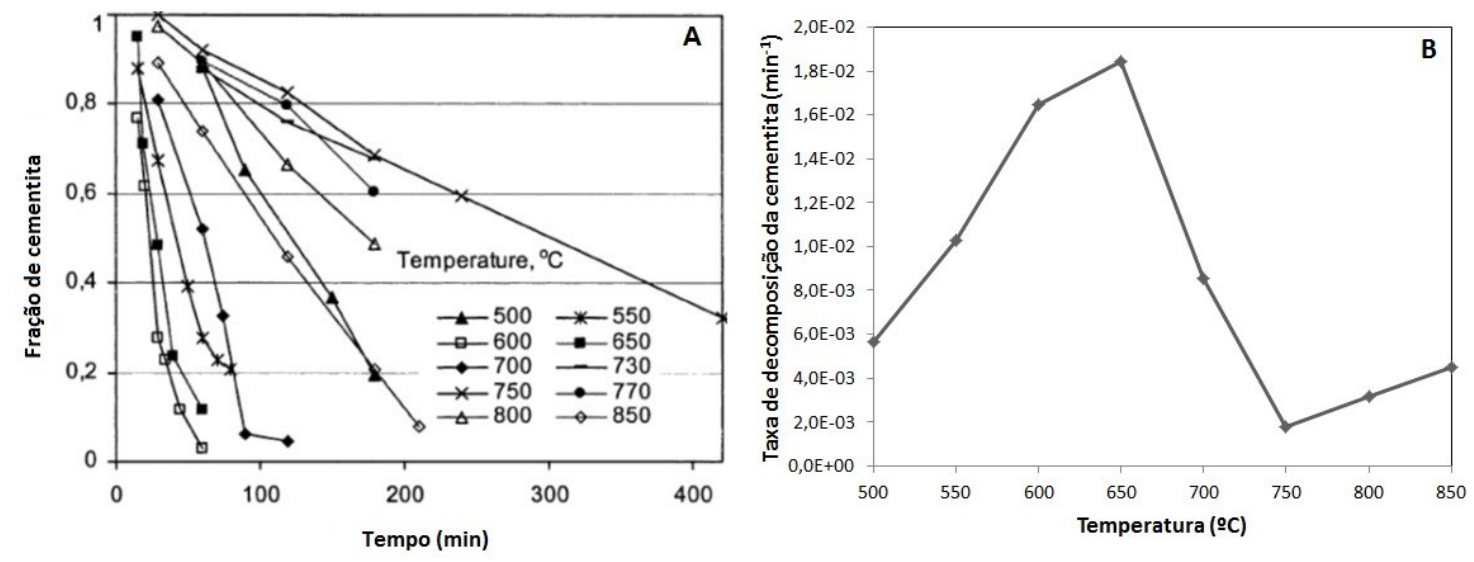

Fonte: A - Zhang e Ostrovski ${ }^{31}$; B - o autor.

O comportamento fragmentado da decomposição da cementita, em relação à temperatura, foi atribuído às diferenças de difusão do carbono nas fases presentes no ferro durante os ensaios. A difusão de carbono pelo ferro 
CCC (ferrita), que é estável até a temperatura de $723^{\circ} \mathrm{C}$, conforme o diagrama de equilíbrio metaestável apresentado na Figura 8, é uma ordem de grandeza maior que o coeficiente de difusão no ferro CFC (austenita). Assim, na faixa de transição entre as estruturas (650 a $750^{\circ} \mathrm{C}$ ), quão maior a fração de austenita, menor a difusividade do carbono, e, consequentemente, menor a decomposição da cementita. Fora desse intervalo, o aumento da temperatura aumenta a difusividade de carbono e, consequentemente, a decomposição de $\mathrm{Fe}_{3} \mathrm{C}$.

Figura 8 - Diagrama de equilíbrio metaestável Fe-C.

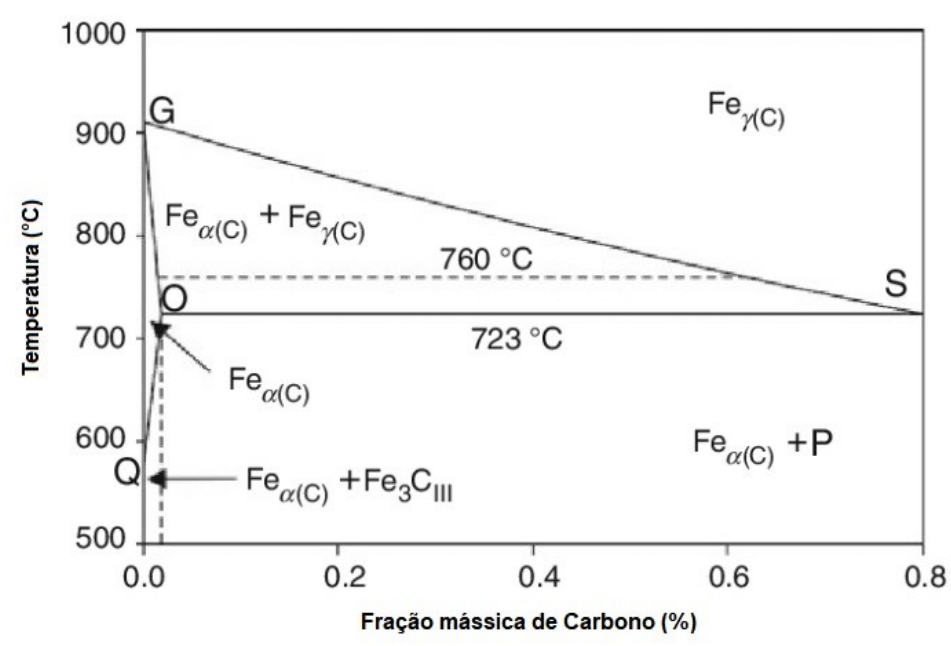

Fonte: Zaludová et al. ${ }^{32}$

Grabke $^{33}$ realizou um estudo de carburação de folhas de ferro pela reação com misturas $\mathrm{CH}_{4}-\mathrm{H}_{2}$. A montagem experimental consistia de duas folhas de ferro metálico de $0,1 \mathrm{~mm}$ de espessura, colocadas em dois tubos cerâmicos distintos num mesmo forno. Uma delas servia apenas como referência e era mantida em atmosfera de $\mathrm{H}_{2}$, enquanto a outra era exposta a misturas de $\mathrm{CH}_{4-}$ $\mathrm{H}_{2}$. A escolha pela geometria do catalisador teve como objetivo excluir a influência da difusão gasosa sobre as análises. Durante os experimentos, mediase a resistência elétrica das folhas e a concentração de $\mathrm{CH}_{4}$ e $\mathrm{H}_{2}$ na saída dos reatores. Após a carburação, a amostra exposta à atmosfera carburante era descarburada em meio de $\mathrm{H}_{2}$. 
Através da comparação entre a diferença das resistências das duas folhas, e de um padrão previamente calibrado, foi possível construir curvas que relacionavam a concentração do carbono em função do tempo, conforme apresentado na Figura 9.

Figura 9 - Porcentagem mássica de carbono em função do tempo a $1000^{\circ} \mathrm{C}$.

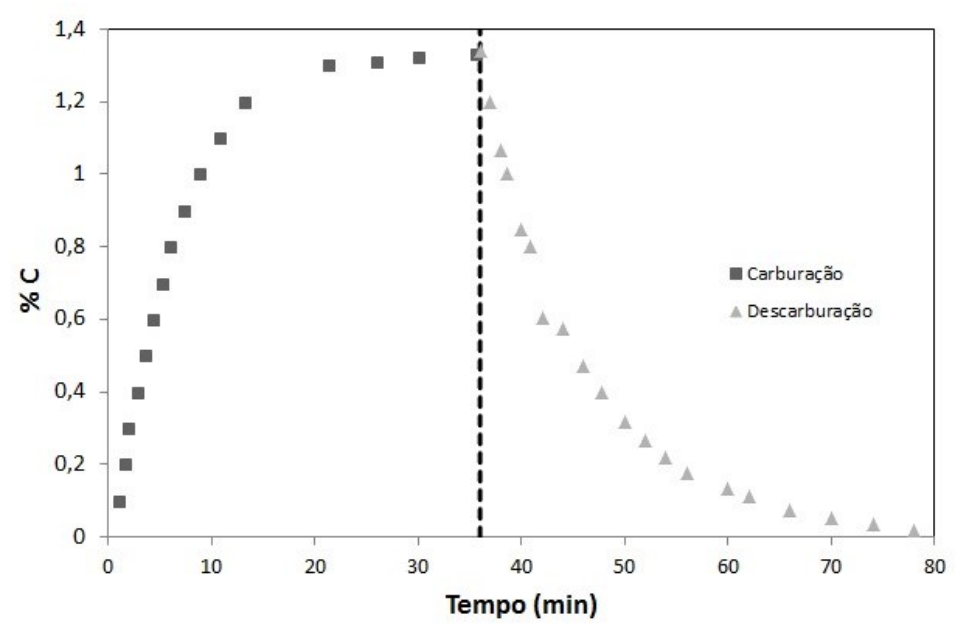

Fonte: construído com os dados experimentais reportados por Grabke. ${ }^{33}$

A carburação do ferro foi atribuída à reação de decomposição do metano:

$$
\mathrm{CH}_{4(g)}=[\mathrm{C}]+2 \mathrm{H}_{2(g)}
$$

A reação (14) apresenta diversas etapas intermediárias, conforme as reações apresentadas a seguir:

$$
\begin{gathered}
2 \mathrm{H}_{(a d)}=\mathrm{H}_{2} \\
\mathrm{CH}_{4}=\mathrm{CH}_{4(a d)} \\
\mathrm{CH}_{4(a d)}=\mathrm{CH}_{3(a d)}+H_{(a d)}
\end{gathered}
$$




$$
\begin{gathered}
C H_{3(a d)}=C H_{2(a d)}+H_{(a d)} \\
C H_{2(a d)}=C H_{(a d)}+H_{(a d)} \\
C H_{(a d)}=C_{(a d)}+H_{(a d)} \\
C_{(a d)}=C_{(\text {dissolvido })}
\end{gathered}
$$

O autor calculou, de maneira analítica, as taxas de cada uma das etapas intermediárias da reação (14), considerando todas as demais em equilíbrio. 0 autor comparou as taxas obtidas analiticamente com as taxas obtidas experimentalmente e concluiu que a etapa controladora da cinética do processo era a dissociação do radical $\mathrm{CH}_{3(\mathrm{ad})}$, representada pela reação (21).

A taxa da reação (14) é descrita pela Equação (25) e a comparação do modelo aos dados experimentais é apresentada na Figura 10.

$$
r_{(14)}=k_{(14)} \frac{p_{C H_{4}}}{p_{H_{2}}^{0,5}}-k^{\prime}{ }_{(14)} \% C\left(p_{H_{2}}\right)^{\frac{3}{2}}
$$

Onde,

$r_{(14)}$ é a velocidade da reação (14), dada em [mols de C. $\mathrm{cm}^{-2} \cdot \mathrm{s}^{-1}$ ]

$k_{(14)}$ e $k_{(14)}^{\prime}$ são as constantes da ordem direta e inversa da reação (14)

$\% C$ é a porcentagem mássica de carbono

$p_{\mathrm{CH}_{4}}$ e $p_{H_{2}}$ são as pressões parciais de metano e hidrogênio no sistema, respectivamente. 
Figura 10 - Taxa global, taxa de carburação e taxa de descarburação, em função da porcentagem de carbono a $1000^{\circ} \mathrm{C}$.

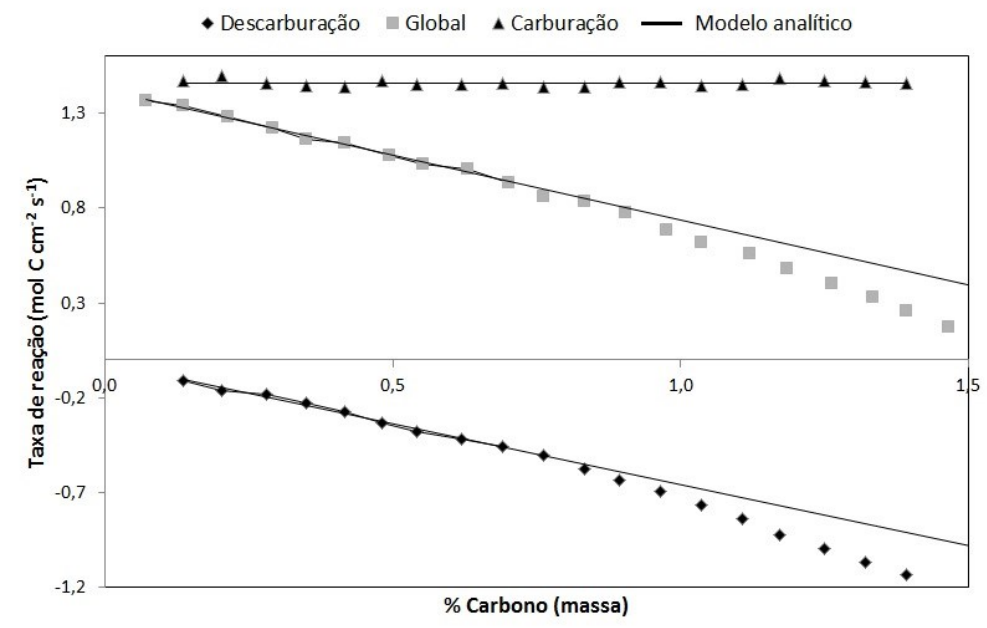

Fonte: construído com os resultados reportados por Grabke. ${ }^{33}$

As taxas global e de descarburação não apresentaram um bom ajuste aos dados experimentais, especificamente após teores de carbono superiores a 0,8 \%. Para promover um melhor ajuste das taxas ao modelo proposto, o autor alterou a porcentagem de $\mathrm{C}$ pela atividade de $\mathrm{C}\left(\mathrm{a}_{\mathrm{C}}\right)$, o que gerou a Equação (26) e a comparação apresentada na Figura 11. A constante de reação, $k_{(14)}$, foi calculada em $3,8 \cdot 10^{-13} \mathrm{~mol}$ de $\mathrm{C} \cdot \mathrm{cm}^{-2} \cdot \mathrm{s}^{-1} \cdot$ bar $^{-0,5}$, para ensaios a $920{ }^{\circ} \mathrm{C} .{ }^{34}$

$$
r_{(14)}=k_{(14)} \frac{p_{C H_{4}}}{p_{H_{2}}^{0,5}}-k^{\prime}{ }_{(14)} a_{C}\left(p_{H_{2}}\right)^{\frac{3}{2}}
$$


Figura 11 - Taxa de descarburação em função da atividade de carbono a $1000{ }^{\circ} \mathrm{C}$.

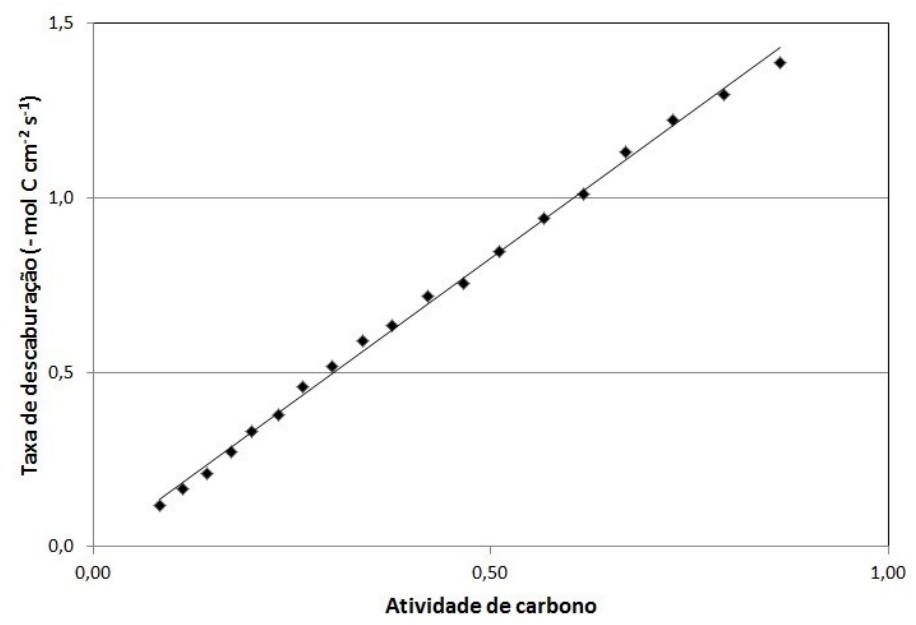

Fonte: construído com os resultados reportados por Grabke. ${ }^{33}$

\subsubsection{Carburação por reação com mistura $\mathrm{CO}-\mathrm{H}_{2}$}

Grabke e Tauber $^{35}$ promoveram um estudo da cinética de carburação de folhas de ferro por reação com misturas $\mathrm{CO}-\mathrm{H}_{2}-\mathrm{H}_{2} \mathrm{O}$. A montagem e o método experimental são os mesmos adotados no estudo de carburação de ferro em atmosferas de $\mathrm{CH}_{4}-\mathrm{H}_{2}{ }^{33}$ descrito anteriormente. As temperaturas utilizadas nos ensaios variaram de $600^{\circ} \mathrm{C}$ a $1000^{\circ} \mathrm{C}$. A reação (12) representa a reação global de carburação, enquanto as reações (27) a (29) representam suas etapas intermediárias:

$$
\begin{gathered}
\mathrm{CO}+\mathrm{H}_{2}=[\mathrm{C}]+\mathrm{H}_{2} \mathrm{O} \\
\mathrm{CO}=\mathrm{CO}_{(a d)} \\
\mathrm{CO}_{(a d)}=[\mathrm{C}]+\mathrm{O}_{(a d)} \\
O_{(a d)}+\mathrm{H}_{2}=\mathrm{H}_{2} \mathrm{O}
\end{gathered}
$$

Novamente, os autores compararam as curvas de carburação obtidas experimentalmente às equações analíticas desenvolvidas para cada etapa 
intermediária da reação (12). A etapa controladora da cinética de carburação foi atribuída à reação (27). Dois modelos foram desenvolvidos para representar a carburação por reação com misturas $\mathrm{CO}-\mathrm{H}_{2}-\mathrm{H}_{2} \mathrm{O}$. O primeiro, descrito pela Equação (30), é válido para baixas concentrações de $\mathrm{H}_{2} \mathrm{O}$ na atmosfera $\left(p_{\mathrm{H}_{2} \mathrm{O}} / p_{\mathrm{H}_{2}} \leq 0,05\right)$ e altas temperaturas (acima de $\left.750{ }^{\circ} \mathrm{C}\right) \cdot:^{34}$

$$
r_{(12)}=k_{(12)} p_{C O}-k_{(12)}^{\prime} a_{c} p_{H_{2} O} / p_{H_{2}}
$$

Onde,

$r_{(12)}$ é a velocidade da reação (12), dada em [mols de C. $\mathrm{cm}^{-2} \cdot \mathrm{s}^{-1}$ ]

$\mathrm{k}_{(12)}$ e $\mathrm{k}_{(12)}$ são as constantes da ordem direta e inversa da reação (12)

$a_{c}$ é a atividade de carbono obtida indiretamente pela medidas de resistêncie elétrica das folhas de ferro

$p_{i}$ é a pressão parcial do gás i no sistema.

Para baixas temperaturas (abaixo de $750^{\circ} \mathrm{C}$ ) e altas porções de $\mathrm{H}_{2} \mathrm{O}$ $\left(p_{H_{2} \mathrm{O}} / p_{\mathrm{H}_{2}}>0,05\right)$ no sistema ${ }^{34}$, os autores consideram que há uma influência considerável do oxigênio adsorvido na superfície do ferro sobre a carburação. $O$ oxigênio resultante da decomposição de vapor de água ocupa os sítios ativos da superfície do ferro até atingimento de equilíbrio termodinâmico. Dessa forma, o CO só tem possibilidade de interagir com os sítios não ocupados pelo oxigênio. Para considerar esse efeito, os autores adotaram um parâmetro, $\theta$, que corresponde à área superficial da folha de ferro coberta com oxigênio adsorvido e é representado pela isoterma de Lagmuir:

$$
\theta=\frac{K_{O} p_{\mathrm{H}_{2} \mathrm{O}} / p_{\mathrm{H}_{2}}}{1+K_{O} p_{\mathrm{H}_{2} \mathrm{O}} / p_{\mathrm{H}_{2}}}
$$


Onde,

$K_{O}$ é a constante de equilíbrio para a reação (29).

Os autores rescreveram o modelo cinético descrito pela Equação (30), adaptando-o para atmosferas com alto teor de $\mathrm{H}_{2} \mathrm{O}$, conforme a Equação (32). A ordem direta da reação representa a etapa de carburação que só pode ocorrer nos sítios livres da superfície do ferro (1- $\theta)$, enquanto a ordem inversa da reação representa a etapa de descarburação e ocorre em sítios com a presença de carbono e oxigênio adsorvido $(\theta)$.

$$
r_{(12)}^{\prime}=k_{(12)} p_{C O}(1-\theta)-k_{(12)}^{\prime \prime} a_{c} \theta
$$

Onde,

$r_{(12)}^{\prime}$ é a velocidade da reação (12), dada em [mols de C.cm ${ }^{-2} \cdot \mathrm{s}^{-1}$ ]

$k_{(12)}$ e $k^{\prime \prime}{ }_{(12)}$ são as constantes da ordem direta e inversa da reação (12)

O valor de $k_{(12)}$ reportado pelos autores foi de $6,6 \cdot 10^{-6}$ mols de C.cm ${ }^{-2} \cdot \mathrm{s}^{-}$ ${ }^{1}$.bar ${ }^{-1}$, a $920{ }^{\circ} \mathrm{C} .[34]$

Turkdogan e Vinters ${ }^{36}$ realizaram estudos de carburação de partículas de ferro ( $700 \mathrm{mg}$, com tamanho médio de $1 \mathrm{~mm}$ ) em atmosferas de $\mathrm{He}-\mathrm{CO}$ e $\mathrm{H}_{2}$ CO. As temperaturas variaram entre $400{ }^{\circ} \mathrm{C}$ e $1000^{\circ} \mathrm{C}$ e as vazões totais entre 2 e $5 \mathrm{NL} / \mathrm{min}$. Os autores utilizaram o método termogravimétrico para observar a variação da massa amostral.

Previamente aos testes, as amostras de ferro foram produzidas por reação entre minério de ferro e hidrogênio. Quão maiores as temperaturas empregadas durante a redução, menores foram as taxas de deposição de carbono durante os testes de carburação. Esse efeito foi atribuído à diminuição da área superficial dos poros conforme se aumentava a temperatura de redução, possivelmente devido a sinterização do ferro metálico. $O$ aumento da temperatura durante a carburação também reduziu as taxas de deposição de $\mathrm{C}$, uma vez que as reações de carburação com misturas $\mathrm{H}_{2}$ e CO são exotérmicas. 
No estudo da carburação com He-CO, os atores identificaram que a taxa de carburação é proporcional à massa de Fe utilizada como catalisador, à pressão de CO (até $0,4 \mathrm{~atm}$ de $\mathrm{CO}$ ) e à temperatura na faixa de $400^{\circ} \mathrm{C}$ a $800^{\circ} \mathrm{C}$.

Como continuação do trabalho anterior, Olson e Turkdogan ${ }^{37}$ estudaram o efeito da adição de $\mathrm{H}_{2} \mathrm{O}, \mathrm{CO}_{2}, \mathrm{SO}_{2}$ e $\mathrm{H}_{2} \mathrm{~S}$ na decomposição de $\mathrm{CO}$, utilizando ferro como catalisador. A estrutura experimental é a mesma utilizada no primeiro trabalho ${ }^{36} \mathrm{e}$ os ensaios foram realizados em temperaturas de $400{ }^{\circ} \mathrm{C}, 600^{\circ} \mathrm{C} \mathrm{e}$ $800^{\circ} \mathrm{C}$ e pressões atmosféricas. Os autores atribuíram o fenômeno da carburação às reações (12) e (13):

$$
\begin{gathered}
\mathrm{CO}+\mathrm{H}_{2}=[\mathrm{C}]+\mathrm{H}_{2} \mathrm{O} \\
2 \mathrm{CO}=\mathrm{C}+\mathrm{CO}_{2}
\end{gathered}
$$

A taxa global de carburação foi determinada pela variação da massa amostral através do método termogravimétrico. Para diferenciar o carbono depositado pelas duas reações, os autores estimaram o teor de carbono depositado a partir das análises dos teores de $\mathrm{H}_{2} \mathrm{O}$ e $\mathrm{CO}_{2}$ nos gases de saída. Os resultados dos ensaios com misturas $\mathrm{H}_{2}-\mathrm{CO}$ são apresentados na Figura 12.

Figura 12 - Efeito de hidrogênio na carburação por monóxido de carbono.
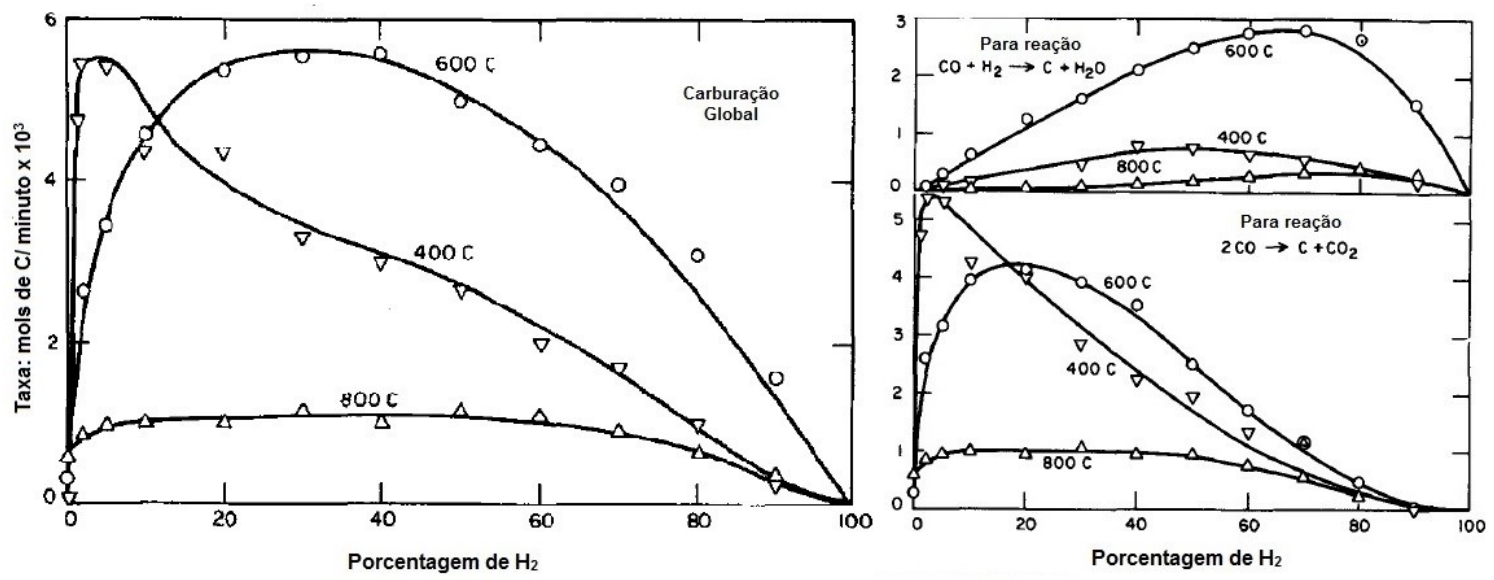
Fonte: Olson e Turkdogan. ${ }^{37}$

Nota-se que até $50 \%$ de $\mathrm{H}_{2}$ na atmosfera, a reação (13) é a maior responsável pela carburação e, após esse ponto, a reação (12) começa a assumir a predominância do fenômeno global.

Adições de $\mathrm{CO}_{2}, \mathrm{SO}_{2}$ e $\mathrm{H}_{2} \mathrm{~S}$ diminuíram as taxas de carburação e, dependendo da concentração, chegaram a cessar o processo. No caso do $\mathrm{CO}_{2}$, o fato é atribuído ao deslocamento da reação 13 no sentido de formação do CO. A diminuição das taxas de carburação quando da injeção $\mathrm{SO}_{2}$ e $\mathrm{H}_{2} \mathrm{~S}$ é atribuída à competição de formação entre $\mathrm{Fe}_{3} \mathrm{C}$ e $\mathrm{FeS}$. Já a adição de vapor de água também promoveu um decréscimo das taxas de carburação. Os autores não explicaram o efeito da adição de $\mathrm{H}_{2} \mathrm{O}$ sobre a carburação, entretanto as taxas de carburação podem ter reduzido em virtude da formação de oxigênio adsorvido e consequente ocupação de sítios ativos na superfície do ferro, conforme discutido no trabalho de Grabke e Tauber. ${ }^{35}$

Os autores não propõem mecanismos que expliquem o efeito catalítico do hidrogênio na decomposição do CO sobre superfície de ferro. Entretanto, como discutido no trabalho de Grabke e Tauber ${ }^{35}$, o hidrogênio poderia reagir com oxigênio adsorvido na superfície do ferro gerando $\mathrm{H}_{2} \mathrm{O}$, liberando a superfície para que mais CO pudesse adsorver e se decompor, conforme as reações (27) e (28). Ademais, o aumento do teor de hidrogênio no sistema poderia favorecer a reação (12) no sentido de formação do carbono. 


\subsection{Reforma catalítica de metano}

Por definição, um catalisador é uma substância que acelera transformações químicas por ação termodinâmica, e.g. através da diminuição da energia de ativação necessária para ocorrência de determinada reação, ou cinética, e.g. alterando o mecanismo pelo qual a reação ocorre. ${ }^{38}$

Nos processos mais tradicionais da área de redução direta (Midrex e HyLIII), os gases redutores $\left(\mathrm{CO}\right.$ e $\left.\mathrm{H}_{2}\right)$ são comumente produzidos pela reforma de gás metano, catalisada por um leito de níquel suportado em alumina. Entretanto, como apresentado anteriormente, o enfoque do presente trabalho é sobre as reações predominantes do processo Energiron-ZR, dentre as quais a reforma do metano é catalisada pela superfície do ferro recém-produzido no próprio reator de redução.

A Tabela 4 apresenta as principais reações de reforma do metano, que apresentam um caráter endotérmico.

Tabela 4 - Principais reações de reforma do metano, suas energias livres de Gibbs padrão e faixas de validade em função da temperatura.

\begin{tabular}{cccc}
\hline Fórmula da reação & Equação & $\begin{array}{c}\Delta \boldsymbol{G}_{T}^{\mathbf{0}} \\
\left(\mathbf{k J} / \mathbf{m o l} \mathbf{~ d e ~} \mathbf{C H}_{4}\right)\end{array}$ & $\begin{array}{c}\text { Faixa de } \\
\text { validade (K) }\end{array}$ \\
\hline $\mathrm{CH}_{4}+\mathrm{H}_{2} \mathrm{O}=\mathrm{CO}+3 \mathrm{H}_{2}$ & $(1)$ & $22,7-0,25 . \mathrm{T}$ & 473 a 1473 \\
\hline $\mathrm{CH}_{4}+\mathrm{CO}_{2}=2 \mathrm{CO}+2 \mathrm{H}_{2}$ & $(2)$ & $26,2-0,29 . \mathrm{T}$ & 298 a 1473 \\
\hline
\end{tabular}

Fonte: construída com os dados obtidos de Gaskell. ${ }^{29}$

A Figura 13 apresenta as curvas de conversão teórica de metano para os equilíbrios das reações (1) e (2), em função da temperatura e da pressão total do sistema. Até a temperatura de $700^{\circ} \mathrm{C}$, do ponto de vista termodinâmico, a conversão do metano é mais eficiente quando feita pelo $\mathrm{H}_{2} \mathrm{O}$ do que pelo $\mathrm{CO}_{2} \mathrm{e}$ o efeito é inverso após $700^{\circ} \mathrm{C}$. Ademais, observa-se que o aumento da pressão tende a diminuir os graus de conversão do metano, uma vez que a reação 
transforma dois mols de reagentes gasosos em quatro mols de produtos gasosos, e assim há um deslocamento da reação no sentido dos reagentes.

Figura 13 - Conversão teórica do metano em função da temperatura e da pressão.

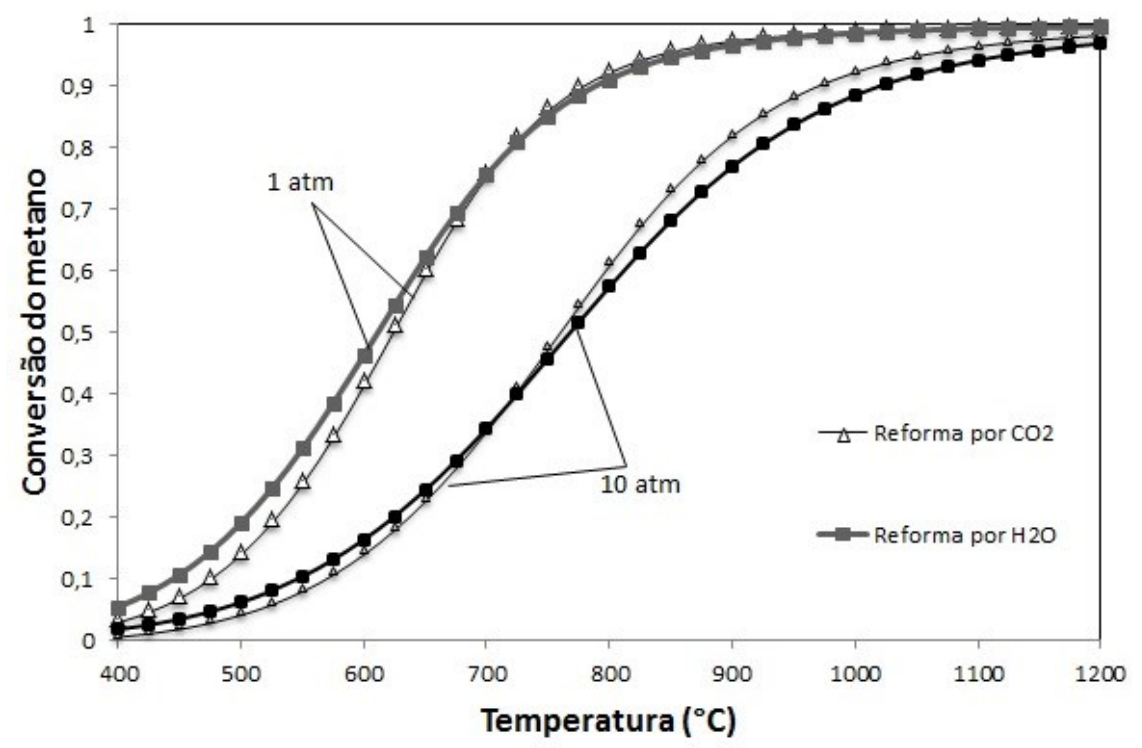

Fonte: o autor.

Münster e Grabke ${ }^{39,40}$ estudaram a reforma catalítica de metano pela reação com vapor de água, catalisada por ferro metálico. Para os autores, a reação (1) pode ser desmembrada em duas etapas intermediárias, conforme as seguintes reações:

$$
\begin{aligned}
& \mathrm{CH}_{4(g)}=[\mathrm{C}]+2 \mathrm{H}_{2(g)} \\
& {[\mathrm{C}]+\mathrm{H}_{2} \mathrm{O}=\mathrm{CO}+\mathrm{H}_{2}}
\end{aligned}
$$

A constante cinética da reação (14) a $920^{\circ} \mathrm{C}$ é cinco ordens de grandeza menor que a constante cinética da reação (33) na mesma temperatura. ${ }^{34}$ Desta forma, é provável que a etapa controladora da cinética de reforma catalítica do metano por vapor de água seja a reação 14 . Em um primeiro momento, os autores propõem a seguinte equação para representar a cinética da reação (1): 


$$
r_{(1)}=k_{(14)} f\left(a_{O}\right) \frac{p_{C H_{4}}}{p_{H_{2}}^{0,5}}
$$

Onde,

$r_{(1)}$ é a taxa de consumo de metano $\left[\mathrm{mol} \cdot \mathrm{cm}^{-2} \cdot \mathrm{s}^{-1}\right]$

$f\left(a_{0}\right)$ é uma função que calcula a porção de sítios ativos livres na superfície do ferro (1- $\theta$ ). A função $\theta$ foi utilizada em trabalho prévio de Grabke e Tauber $^{35}$ para descrever a fração de sítios ativos ocupados pelo oxigênio adsorvido, sendo calculada a partir da reação (29). A relação $p_{C H_{4}} / p_{H_{2}}^{0,5}$ também tem origem nos trabalhos de carburação do ferro por metano ${ }^{33}$ e corresponde a etapa de decomposição do radical $\mathrm{CH}_{3}$ (reação (22)).

Para validar o modelo representado pela Equação (34), os autores realizaram experimentos em um reator diferencial, em que misturas de $\mathrm{CH}_{4}-\mathrm{H}_{2}$ $\mathrm{H}_{2} \mathrm{O}$ fluíam através de tubos de quartzo inseridos em um forno. Foram utilizados dois tubos contendo uma folha de ferro de $5 \mu \mathrm{m}$ cada, sendo uma de referência (mantida em atmosfera de $\mathrm{H}_{2}$ ) e uma que reagiria com as misturas préestabelecidas. Mediam-se a concentração de carbono nas folhas através da resistência elétrica, como descrito na Seção 2.3.1, e a concentração de metano e monóxido de carbono nos gases de saída secos.

A Figura 14-A apresenta os resultados obtidos através da variação da relação $\mathrm{CH}_{4} / \mathrm{H}_{2}$, mantendo-se constante a relação $\mathrm{H}_{2} \mathrm{O} / \mathrm{H}_{2}$, isto é, não impactando sobre $f\left(a_{0}\right)$. A Figura 14-B mostra os resultados obtidos pela variação da relação $\mathrm{H}_{2} \mathrm{O} / \mathrm{H}_{2}$, mantendo fixas a relação $\mathrm{CH}_{4} / \mathrm{H}_{2}$ e a temperatura.

O aumento da temperatura, que influencia diretamente a constante cinética, elevou a velocidade da reação. A taxa de consumo de metano apresentou um comportamento linear em função da relação $p_{C_{4}} / p_{H_{2}}^{0,5}$, comprovando a dependência da reforma em relação à decomposição do metano (reação (14)). $\mathrm{O}$ aumento da relação $p_{\mathrm{H}_{2} \mathrm{O}} / p_{\mathrm{H}_{2}}$ diminuiu as taxas de reforma para 
uma mesma temperatura, pela maior ocupação de sítios ativos na superfície do ferro por oxigênio adsorvido, proveniente da reação (29).

Figura 14 - Dados experimentais para velocidade de consumo de metano $(r)$ utilizando ferro como catalisador: A) Resultados para relação $\mathrm{pH}_{2} \mathrm{O} / \mathrm{pH}_{2}$ constante e diferentes temperaturas; B) Resultados para temperatura constante e diferentes relações $\mathrm{pH}_{2} \mathrm{O} / \mathrm{pH}_{2}$.
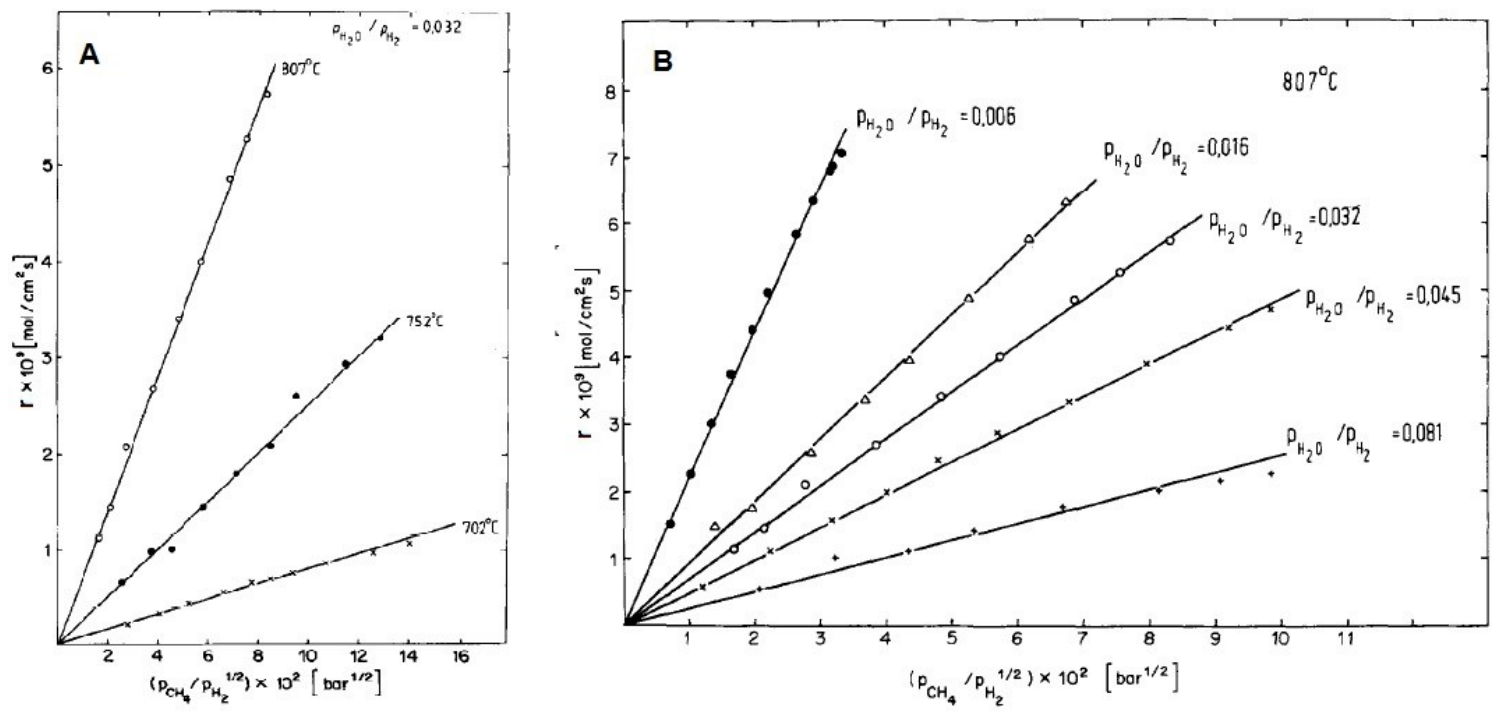

Fonte: Münster e Grabke. ${ }^{40}$

Para representar os sítios ocupados por oxigênio adsorvido, os autores substituíram o termo $f\left(a_{O}\right)$ pela isoterma de Langmuir, de forma que a fração de sítios ativos ocupados por oxigênio é representado por 1- $\theta$ e $\theta$ pela Equação (31). Entretanto, os dados experimentais a altas temperaturas não se adequaram ao modelo de Langmuir. Em um segundo artigo $^{40}$, os autores realizaram experimentos variando a temperatura e a relação $p_{H_{2} \mathrm{O}} / p_{H_{2}}$, mantendo-se constante a relação $p_{\mathrm{CH}_{4}} / p_{\mathrm{H}_{2}}$. Para obter o ajuste observado nos resultados apresentados na Figura 15, os autores alteraram a isoterma de Langmuir pela isoterma de Temkin. 
Figura 15 - Dados experimentais da velocidade de consumo de metano ( $r$ ) utilizando ferro como catalisador, em função da temperatura e da relação $\mathrm{pH}_{2} \mathrm{O} / \mathrm{pH}_{2}$.

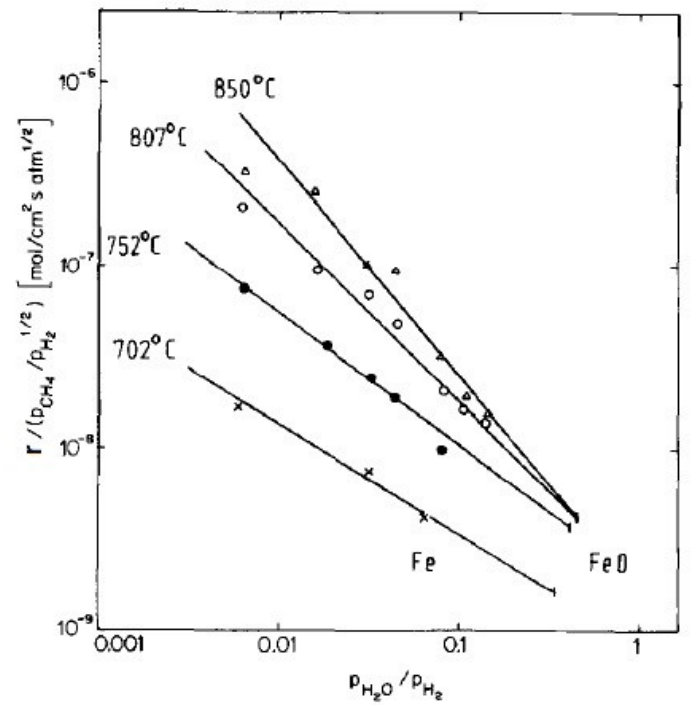

Fonte: Münster e Grabke. ${ }^{40}$

Desta forma, a função $f\left(a_{o}\right)$ foi definida como sendo $f\left(a_{o}\right)=a_{o}^{-n}$, com $0,6 \leq \mathrm{n} \leq 1$ e $a_{O}$ é a atividade de oxigênio adsorvida na superfície do ferro. Esse equacionamento representa a isoterma de Temkin

Ribeiro et $\mathrm{al}^{41}$ promoveu estudos da cinética de reforma de metano utilizando pelotas de ferro esponja como catalisador. As pelotas foram carregadas em um reator posicionado dentro de um forno de resistências e pendurado em uma balança. Os testes foram conduzidos de forma a manter constante, em um mesmo ensaio, a temperatura, a massa de DRI, a pressão (1 atm) e a composição do gás de entrada. Durante os ensaios, variou-se a vazão total dos gases. A Tabela 5 concentra os parâmetros dos ensaios de reforma catalítica de metano. Além da massa do sistema, mediam-se as concentrações de $\mathrm{CO}$ e $\mathrm{CO}_{2}$ nos gases de saída, após secagem do gás com auxílio de um condensador e um leito de sílica gel. 
Tabela 5 - Parâmetros dos ensaios de reforma catalítica de metano de Ribeiro et al.

\begin{tabular}{|c|c|c|c|c|c|c|c|c|}
\hline \multirow{2}{*}{ Comp } & \multicolumn{5}{|c|}{ Vol \% } & \multirow{2}{*}{$\begin{array}{c}\text { Temperatura } \\
\left({ }^{\circ} \mathrm{C}\right)\end{array}$} & \multirow{2}{*}{$\begin{array}{c}\text { Massa } \\
\text { de DRI } \\
\text { (g) }\end{array}$} & \multirow{2}{*}{$\begin{array}{c}\text { Vazão total de } \\
\text { entrada } \\
\text { (NL/min) }\end{array}$} \\
\hline & $\mathbf{H}_{2}$ & $\mathrm{CH}_{4}$ & $\mathrm{H}_{2} \mathrm{O}$ & $\mathrm{Ar}$ & $\mathrm{CO}$ & & & \\
\hline 1 & 52 & 13 & 26 & 10 & 0 & $\begin{array}{c}875,900,950 \\
1000 \text { e } 1050\end{array}$ & $\begin{array}{c}25,50 \\
65,85 \mathrm{e} \\
100\end{array}$ & 2,5 a 8,0 \\
\hline 2 & 62 & 14 & 14 & 10 & 0 & $\begin{array}{c}875,950 \mathrm{e} \\
1050\end{array}$ & 25 e 50 & 2,5 a 12 \\
\hline
\end{tabular}

Fonte: Ribeiro et al. ${ }^{41}$

O cálculo da conversão do metano, $X$, foi baseado no balanço de carbono das espécies gasosas, considerando que não havia carburação do DRI, conforme descrito na Equação (35).

$$
X=F_{C_{4}}^{0}-F_{C H_{4}}=F_{C O}+F_{C O_{2}}
$$

Onde,

$F_{C_{4}}^{0}$ e $F_{C_{4}}$ são as vazões de metano na entrada e na saída do sistema, respectivamente

$F_{\mathrm{CO}}$ e $F_{\mathrm{CO}_{2}}$ são as vazões de monóxido e dióxido de carbono, respectivamente, na saída do sistema.

Os autores trataram o reator utilizado nos ensaios de reforma como um reator catalítico de leito fixo preenchido por DRI. O balanço de massa deste tipo de reator resulta na Equação (36), na qual a derivada da conversão do metano em função da relação $\mathrm{W} / \mathrm{F}_{\mathrm{CH}}^{0}$, onde $\mathrm{W}$ é a massa de $\mathrm{DRI}$ do leito, é igual à taxa de reação $\left(-r_{\mathrm{CH}_{4}}\right)$. O balanço também é apresentado na forma integral. Nos experimentos, os autores variaram tanto a massa de DRI (W), quanto a vazão de 
entrada de metano $\left(F_{\mathrm{CH}_{4}}^{0}\right)$, de forma a se obter uma faixa extensa de conversão do metano. Os resultados destes ensaios são apresentados na Figura 16.

$$
-r_{C H_{4}}=\frac{d X}{d\left(W / F_{C H_{4}}^{0}\right)} \text { ou } \int_{0}^{X} \frac{d X}{-r_{C H_{4}}}=\frac{W}{F_{C H_{4}}^{0}}
$$

Figura 16 - Dados experimentais de conversão do metano em função da relação $\mathrm{W} / F_{C H_{4}}^{0}$ para diferentes temperaturas e composições gasosas.

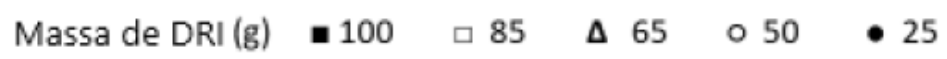
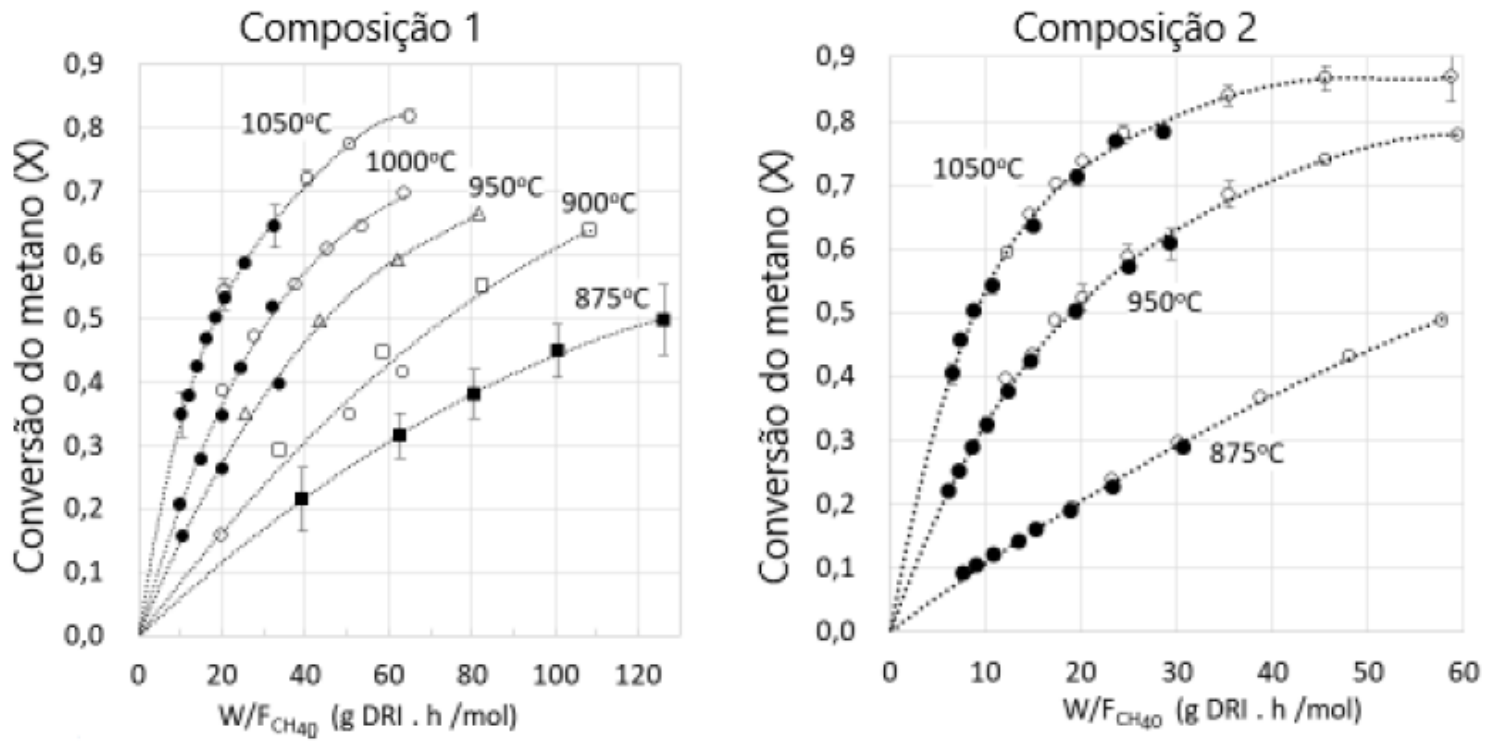

Fonte: Ribeiro et al. ${ }^{41}$

O aumento da temperatura eleva a conversão do metano para uma mesma relação $\mathrm{W} / \mathrm{F}_{\mathrm{CH}}^{0}$, enquanto o aumento da relação aumenta a conversão para uma mesma temperatura. Sob as mesmas condições de temperatura e relação $\mathrm{W} / \mathrm{F}_{\mathrm{CH}}^{0}$, a composição 2 apresentou maiores conversões de metano em comparação à composição 1 , possivelmente pelo menor teor de $\mathrm{H}_{2} \mathrm{O}$ em sua mistura, gerando uma menor quantidade de oxigênio adsorvido na superfície do ferro e liberando mais sítios ativos para que a reforma pudesse se proceder. 
Para avaliar o mecanismo controlador da cinética da reforma catalítica do metano, os autores consideraram as seguintes etapas para reação: difusão dos reagentes e produtos pela camada limite gasosa; difusão dos reagentes e produtos pelos poros do DRI; reação química na superfície interna do DRI.

A difusão de espécies através da camada limite gasosa foi avaliada pela realização de ensaios com variação da velocidade dos gases ao redor do DRI, de forma a alterar a espessura da camada limite gasosa. A difusão por poros foi avaliada através de ensaios com DRIs de diferentes diâmetros, de forma a alterar o volume de poros disponível para difusão dos gases. Em nenhum destes experimentos foi constatada diferenças significativas na conversão do metano que pudessem apontar para o controle da cinética da reforma de $\mathrm{CH}_{4}$.

Para testar a hipótese do controle por reação química, os autores acoplaram o modelo definido por Münster e Grabke ${ }^{39,40}$, descrito na Equação (34), ao balanço de massa apresentado na Equação (36). A função $f\left(a_{o}\right)$ foi interpretada como a quantidade de sítios ativos livres na superfície do DRI e substituída por 1- $\theta$, na qual $\theta$ é definido pela Equação (31). O modelo resultante é apresentado na Equação (37) e a Figura 17 apresenta a aplicação do modelo aos dados experimentais apresentados na Figura 16.

$$
\int_{0}^{X} \frac{d X}{\frac{1}{1+K_{O} p_{H_{2} O} / p_{H_{2}}} \cdot \frac{p_{C H_{4}}}{p_{H_{2}}^{0,5}}}=k \frac{W}{F_{C H_{4}}^{0}}
$$


Figura 17 - Aplicação do modelo de controle por reação química (Equação (37)) aos dados obtidos nos experimentos de reforma catalítica de metano para composição 1 e conversão de metano até 0,5 e composição 2 .

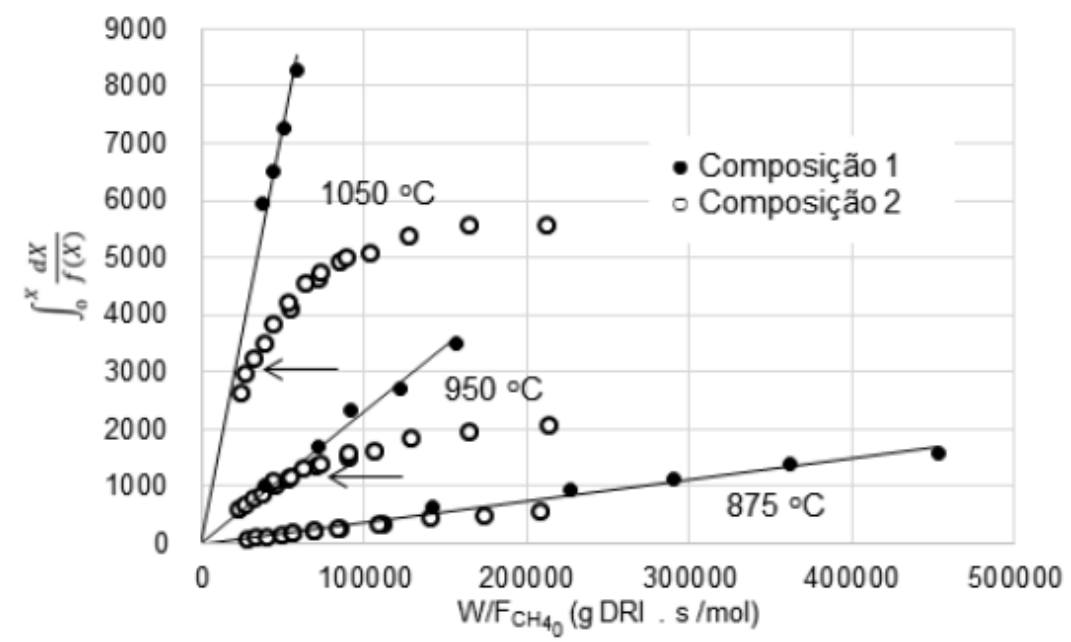

Fonte: Ribeiro et al. ${ }^{41}$

O modelo proposto por Ribeiro et $\mathrm{al}^{41}$ apresenta um bom ajuste aos dados experimentais obtidos nos ensaios de reforma de metano que utilizaram a composição 1 e que apresentaram conversões de até $50 \%$. Os resultados dos ensaios que utilizaram a composição 2 apresentam um bom ajuste ao modelo até os pontos indicados pelas setas na Figura 17, que correspondem à conversão de metano de, aproximadamente, $50 \%$. Todos os pontos abertos da curva de $875^{\circ} \mathrm{C}$ apresentaram conversões inferiores a $50 \%$. Desta forma, o modelo proposto por Münster e Grabke descreve adequadamente o controle da reação de reforma de metano até conversões de $50 \%$. A energia de ativação calculada através do modelo foi de $258 \mathrm{~kJ} / \mathrm{mol}$.

Os autores tentaram investigar a presença de outros mecanismos ou fenômenos que explicassem o desvio do modelo cinético proposto aos dados obtidos experimentalmente após $50 \%$ de conversão do metano. Uma das hipóteses investigadas seria a de carburação do DRI pela decomposição do metano, o que impactaria sobre o cálculo das taxas de conversão do $\mathrm{CH}_{4}$. As taxas de carburação reportadas correspondiam a um consumo de até $2 \%$ do metano injetado. Logo, esta carburação não influenciou significativamente no cálculo da conversão do metano. Entretanto, o carbono depositado poderia 
alterar as propriedades catalíticas do DRI pela ocupação de sítios ativos ou pela formação de cementita. Essa última hipótese será discutida no presente trabalho.

A revisão bibliográfica pertinente ao tema da redução direta com reforma in situ de metano serve como base para montagem da estrutura experimental e dos ensaios que serão utilizados no presente trabalho. 


\section{Objetivo}

Promover a análise cinética da carburação de pelotas de ferro esponja quando são utilizadas como catalisadoras da reforma de metano por vapor de água. Para tanto, foram realizados ensaios interrompidos de carburação com intuito de se construírem curvas de ganho de massa do DRI em função do tempo. Além da medida da taxa de reação, buscou-se entender os mecanismos de reação e as etapas controladoras do processo. 


\section{Materiais e métodos}

Os procedimentos experimentais foram feitos com a utilização de pelotas de minério de ferro produzidas pela Vale para processos de redução direta HyL/Energiron. As pelotas selecionadas para os ensaios possuíam granulometria entre $9,5 \mathrm{~mm}$ e $16 \mathrm{~mm}$. A composição química dessas pelotas está descrita na Tabela 6.

Tabela 6 - Composição química das pelotas de minério de ferro Vale para redução direta. Valores em \% em massa.

\begin{tabular}{ccccccccc}
\hline $\begin{array}{c}\mathrm{Fe} \\
\text { total }\end{array}$ & $\mathrm{SiO}_{2}$ & $\mathrm{Al}_{2} \mathrm{O}_{3}$ & $\mathbf{P}$ & $\mathbf{M n}$ & $\mathbf{C a O}$ & $\mathbf{M g O}$ & $\mathrm{TiO}_{2}$ & $\begin{array}{c}\text { Perda ao } \\
\text { Fogo }\end{array}$ \\
\hline 66,8 & 1,6 & 0,5 & 0,03 & 0,08 & 1,8 & 0,3 & 0,04 & 0,1 \\
\hline
\end{tabular}

Fonte: o autor.

Os gases utilizados no processo são argônio e hidrogênio ultra-puros $(99,999 \%$ mín) e metano científico $(99,97 \%)$. Os gases foram fornecidos pela Messer Gases.

\subsection{Sistema experimental de redução de pelotas e carburação de DRI}

A Figura 18 apresenta uma representação esquemática da estrutura experimental. $\mathrm{O}$ procedimento experimental iniciava-se com a pesagem das pelotas (minério ou DRI) e alimentação na retorta metálica. Posterior à alimentação das pelotas, a parte superior do reator era vedada pela aplicação de pasta de silicone entre o flange e a tampa da retorta.

Os gases utilizados estavam armazenados em cilindros e suas vazões eram controladas por controladores de fluxo de massa (CFM). No caso dos ensaios de carburação e reforma, aos gases era adicionado um fluxo de água líquida controlado por uma bomba peristáltica. A mistura era alimentada a um reator de aço inoxidável inserido em um forno de resistências elétricas 
(evaporador), mantido a $250^{\circ} \mathrm{C}$ para que se promovesse a evaporação da água, bem como um pré-aquecimento da mistura de reação. Após o evaporador, a mistura de reação era conduzida por tubulação de aço inoxidável aquecida por fitas térmicas com resistência elétrica para evitar a condensação de água.

Figura 18 - Representação esquemática da estrutura experimental.

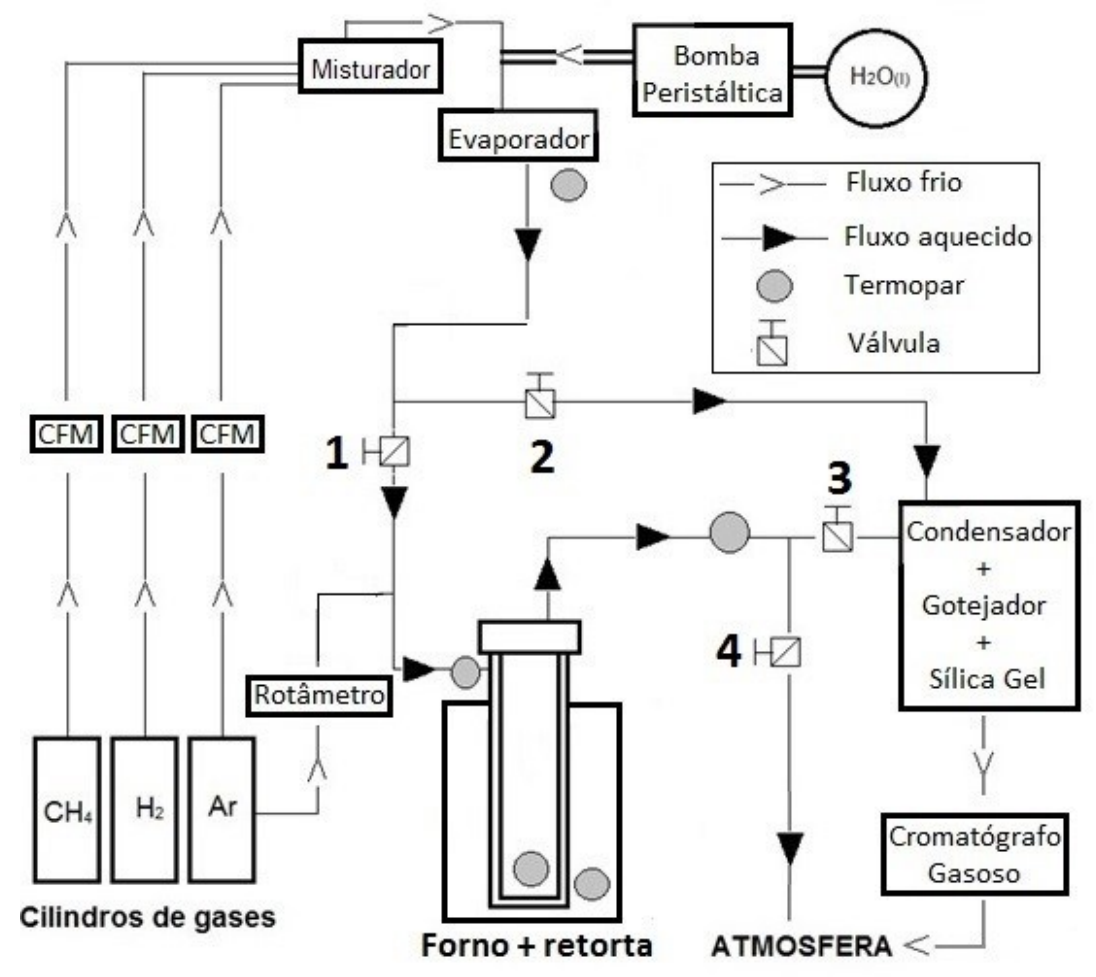

Fonte: o autor.

A mistura de reação era injetada em um reator metálico construído em aço inoxidável 316L, cujo desenho esquemático é apresentado na Figura 19. Essa retorta era mantida em um forno de resistências elétricas da marca Termolab. O reator é uma retorta de dupla câmara, no qual os gases eram injetados na câmara exterior, fluindo de maneira descendente e se aquecendo pelo contato com as paredes. Ao atingir o fundo, a mistura gasosa fluía de forma ascendente, atravessando a placa onde as pelotas ou DRI eram dispostas. A temperatura do leito era determinada por um termopar tipo $\mathrm{K}$, mantido em um 
tubo pirométrico posicionado no eixo central da retorta, atravessando a tampa da mesma.

Figura 19 - Desenho esquemático da retorta de aço inoxidável utilizada nos experimentos de carburação e reforma de metano.

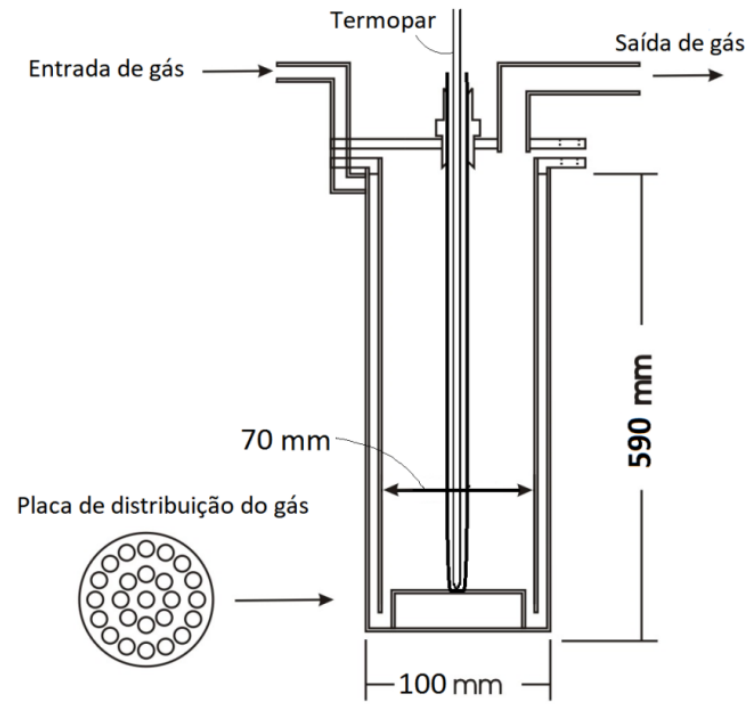

Fonte: o autor.

Os gases de saída do reator eram conduzidos até um condensador, composto por uma serpentina de cobre refrigerada à água, e após até um leito de sílica gel para retenção do vapor de água. Os gases secos eram então conduzidos ao cromatógrafo gasoso (CG) da marca Shimadzu, modelo GC-14B, para análise da composição gasosa. O cromatógrafo foi calibrado a partir da leitura de misturas padrão, cujas composições são descritas na Tabela 7.

Tabela 7 - Composições das misturas padrão utilizadas para calibração do cromatógrafo gasoso.

\begin{tabular}{cccccc}
\hline \multirow{2}{*}{ Mistura } & \multicolumn{5}{c}{ Composição (\%) } \\
\cline { 2 - 6 } & $\mathbf{H}_{\mathbf{2}}$ & $\mathbf{C O}$ & $\mathbf{C O}_{\mathbf{2}}$ & $\mathbf{C H}_{\mathbf{4}}$ & $\mathbf{A r}$ \\
\hline 1 & 20 & 20 & 20 & 20 & 20 \\
\hline 2 & 45 & 15 & 15 & 15 & 10 \\
\hline 3 & 67,5 & 22,5 & - & - & 10 \\
\hline
\end{tabular}




\begin{tabular}{llllll}
\hline 4 & 35 & 15 & 30 & - & 20
\end{tabular}

Fonte: o autor.

A Figura 20 apresenta a estrutura geral do aparato experimental, enquanto a Figura 21 exibe o conjunto do forno e da retorta metálica em detalhes. 
Figura 20 - Estrutura geral do aparato experimental mostrando a retorta metálica inserida dentro do forno de resistências elétricas, além do sistema de produção de vapor composto pelo reservatório de $\mathrm{H}_{2} \mathrm{O}$, a bomba peristáltica e o evaporador.

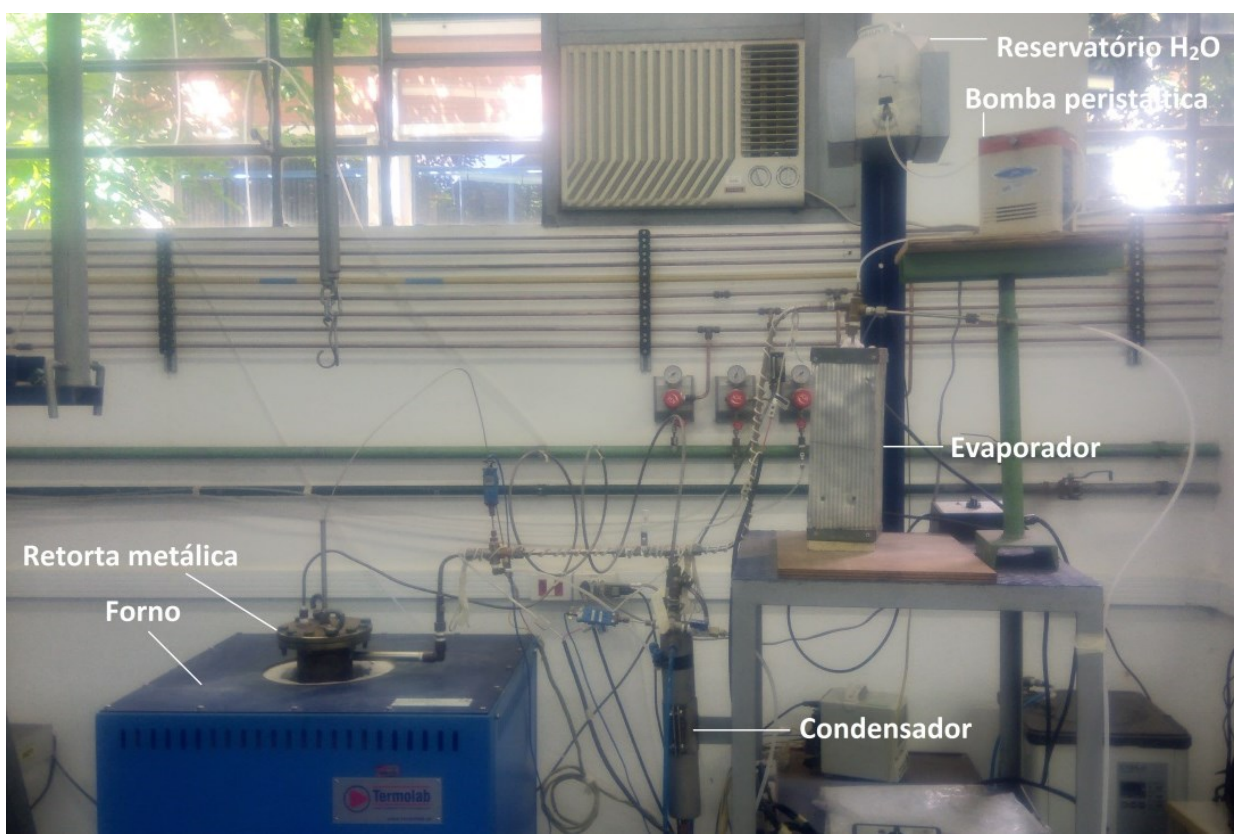

Fonte: o autor.

Figura 21 - Estrutura experimental mostrando a retorta metálica inserida no forno, a entrada e a saída dos gases do reator e o termopar inserido no poço pirométrico.

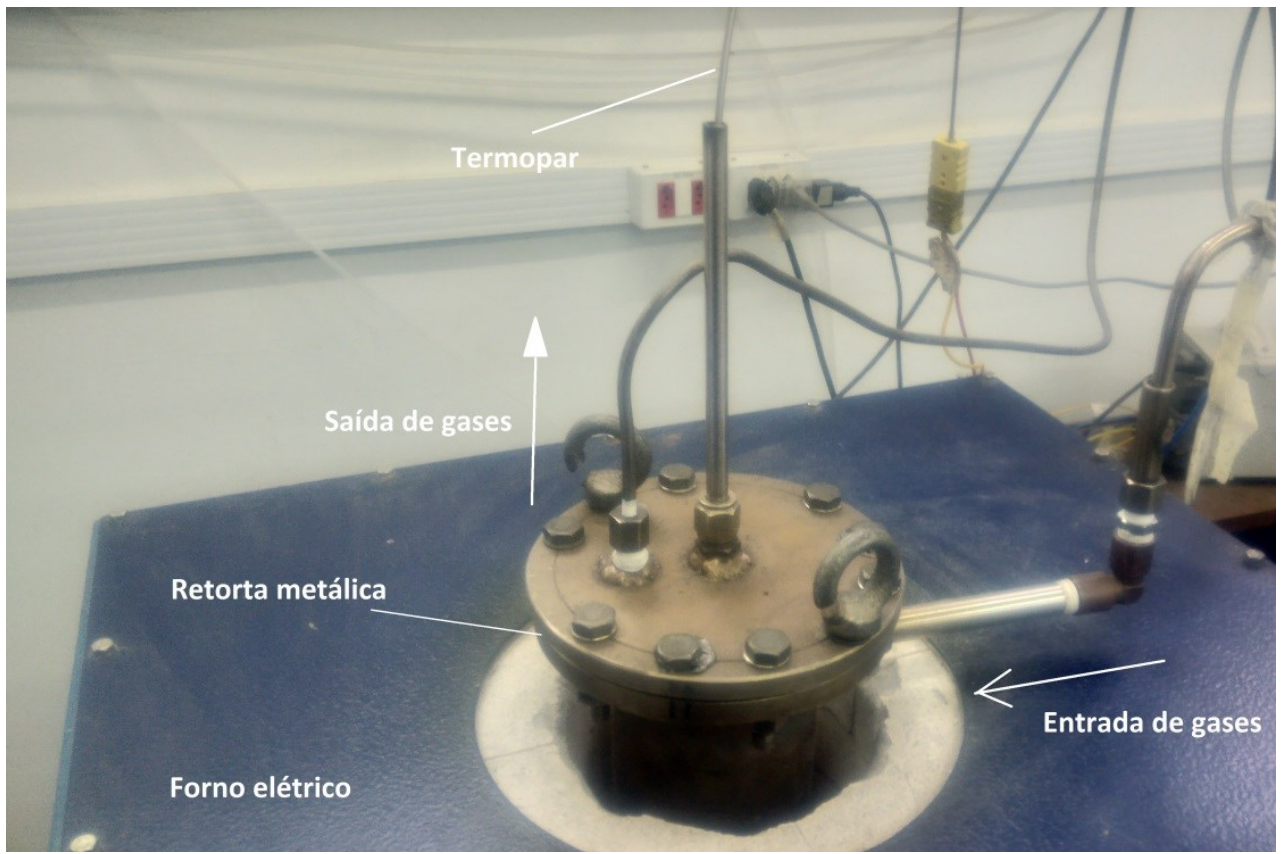

Fonte: o autor 


\subsection{Metodologia dos ensaios de redução direta}

As pelotas de minério de ferro, previamente aos ensaios de redução direta, foram secas em forno tipo mufla da marca Grion por 24 horas a $200^{\circ} \mathrm{C}$. Após alimentação de cerca de $300 \mathrm{~g}$ de pelotas secas na retorta, o sistema era aquecido com taxa de $10^{\circ} \mathrm{C} / \mathrm{min}$ até $950^{\circ} \mathrm{C}$, sendo mantido nesta temperatura por 2 horas e posteriormente resfriado. Argônio era injetado a uma vazão de $1,5 \mathrm{NL} / \mathrm{min}$ durante o aquecimento e o resfriamento de modo a manter a atmosfera inerte. Durante o patamar, as pelotas eram expostas a uma mistura $90 \% \mathrm{H}_{2}-10 \% \mathrm{Ar}$, com vazão total de $10 \mathrm{NL} / \mathrm{min}$. A escolha de uma mistura de hidrogênio e argônio foi feita para que o DRI produzido não contivesse carbono e, desta forma, não impactasse sobre os ensaios de carburação simultânea à reforma do metano. Ao término dos ensaios, as pelotas eram novamente pesadas e armazenadas a vácuo para evitar o contato com oxigênio.

Foram realizados quatorze ensaios de redução, nos quais foram produzidos, aproximadamente, $3,10 \mathrm{~kg}$ de DRI.

O grau de redução das pelotas (GR) foi estimado a partir da perda de massa das amostras, através da seguinte equação:

$$
G R(\%)=\frac{100 *\left(m_{0}-m_{f}\right)}{O_{F e}}
$$

Onde,

$m_{0}$ e $m_{f}$ são as massas das pelotas medidas aferidas antes e depois dos ensaios, respectivamente

$\mathrm{O}_{\mathrm{Fe}}$ é porcentagem mássica de oxigênio ligado ao ferro que, de acordo com a Tabela 6 , é de $28,75 \%$. 


\subsection{Metodologia dos ensaios de carburação simultânea à reforma catalítica de metano}

Cerca de $70 \mathrm{~g}$ de DRI era alimentado ao reator. As taxas de aquecimento $\left(10{ }^{\circ} \mathrm{C} / \mathrm{min}\right.$ ) e resfriamento, bem como a injeção de $1,5 \mathrm{NL} / \mathrm{min}$ de argônio nesses períodos, foram iguais em todos os testes.

Numa primeira fase dos testes de carburação do DRI simultâneos à reforma catalítica do metano, o objetivo foi determinar uma mistura gasosa que promovesse conversões de metano (desconsiderando a conversão para carburação) acima de $50 \%$ e carburasse o DRI em até $4 \%$ de carbono em massa. O intervalo de conversão de metano desejado é baseado na faixa na qual o modelo desenvolvido por Ribeiro et $\mathrm{al}^{41}$ não foi capaz de estabelecer o mecanismo controlador da cinética de reforma do metano. Já o limite para carburação é referente à porcentagem média de carbono presente no DRI obtido do processo Energiron. ${ }^{21} \mathrm{~A}$ temperatura desses ensaios foi de $1050^{\circ} \mathrm{C}$, que é a temperatura na qual os gases são injetados no reator industrial desse processo. As diferentes misturas foram injetadas com vazão de 7,0 NL/min por 90 minutos, A Tabela 8 exibe os parâmetros dos ensaios da primeira fase.

Tabela 8 - Parâmetros dos testes de carburação simultânea à reforma de metano com variação da composição gasosa. A atividade de carbono sólido na mistura gasosa foi calculada através do software Fact Sage 6.4, pacote FactPS.

\begin{tabular}{ccccccc}
\hline \multirow{2}{*}{ Mistura } & \multicolumn{3}{c}{ Composição (\%) } & $\mathbf{C H}_{4} / \mathbf{H}_{\mathbf{2}} \mathbf{O}$ & $\begin{array}{c}\text { Atividade de carbono na } \\
\text { mistura gasosa }\end{array}$ \\
\cline { 2 - 5 } & $\mathbf{H}_{\mathbf{2}}$ & $\mathbf{C H}_{\mathbf{4}}$ & $\mathbf{H}_{\mathbf{2}} \mathbf{O}$ & $\mathbf{A r}$ & & 21,5 \\
\hline 1 & 60 & 20 & 10 & 10 & 2,0 & 9,81 \\
\hline 2 & 65 & 15 & 10 & 10 & 1,5 & 3,74 \\
\hline 3 & 68 & 12 & 10 & 10 & 1,2 & 0,40 \\
\hline 4 & 62 & 14 & 14 & 10 & 1,0 & \\
\hline
\end{tabular}

Fonte: o autor. 
Pelos resultados obtidos na primeira fase, definiu-se uma composição gasosa (Mistura 3) para continuidade do trabalho. Para segunda fase de testes, cujo objetivo era avaliar a cinética de carburação simultânea à reforma de metano, utilizaram-se temperaturas entre 900 e $1050{ }^{\circ} \mathrm{C}$, que variaram de ensaio para ensaio, bem como o tempo de patamar nas temperaturas indicadas que variou entre 30 e 90 minutos.

Após os ensaios, escolhiam-se de forma aleatória 20 gramas de pelotas, que eram moídas em moinho de anéis para que $100 \%$ do material fosse passante em peneira de abertura de 0,149 mm (100 \#). A moagem tinha como objetivo melhorar a qualidade das análises do teor de carbono final das pelotas, que foi realizada por combustão em equipamento da marca Leco, modelo CS300.

A partir do teor de carbono médio do DRI, foi possível construir curvas de massa de carbono em função do tempo e determinar a taxa de carburação, $r_{c}$, dada em mols/s, de cada temperatura a partir da regressão linear dos pontos experimentalmente obtidos.

As taxas de carburação, por sua vez, foram utilizadas para comparação com modelos existentes na literatura e, consequentemente, na definição do mecanismo controlador da cinética do fenômeno.

A conversão do metano foi avaliada tanto para reação de reforma (reação

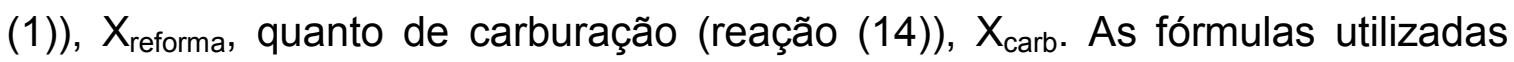
para estimativa destes dois tipos de reforma são descritas a seguir:

$$
X_{c a r b}=\frac{r_{C}}{F_{C H_{4, i n}}}
$$

Onde,

$$
F_{C H_{4, i n}} \text { é o fluxo molar de metano, dado em mols/s, alimentado no sistema }
$$
ao longo do ensaio. 


$$
X_{\text {reforma }}=X_{\text {total }}-X_{\text {carb }}
$$

Onde,

$X_{\text {total }}$ é a conversão total do metano, definida pela seguinte equação:

$$
X_{\text {total }}=1-\frac{F_{C H_{4, o u t}}}{F_{C H_{4, \text { in }}}}
$$

Onde,

$F_{C H_{4, o u t}}$ é o fluxo molar de metano, dado em mols/s, na saída do sistema.

O fluxo molar de metano na entrada do sistema é conhecido e determinado pela vazão de metano ajustada no respectivo CFM. Já o fluxo molar de metano na saída do sistema é calculado através da concentração de metano no gás de saída seco, obtido pelas análises do cromatógrafo gasoso.

O CG apresenta uma limitação na determinação da concentração de hidrogênio do gás de saída seco, uma vez que utiliza como gás carreador He, cujo massa molar ( $4 \mathrm{~g} / \mathrm{mol})$ é próxima ao do gás $\mathrm{H}_{2}(2 \mathrm{~g} / \mathrm{mol})$ e, desta forma, os picos de $\mathrm{H}_{2}$ não são identificáveis. Assim, a composição do hidrogênio no gás de saída seco é determinada através do balanço de massa do sistema. 


\section{Resultados e discussões}

Primeiramente, serão apresentados os resultados dos ensaios de redução das pelotas de minério de ferro, seguidos dos resultados dos ensaios de carburação simultânea à reforma de metano e a respectiva análise cinética.

\subsection{Redução das pelotas de minério de ferro}

A Figura 22 apresenta o perfil de temperatura do décimo segundo ensaio de redução direta. Durante os ensaios, a temperatura medida nas pelotas foi inferior em $10^{\circ} \mathrm{C}$ à temperatura pré-estabelecida no controlador do forno, que era de $950^{\circ} \mathrm{C}$. Logo após o início dos ensaios, há uma queda na temperatura das pelotas de $940{ }^{\circ} \mathrm{C}$ para temperaturas próximas de $900{ }^{\circ} \mathrm{C}$, voltando a se estabilizar no patamar de $940^{\circ} \mathrm{C}$ após cerca de 30 minutos. Esta queda é relacionada ao caráter endotérmico da redução dos óxidos de ferro por hidrogênio. $O$ perfil apresentado se repetiu para os demais experimentos de redução realizados ao longo do trabalho.

Figura 22 - Perfil de temperatura do leito de pelotas de minério de ferro durante o décimo segundo ensaio de redução direta.

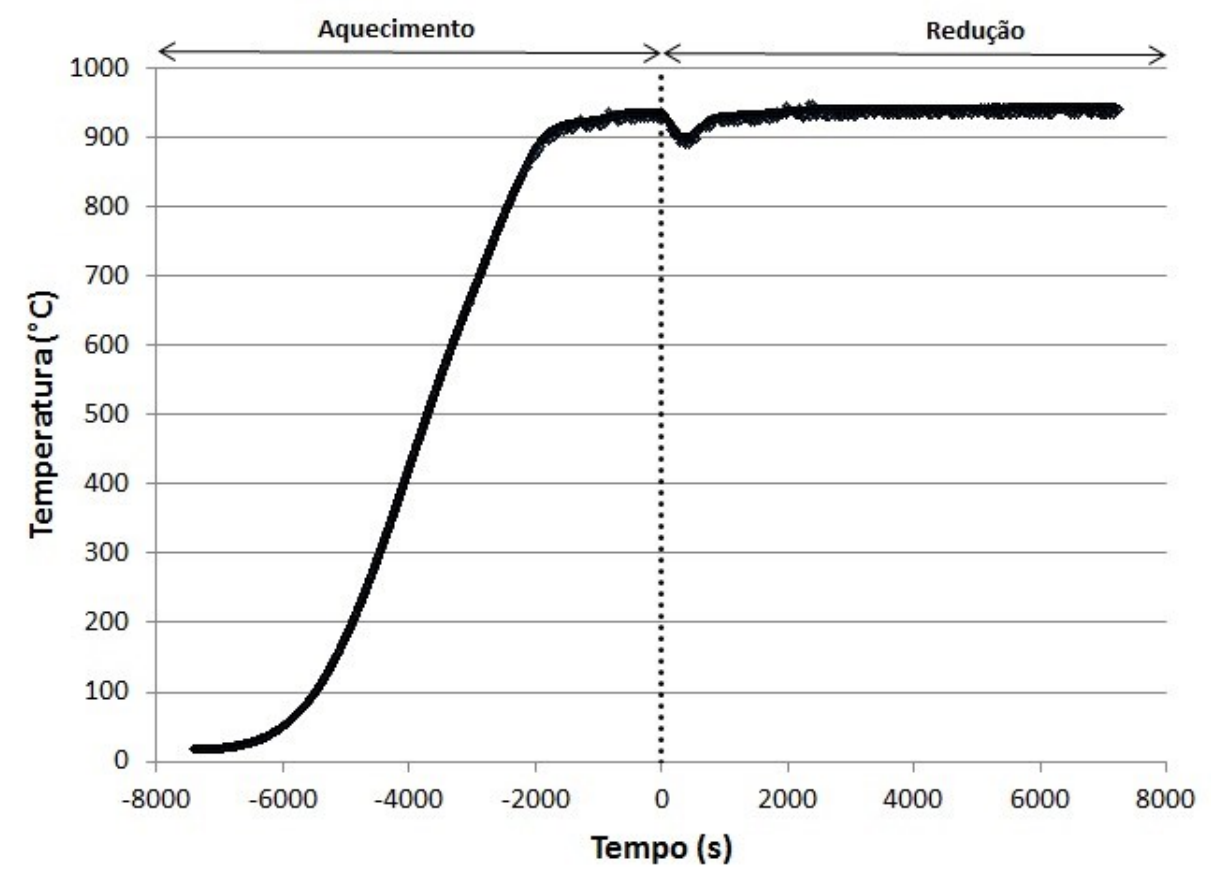

Fonte: o autor. 
A Tabela 9 exibe os dados dos ensaios de redução direta e o grau de redução obtido, conforme a Equação (38). O grau de redução médio obtido foi de $98,8 \%$.

Tabela 9 - Massa inicial e final das pelotas durante os ensaios de redução gasosa de minério de ferro, e o grau de redução estimado.

\begin{tabular}{cccc}
\hline Ensaio & Massa inicial - pelotas $(\mathbf{g})$ & Massa final DRI (g) & GR (\%) \\
\hline 01 & 276,8 & 192,1 & 106 \\
\hline 02 & 300,7 & 214,1 & 100 \\
\hline 03 & 299,7 & 217,6 & 95,3 \\
\hline 04 & 300,0 & 215,8 & 97,6 \\
\hline 05 & 299,1 & 214,1 & 98,8 \\
\hline 06 & 304,3 & 218,5 & 98,1 \\
\hline 07 & 299,0 & 214,1 & 98,8 \\
\hline 08 & 299,8 & 219,0 & 93,7 \\
\hline 09 & 301,4 & 218,7 & 95,4 \\
\hline 10 & 300,8 & 217,3 & 96,6 \\
\hline 11 & 303,3 & 218,0 & 97,8 \\
\hline 12 & 301,5 & 217,6 & 96,8 \\
\hline 13 & 301,5 & 216,6 & 97,9 \\
\hline 14 & 300,7 & 215,9 & 98,1 \\
\hline
\end{tabular}

Fonte: o autor.

O teor médio de carbono do DRI, em massa, produzido nos ensaios de redução foi de $0,022 \%$. Nota-se que não houve carburação das amostras, como se esperava.

As pelotas de minério de ferro e o DRI de alguns ensaios foram caracterizados quanto sua porosidade em um porosímetro de imagens com auxílio de uma câmera fotográfica digital da marca Fujinon, modelo SE, e o software de cálculo de porosidade da marca Automática Tecnologia S.A., versão 
1.2. A porosidade média das pelotas de minério de ferro e do DRI foram determinadas em $39 \pm 4 \%$ e $65 \pm 1 \%$, respectivamente. O crescimento da porosidade pela redução das pelotas era esperado, uma vez que há retirada do oxigênio ligado ferro e, consequentemente, produzem-se vazios no DRI obtido.

\subsection{Ensaios de carburação simultânea à reforma de metano}

Em uma primeira fase de testes, foi determinada a mistura de reação adequada aos ensaios interrompidos de carburação. Na sequência, foram realizados os testes de carburação simultânea à reforma de metano com a composição química definida na primeira fase, variando o tempo e a temperatura.

\subsubsection{Avaliação do efeito da relação $\mathrm{CH}_{4} / \mathrm{H}_{2} \mathrm{O}$ no gás de entrada sobre a carburação}

Para avaliar o efeito da relação $\mathrm{CH}_{4} / \mathrm{H}_{2} \mathrm{O}$ sobre a carburação e determinar da mistura de reação a ser utilizada nos ensaios interrompidos de carburação simultânea à reforma de metano, foram realizados testes com diferentes composições gasosas, apresentadas na Tabela 8.

O objetivo destes ensaios foi de determinar uma composição que promovesse conversões de metano acima de $50 \%$ e carburasse o DRI em até $4 \%$ de carbono em massa, conforme discutido na Seção 4.3. A Figura 23 apresenta a curva do teor final de carbono dos DRl's ensaiados a $1050{ }^{\circ} \mathrm{C} \mathrm{em}$ função da relação $\mathrm{CH}_{4} / \mathrm{H}_{2} \mathrm{O}$ das diferentes composições utilizadas nos ensaios. 
Figura 23 - Porcentagem final de carbono do $\mathrm{DRI}$ em função da relação $\mathrm{CH}_{4} / \mathrm{H}_{2} \mathrm{O}$ nos ensaios de carburação simultânea à reforma de metano a $1050^{\circ} \mathrm{C}$ por 90 minutos.

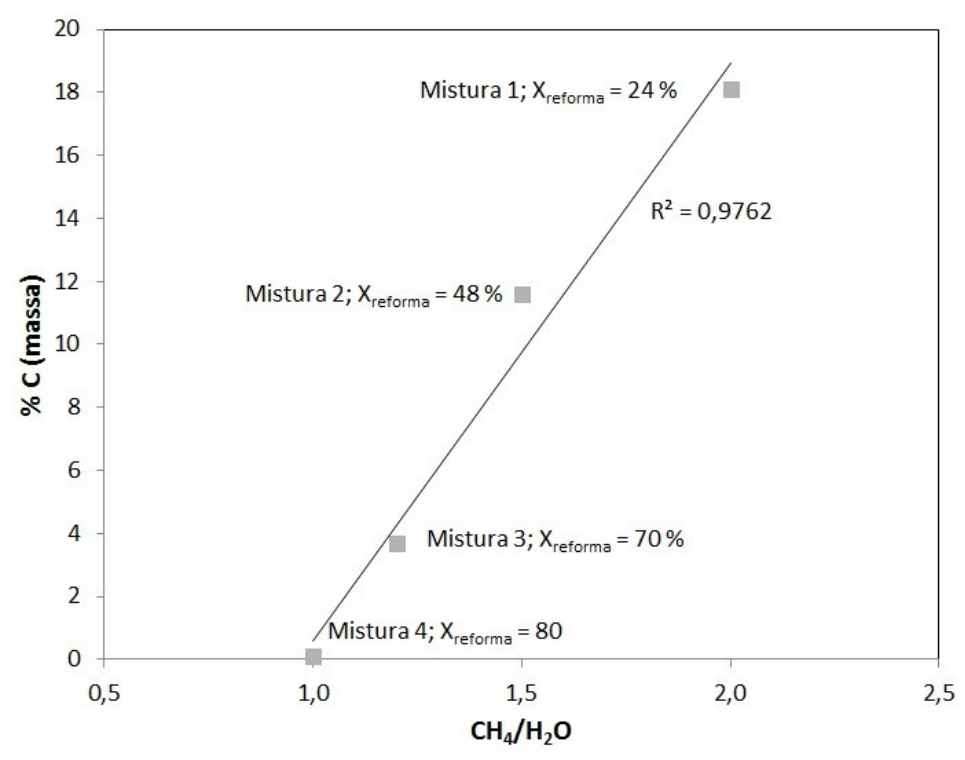

Fonte: o autor.

$\mathrm{O}$ aumento da relação $\mathrm{CH}_{4} / \mathrm{H}_{2} \mathrm{O}$ de 1,0 a 2,0 promoveu o aumento do teor de carbono final do DRI de maneira praticamente linear. Esse acréscimo concorda com o aumento da atividade de carbono na mistura gasosa, conforme apresentado na Tabela 8. Ademais, a diminuição do teor de $\mathrm{H}_{2} \mathrm{O}$ sistema pode ter um efeito significativo para o aumento do teor de carbono, por gerar uma menor quantidade de oxigênio adsorvido na superfície do DRI através da reação (29). Dessa forma, a superfície do DRI estaria mais disponível para carburação, em decorrência da menor ocupação de sítios ativos pelo oxigênio adsorvido.

O ensaio de carburação com a Mistura $3\left(68 \% \mathrm{H}_{2}-12 \% \mathrm{CH}_{4}-10 \% \mathrm{H}_{2} \mathrm{O}\right.$ - $10 \%$ Ar) apresentou $70 \%$ de conversão do metano por reforma gasosa e teor de carbono final no DRI de 3,67 \%, valores que estão dentro da faixa desejada. Além desses fatores, avaliou-se também a influência da carburação sobre a reforma do metano. Para tanto, verificou-se a composição do gás de saída seco ao longo do ensaio com auxílio das leituras realizadas pelo cromatógrafo gasoso. Os resultados são apresentados na Figura 24. 
Figura 24 - Temperatura das pelotas e concentração de espécies gasosas ao longo do ensaio de carburação simultânea à reforma utilizando a mistura 3 .

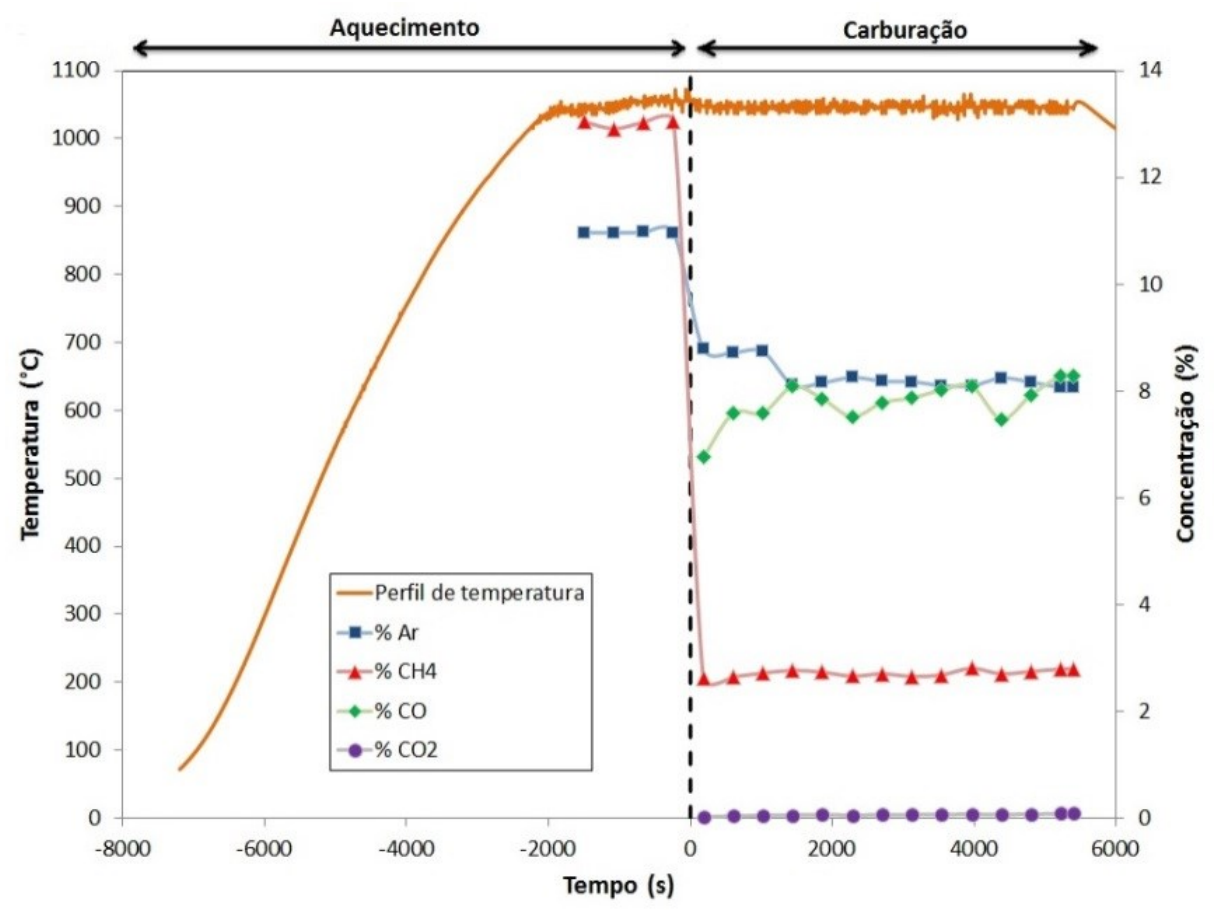

Fonte: o autor.

Após a injeção da mistura de reação, a temperatura do leito de DRI passou $1055{ }^{\circ} \mathrm{C}$ para $1045{ }^{\circ} \mathrm{C}$, mantendo-se neste patamar ao longo do restante do ensaio. Essa diminuição da temperatura está relacionada ao caráter endotérmico da reação de reforma do metano

A concentração média de monóxido de carbono ao longo do ensaio foi de $7,87 \pm 0,42 \%$. O CO foi o gás que apresentou maior variação em sua composição, valor que foi inferior a $0,5 \%$. Caso houvesse uma influência da carburação sobre a reforma, o teor de CO diminuiria ao longo do ensaio. Esse comportamento não foi observado nos resultados apresentados na Figura 24.

A conversão do metano para carburação, $X_{\text {carb }}$, foi estimada em 0,06 ,

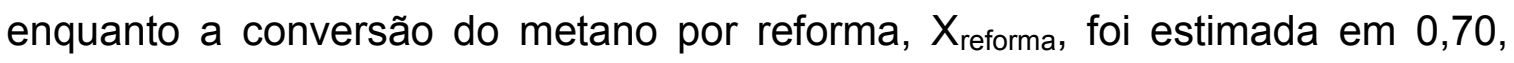
mostrando que a carburação foi responsável pelo consumo de apenas $6 \%$ do metano injetado no sistema, sendo 10 vezes menor que o consumo de metano para reforma gasosa. 
Esses resultados mostraram que a carburação não influenciou significativamente sobre a reforma. Desta forma, a Mistura 3 foi escolhida para continuidade do trabalho.

\subsubsection{Ensaios interrompidos de carburação simultânea à reforma de metano}

A Figura 25 apresenta o teor de carbono do DRI, em mols/g de DRI (mols/gDR $)$, após os ensaios de carburação com a mistura 3 , em função do tempo. No Anexo A é possível ver em detalhes os dados e resultados de todos os ensaios de carburação simultânea à reforma catalítica de metano por vapor de água, utilizando ferro esponja como catalisador.

Figura 25 - Teor final de carbono do DRI, em mols/gRl, em função do tempo e da temperatura dos ensaios de carburação simultânea à reforma de metano, utilizando a mistura 3.

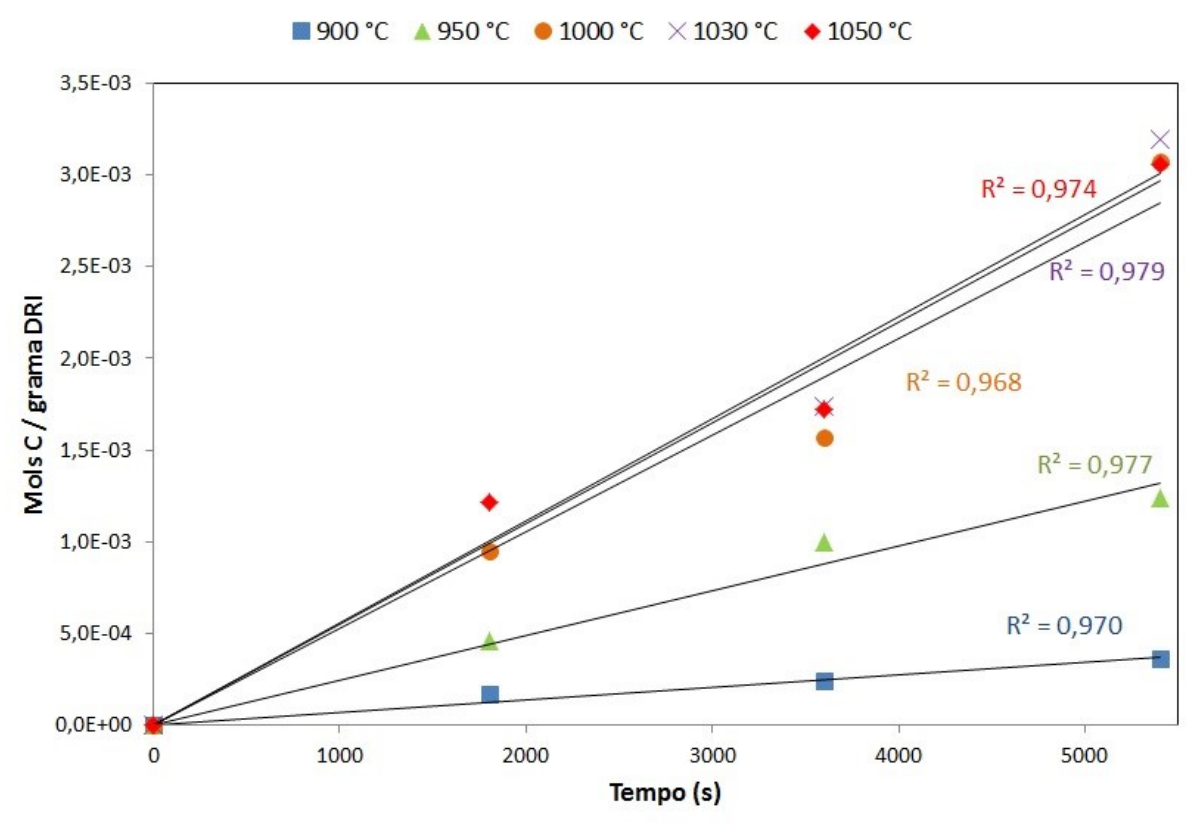

Fonte: o autor.

Nota-se que o teor de carbono final do DRI aumenta com o aumento da temperatura e do tempo dos ensaios. Para cada temperatura, estabeleceu-se 
uma regressão linear a partir dos dados obtidos experimentalmente, cujo coeficiente angular representa a taxa de carburação, dada em mols de C.min ${ }^{1} . g_{\mathrm{DRI}}{ }^{-1}$. O ajuste dos dados experimentais às retas foi satisfatório, com valores de $R^{2}$ superiores a 0,96 , indicando que taxas de carburação são constantes em relação ao tempo, nos intervalos medidos neste trabalho.

Observa-se que nas temperaturas de $1000{ }^{\circ} \mathrm{C}, 1030{ }^{\circ} \mathrm{C}$ e $1050{ }^{\circ} \mathrm{C}$, os teores de carbono obtidos foram semelhantes entre si. Esses resultados mostram que acima de $1000{ }^{\circ} \mathrm{C}$, o aumento da temperatura tem efeito menos pronunciado sobre a taxa de carburação.

A Tabela 10 apresenta os valores da conversão de metano para os cenários de reforma gasosa e carburação. Observa-se que as conversões por reforma gasosa, bem como por carburação, são maiores conforme se aumenta a temperatura. Entretanto, variam pouco ao longo do tempo de ensaio. As variações em ensaios a uma mesma temperatura e diferentes tempos podem estar relacionadas às pequenas diferenças de granulometria do DRI entre um ensaio e outro, que podem resultar em diferenças na distância de difusão das espécies gasosas.

Tabela 10 - Conversões de metano por reforma gasosa, por carburação e total em função do tempo e da temperatura dos ensaios.

\begin{tabular}{ccccc}
\hline Temperatura $\left({ }^{\circ} \mathbf{C}\right)$ & Tempo $(\mathbf{m i n})$ & $\mathbf{X}_{\text {reforma }}$ & $\mathbf{X}_{\text {carb }}$ & $\mathbf{X}_{\text {total }}$ \\
\hline \multirow{3}{*}{900} & 30 & 0,47 & 0,01 & 0,48 \\
\cline { 2 - 5 } & 60 & 0,44 & 0,01 & 0,45 \\
\cline { 2 - 5 } & 90 & 0,48 & 0,01 & 0,49 \\
\hline \multirow{3}{*}{950} & 30 & 0,63 & 0,03 & 0,66 \\
\cline { 2 - 5 } & 60 & 0,59 & 0,03 & 0,62 \\
\cline { 2 - 5 } 1000 & 90 & 0,60 & 0,03 & 0,63 \\
& 30 & 0,68 & 0,06 & 0,74 \\
\hline \multirow{3}{*}{1030} & 60 & 0,70 & 0,05 & 0,75 \\
& 90 & 0,73 & 0,07 & 0,80 \\
\hline \multirow{3}{*}{1050} & 60 & 0,74 & 0,05 & 0,79 \\
& 90 & 0,74 & 0,07 & 0,81 \\
\cline { 2 - 5 } & 30 & 0,72 & 0,08 & 0,80 \\
\cline { 2 - 5 } & 60 & 0,72 & 0,05 & 0,77 \\
\hline
\end{tabular}


Fonte: o autor.

Para avaliação cinética dos dados levantados, consideraram-se as seguintes etapas para a reação de carburação do DRI simultânea à reforma catalítica do metano: (I) difusão dos reagentes/produtos gasosos pela camada limite gasosa; (II) difusão dos reagentes/produtos gasosos pelos poros do DRI; (III) reação química na superfície interna do DRI com deposição de carbono; (IV) difusão do carbono para o interior da matriz de ferro.

\subsubsection{Avaliação da cinética de carburação simultânea à reforma catalítica de metano}

Duas abordagens foram utilizadas para avaliação do controle cinético da carburação simultânea à reforma de metano: a metodologia de avaliação cinética de reações gás/sólido ${ }^{42,43}$ e a metodologia desenvolvida por Grabke ${ }^{33}$ para o controle por reação química.

\subsubsection{Avaliação cinética de reações gás/sólido}

A metodologia de avaliação cinética de reações gás/sólido ${ }^{42,43}$ utiliza de frações de reação para determinação do mecanismo controlador da cinética. Para tanto, cada modelo de controle cinético apresenta uma equação característica, representada por uma função da fração de reação, $f(\alpha)$, que pode ser igualada ao produto da constante cinética, k', pelo tempo, t, conforme a Equação (42):

$$
f(\alpha)=k^{\prime} t
$$


Para determinação do mecanismo controlador da cinética do fenômeno em estudo, utilizou-se como fração de reação a fração de carburação, $\alpha_{c}$, calculada a partir da Equação (43).

$$
\alpha_{c}=\frac{n_{C}}{n_{C, F e_{3} C}}
$$

Onde,

$n_{C}$ é o número de mols de carbono depositado no DRI

$n_{C, F e_{3} C}$ é o número de mols de carbono necessário para que todo $\mathrm{Fe}$ presente no DRI fosse convertido a $\mathrm{Fe}_{3} \mathrm{C}$.

Os valores de $\alpha_{c}$ foram plotados em função do tempo, conforme apresentado no gráfico da Figura 26. Notam-se bons ajustes dos dados obtidos experimentalmente às retas.

Figura 26 - Fração de carburação obtida experimentalmente em função do tempo.

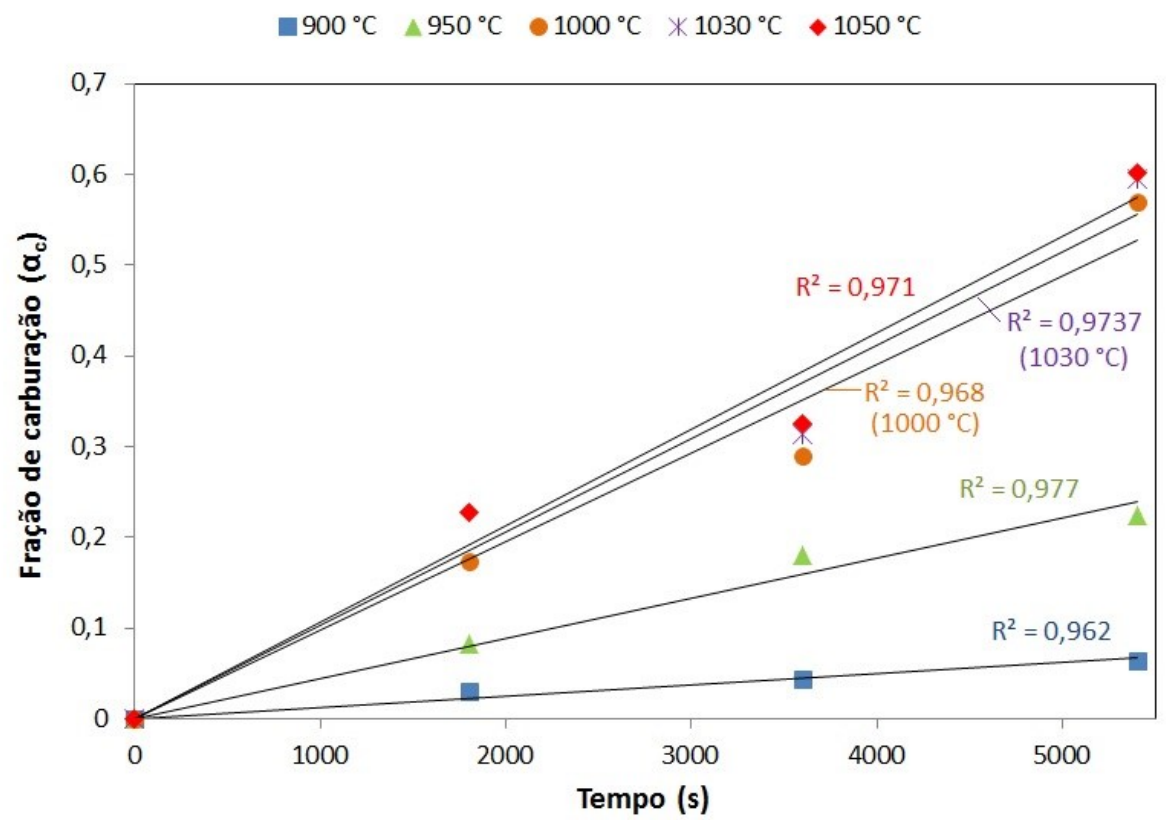

Fonte: o autor. 
Para verificação de qual modelo melhor representa os pontos obtidos experimentalmente, utilizou-se o método do tempo reduzido. Esse método considera que se uma função que descreve um modelo cinético é válida em toda faixa de tempo e de temperaturas em que os dados experimentais foram levantados. No presente trabalho, escolheu-se o tempo necessário para que a fração de carburação fosse de 0,2. Desta forma, substituindo $\alpha_{c}=0,2$ na Equação (42), obtém-se a Equação (44):

$$
f\left(\alpha_{c}=0,2\right)=f(0,2)=k^{\prime} t_{0,2}
$$

Onde,

$t_{0,2}$ é o tempo necessário para que se atinja $\alpha_{c}=0,2$.

Dividindo a expressão geral, destacada na Equação (42), pela Equação (44), obtém-se uma expressão adimensional e que não depende da constante cinética, denominada tempo reduzido, $\mathrm{t}^{*}$, conforme apresentado na Equação (45):

$$
t^{*}=\frac{f\left(\alpha_{c}\right)}{f(0,2)}=\frac{t}{t_{0,2}}
$$

Desta forma, para uma determinada função $f$, pode-se calcular o tempo reduzido para cada $\alpha_{c}$. Plotando os valores de $\alpha_{c}$ em função do tempo reduzido, é possível identificar o modelo cinético que melhor representa o fenômeno observado experimentalmente. A Figura 27 apresenta os valores de fração de carburação em função do tempo reduzido para diversos modelos cinéticos de reações gás/sólido obtidos da literatura ${ }^{42,43}$ e também dos valores calculados a partir dos dados experimentais. A Figura 27-A representa os modelos cinéticos que envolvem controle por reação química, enquanto a Figura 27-B apresenta os 
modelos cinéticos que envolvem controle por difusão. Todos os modelos cinéticos avaliados, e suas respectivas funções, são listados na Tabela 11.

Tabela 11 - Modelos cinéticos de reações gás/sólido e suas respectivas funções da fração de reação $(\alpha)$.

\begin{tabular}{|c|c|}
\hline Modelo & $f(\alpha)=k^{\prime} t$ \\
\hline Difusão 1D & $\alpha^{2}$ \\
\hline Difusão 2D & {$[(1-\alpha) \cdot \ln (1-\alpha)]+\alpha$} \\
\hline Difusão 3D & $\left(1-(1-\alpha)^{1 / 3}\right)^{2}$ \\
\hline Difusão por poros & $0,5-(\alpha / 3)-0,5(1-\alpha)^{2 / 3}$ \\
\hline Ginstling-Brounshtein & $1-(2 \alpha / 3)-(1-\alpha)^{2 / 3}$ \\
\hline Reação química - ordem 1 & $-\ln (1-\alpha)$ \\
\hline Reação química - ordem 2 & $(1 /(1-\alpha))-1$ \\
\hline Reação química - ordem 3 & $0,5 \cdot\left[(1-\alpha)^{-2}-1\right]$ \\
\hline Reação química - partículas cilíndricas & $1-(1-\alpha)^{1 / 2}$ \\
\hline Reação química - partículas esféricas & $1-(1-\alpha)^{1 / 3}$ \\
\hline
\end{tabular}

Fonte: construída com os dados de ${ }^{42,43}$

Pela análise da Figura 27, nota-se claramente que os dados experimentais tiveram um ajuste mais adequado aos modelos cinéticos que envolvem controle por reação química. Entretanto, não fica claro sobre qual modelo os dados experimentais teriam o melhor ajuste. 
Figura 27 - Fração de carburação em função do tempo reduzido para os dados experimentais e diferentes modelos cinéticos obtidos da literatura. ${ }^{42,43}$
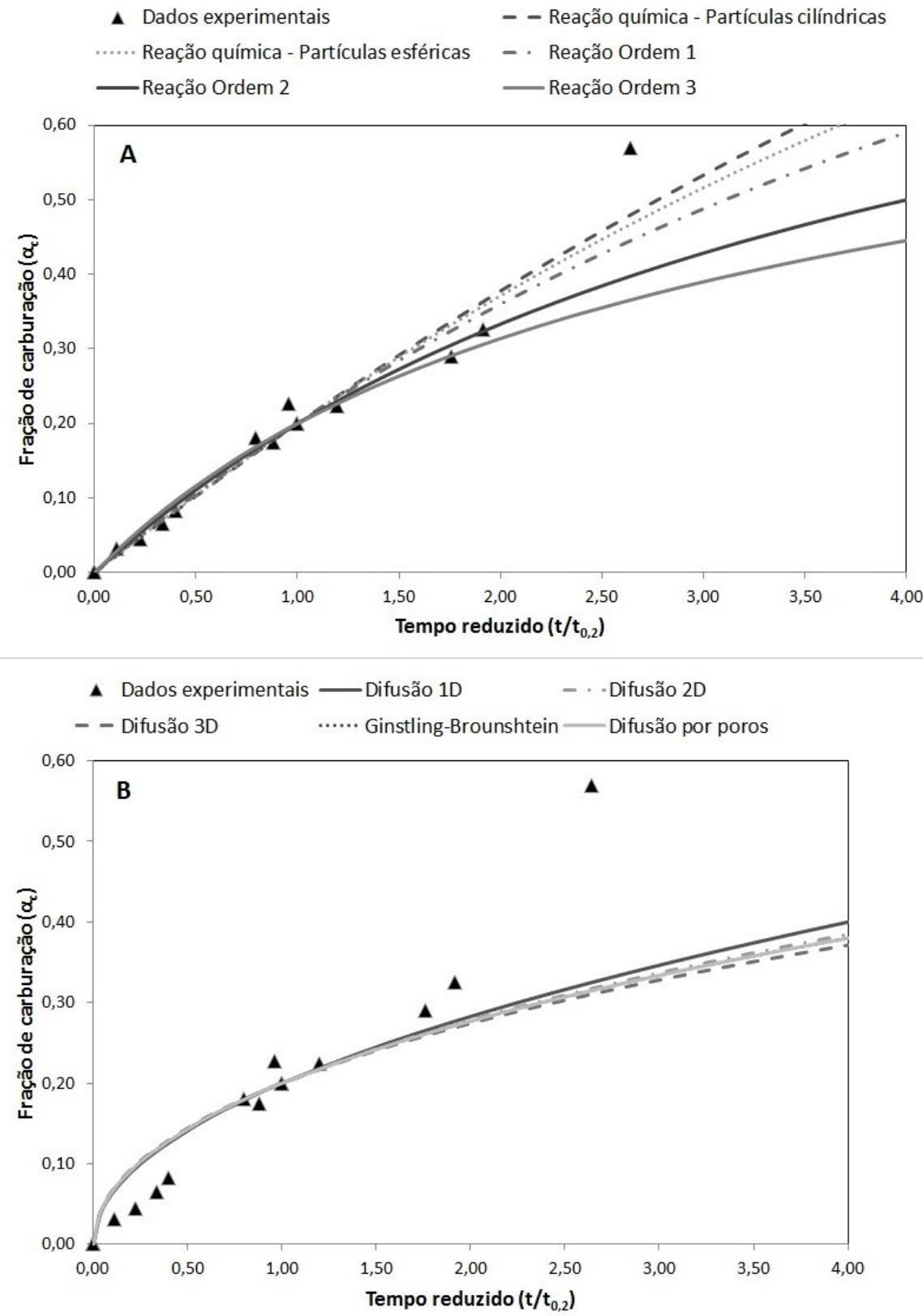

Fonte: o autor.

Os modelos cinéticos utilizados podem ser traduzidos em funções que são igualadas a retas, conforme apresentado na Equação (42). Assim, com intuito de distinguir qual o modelo que melhor se ajusta aos dados obtidos experimentalmente, foram calculados os valores da função $f\left(\alpha_{c}\right)$, através da 
Equação (42), para cada modelo cinético. O modelo escolhido é aquele que apresenta o melhor ajuste linear aos pontos e, para checar esse ajuste, foi utilizado o método do coeficiente de determinação $\left(R^{2}\right)$. Este método é uma medida do ajuste da regressão linear aos dados obtidos experimentalmente, que varia entre 0 e 1 , sendo 1 o valor que representa o ajuste ideal da regressão aos pontos experimentais. A Tabela 12 apresenta os modelos cinéticos, as funções correspondentes a cada modelo e os valores de $\mathrm{R}^{2}$ para cada temperatura.

As diferenças entre os valores de $R^{2}$ para os modelos de reação química de ordem 01, reação química em partículas cilíndricas e reação química em partículas esféricas são pequenas. Foi escolhido o modelo de reação química em partículas esféricas para continuidade da análise, pois $0 \mathrm{R}^{2}$ médio das temperaturas estudadas foi o segundo maior entre todos os modelos e pelo fato de o DRI possuir uma geometria mais próxima a uma esfera. 
Tabela 12 - Modelos cinéticos ${ }^{42,43}$, funções que os descrevem e o coeficiente de determinação $\left(R^{2}\right)$ calculado para cada modelo a partir dos valores de $\alpha_{c}$ apresentados na Figura 27 . Em destaque, os maiores valores de $R^{2}$ para cada temperatura e para média dos quatro valores.

\begin{tabular}{c|c|c|c|c|c|c}
\hline \multirow{2}{*}{ Modelo cinético } & \multirow{2}{*}{$\left(\boldsymbol{\alpha}_{c}\right) \mathbf{k} \mathbf{k}^{\mathbf{\prime} \mathbf{t}}$} & \multicolumn{3}{|c}{$\mathbf{R}^{\mathbf{2}}$} \\
\cline { 3 - 7 } & $-\ln \left(1-\alpha_{c}\right)$ & 0,966 & 0,984 & 0,907 & 0,925 & 0,945 \\
\hline Reação Química - Ordem 01 & $\left(\frac{1}{1-\alpha_{c}}\right)-1$ & 0,970 & 0,987 & 0,825 & 0,840 & 0,905 \\
\hline Reação Química - Ordem 02 & $0,5 *\left[\left(1-\alpha_{c}\right)^{2}-1\right]$ & $\mathbf{0 , 9 7 3}$ & $\mathbf{0 , 9 8 8}$ & 0,743 & 0,749 & 0,863 \\
\hline Reação Química - Ordem 03 & $1-\left(1-\alpha_{c}\right)^{\frac{1}{2}}$ & 0,964 & 0,981 & $\mathbf{0 , 9 4 1}$ & $\mathbf{0 , 9 5 5}$ & $\mathbf{0 , 9 6 0}$ \\
\hline Reação Química em Partículas cilíndricas & $1-\left(1-\alpha_{c}\right)^{\frac{1}{3}}$ & 0,965 & 0,982 & 0,931 & 0,946 & 0,956 \\
\hline Reação Química em Partículas esféricas & & &
\end{tabular}

Fonte: o autor. 
O modelo de reação química em partículas esféricas é uma dedução do modelo cinético de partículas porosas com conversão progressiva. ${ }^{44}$ A partícula em estudo é considerada como um aglomerado de micropartículas densas envolvidas por uma rede de poros. A reação química ocorre ao longo de todo volume da partícula nas superfícies das micropartículas, onde o gás de reação possa interagir, formando uma camada de cinzas (produto sólido). Desta forma, o gás de reação difunde pela camada de cinzas na micropartícula até encontrar o núcleo não reagido, formando uma frente de reação, que avança até a total conversão do núcleo.

O modelo em questão parece ter relações com o fenômeno do presente trabalho (carburação), por se tratar de uma partícula porosa (DRI), que após uma reação na superfície do ferro (carburação pela decomposição do metano), possivelmente forma uma camada de produto sólido (cementita, após reação do carbono com ferro metálico). Um estudo mais detalhado, com um número maior de experimentos, nos quais se pudessem alterar o tamanho e a porosidade do DRI, são necessários para validação deste modelo.

Os valores das constantes cinéticas, k', calculadas para o modelo de reação química em partículas são apresentados na Tabela 13.

Tabela 13 - Constantes cinéticas calculadas a partir dos dados experimentais pelo modelo de reação química em partículas esféricas.

\begin{tabular}{cccccc}
\hline Temperatura $\left({ }^{\circ} \mathrm{C}\right)$ & 900 & 950 & 1000 & 1030 & 1050 \\
\hline $\mathbf{k}^{\prime}(1 / \mathbf{s})$ & $4,2.10^{-6}$ & $1,6.10^{-5}$ & $4,0.10^{-5}$ & $4,3.10^{-5}$ & $4,5.10^{-5}$ \\
\hline
\end{tabular}

Fonte: o autor.

Aplicando a lei de Arrhenius às constantes cinéticas obtidas é possível calcular a energia de ativação do processo. A Figura 28 mostra o gráfico de Arrhenius construído a partir dos dados das constantes apresentados na Tabela 13. 
Figura 28 - Gráfico de Arrhenius obtido a partir das constantes cinéticas apresentadas na Tabela 13.

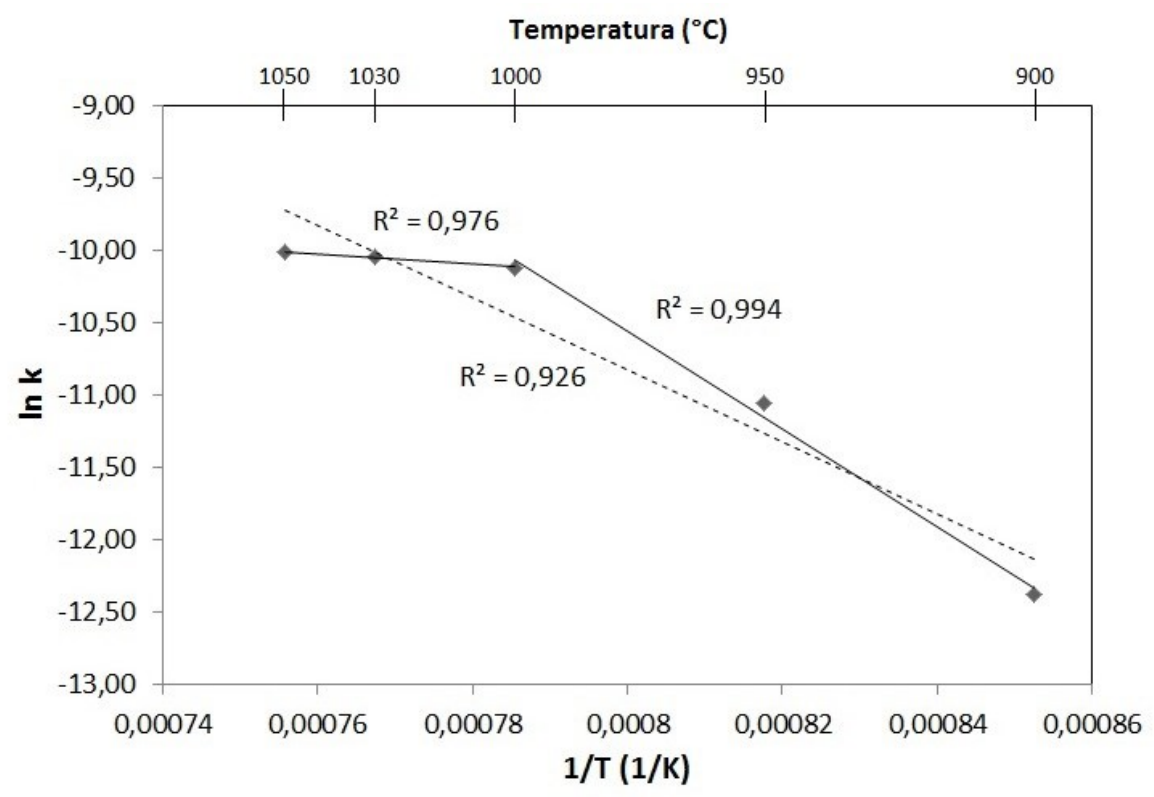

Fonte: o autor.

Observa-se que o ajuste dos pontos a uma única reta não foi razoável $\left(R^{2}\right.$ $=0,926)$. Entretanto, separando os pontos em dois intervalos, de $900{ }^{\circ} \mathrm{C}$ a $1000^{\circ} \mathrm{C}$ e $1000^{\circ} \mathrm{C}$ a $1050^{\circ} \mathrm{C}$, os coeficientes de determinação se aproximam da unidade. Esse resultado indica que há uma mudança do mecanismo controlador da cinética de carburação em temperatura próxima de $1000^{\circ} \mathrm{C}$.

A energia de ativação obtida no intervalo entre $900{ }^{\circ} \mathrm{C}$ e $1000{ }^{\circ} \mathrm{C}$ é de $280 \mathrm{~kJ} / \mathrm{mol}$. Esse valor de energia de ativação é característico de um controle por reação química, concordando com a avaliação cinética realizada até este ponto.

Contudo, a energia de ativação calculada para o intervalo entre $1000{ }^{\circ} \mathrm{C} \mathrm{e}$ $1050{ }^{\circ} \mathrm{C}$ foi de $29,4 \mathrm{~kJ} / \mathrm{mol}$. Esse valor é condizente com energias de ativação para controles cinéticos por difusão, que não foi o modelo cinético escolhido para o cálculo das constantes cinéticas (k'). Logo esses valores de k' e de energia de ativação não podem ser considerados. 


\subsubsection{Avaliação do controle cinético por reação química a partir da metodologia desenvolvida por Grabke}

Para validar a hipótese de controle cinético por reação química sobre os pontos experimentais obtidos entre $900^{\circ} \mathrm{C}$ e $1000^{\circ} \mathrm{C}$, além de avaliar a mudança de controle cinético após $1000^{\circ} \mathrm{C}$, foi realizada a avaliação da cinética de carburação através da metodologia desenvolvida por Grabke. ${ }^{33}$

Como discutido previamente na seção 2.3.1, Grabke desenvolveu uma metodologia em que considerava a carburação pela decomposição do metano, descrita pela reação (14). O autor então desmembrava esta reação em etapas intermediárias, descritas pelas reações (18) a (24).

$$
\begin{gathered}
\mathrm{CH}_{4(g)}=[\mathrm{C}]+2 H_{2(g)} \\
2 H_{(a d)}=H_{2} \\
\mathrm{CH}_{4}=\mathrm{CH}_{4(a d)} \\
\mathrm{CH}_{4(a d)}=\mathrm{CH}_{3(a d)}+H_{(a d)} \\
\mathrm{CH}_{3(a d)}=\mathrm{CH}_{2(a d)}+H_{(a d)} \\
\mathrm{CH}_{2(a d)}=\mathrm{CH}_{(a d)}+H_{(a d)} \\
\mathrm{CH}_{(a d)}=C_{(a d)}+H_{(a d)} \\
C_{(a d)}=C_{(d i s s o l v i d o)}
\end{gathered}
$$

O autor calculou, de maneira analítica, a taxa da reação (14) considerando uma das etapas intermediárias como controladora da cinética de carburação e considerando todas as demais etapas em equilíbrio. Ele repetiu esse método para cada etapa intermediária. A Equação (46) representa uma equação genérica que descreve os modelos obtidos pelo autor. 


$$
-r_{C H_{4}}=r_{c}=k \cdot \frac{p_{C H_{4}}^{m}}{p_{H_{2}}^{n}}
$$

Onde,

$-r_{C H_{4}}$ e $r_{c}$ são as taxas de consumo de metano e formação de carbono, respectivamente, dadas em mols/s

k é uma constante cinética

$\mathrm{m}$ e $\mathrm{n}$ são fatores exponenciais que variam de acordo com a etapa intermediária da reação (14) considerada, para vias de cálculo, como controladora da cinética de carburação.

Assim como no presente trabalho, o autor dispunha dos valores das pressões parciais de metano e hidrogênio no sistema, além dos valores das taxas de carburação. Para encontrar a etapa que controlava a carburação via decomposição do metano, o autor comparou os modelos calculados analiticamente aos dados obtidos experimentalmente, determinando a etapa controladora como aquela em que havia o melhor ajuste do modelo analítico aos dados reais.

No presente trabalho, determinaram-se inicialmente os valores da constante cinética, k, para cada temperatura, a partir da Equação (46), variando os coeficientes $\mathrm{m}$ e $\mathrm{n}$ de acordo com o modelo analítico a ser testado. Para tanto, considerou-se a taxa de carburação obtida da regressão linear das curvas apresentadas na Figura 25 e o valor médio das pressões parciais de metano e hidrogênio de cada temperatura, isto é, a média entre os três ensaios em uma mesma temperatura.

Após a definição das constantes cinéticas, realizou-se o caminho inverso: foi calculada a quantidade de mols de $\mathrm{C} / \mathrm{g}_{\mathrm{DR}}$ que seria produzida em cada ensaio, considerando o tempo e as pressões parciais de $\mathrm{CH}_{4}$ e $\mathrm{H}_{2}$ desses ensaios. Para definição do modelo analítico que melhor representou os dados obtidos experimentalmente, utilizou-se a técnica do Somatório dos Quadrados das Diferenças (SQD): somam-se os quadrados das diferenças entre o número 
de mols de carbono por grama de DRI obtidos experimentalmente e os números de mols de carbono por grama de DRI calculados a partir de cada modelo analítico. O modelo que apresenta o menor valor de SQD define a etapa intermediária como controladora da cinética da reação (14).

Os valores do SQD em função do modelo analítico utilizado são apresentados na Tabela 14. Não foi possível diferenciar analiticamente o modelo que representa a adsorção do gás metano (reação (19)) do modelo de dissociação do metano adsorvido (reação (20)). Desta forma, ambas as etapas estão representadas por um mesmo modelo. Ademais, não há informações sobre a atividade do hidrogênio adsorvido no ferro para que se determine uma equação analítica válida para a reação de formação do hidrogênio gasoso (reação (18)).

Tabela 14 - Somatório dos Quadrados das Diferenças entre os valores de mols de carbono calculados pelos modelos analíticos de cada etapa intermediária da reação de decomposição do metano e dos valores de mols de $\mathrm{C}$ obtidos experimentalmente, em função da temperatura.

\begin{tabular}{|c|c|c|c|c|c|c|c|c|}
\hline \multirow{2}{*}{$\begin{array}{c}\text { Etapa } \\
\text { intermediária }\end{array}$} & \multicolumn{2}{|c|}{$\begin{array}{c}\text { Fatores } \\
\text { exponenciais }\end{array}$} & \multicolumn{6}{|c|}{ Somatório dos Quadrados das Diferenças $\left(10^{-3}\right)$} \\
\hline & $\mathbf{m}$ & $\mathbf{n}$ & $900^{\circ} \mathrm{C}$ & $950^{\circ} \mathrm{C}$ & $1000^{\circ} \mathrm{C}$ & $1030^{\circ} \mathrm{C}$ & $1050^{\circ} \mathrm{C}$ & Total \\
\hline$(18)$ & \multicolumn{8}{|c|}{ Sem informações para cálculos } \\
\hline$(19)$ & \multirow{2}{*}{1} & \multirow{2}{*}{0} & \multirow{2}{*}{0,01} & \multirow{2}{*}{0,15} & \multirow{2}{*}{2,12} & \multirow{2}{*}{1,89} & \multirow{2}{*}{1,39} & \multirow{2}{*}{5,57} \\
\hline$(20)$ & & & & & & & & \\
\hline$(21)$ & 1 & 0,5 & 0,01 & 0,15 & 2,28 & 1,93 & 1,42 & 5,79 \\
\hline$(22)$ & 1 & 1 & 0,01 & 0,15 & 2,44 & 1,97 & 1,45 & 6,02 \\
\hline (23) & 1 & 1,5 & 0,01 & 0,15 & 2,60 & 2,01 & 1,49 & 6,26 \\
\hline$(24)$ & 1 & 2 & 0,01 & 0,15 & 2,77 & 2,66 & 1,53 & 7,12 \\
\hline
\end{tabular}

Fonte: o autor.

Nota-se que todos os modelos apresentaram valores muito próximos do $S Q D$, comparando-se os valores em uma mesma temperatura. Além disso, ocorre um aumento em uma ordem de grandeza nas diferenças entre o número de mols de $\mathrm{C}$ calculados e obtidos experimentalmente a partir dos $1000^{\circ} \mathrm{C}$, indicando que os modelos se ajustaram melhor aos dados experimentais nas temperaturas de $900^{\circ} \mathrm{C}$ e $950^{\circ} \mathrm{C}$. 
A montagem experimental utilizada por Grabke $^{33}$ foi elaborada para avaliar pequenas alterações do teor de carbono das amostras de ferro e, desta maneira, facilitar a distinção da etapa controladora, o que não é possível no presente trabalho. A própria utilização do DRI, que apresenta uma grande variabilidade superficial se comparado às amostras utilizadas no trabalho de Grabke, poderia afetar na escolha da etapa controladora.

Pelos valores dos SQDs apresentados na Tabela 14, a etapa intermediária controladora da cinética da reação (14) seria a de dissociação do metano adsorvido na superfície do ferro metálico (reações (19) e (20)). Entretanto, como não há maneira de distinguir as duas etapas intermediárias e, pelo fato das diferenças entre os diferentes modelos serem pequenas, adotouse, para fins de cálculos, a dissociação do radical $\mathrm{CH}_{3}$ (reação (21)), definida por Grabke em seu trabalho ${ }^{33}$ como a etapa controladora da cinética de carburação por decomposição do $\mathrm{CH}_{4}$.

A Tabela 15 apresenta os valores das constantes cinéticas, $\mathrm{k}$, calculadas a partir do modelo cinético da etapa de dissociação do radical $\mathrm{CH}_{3}$. Observa-se que os valores das constantes obtidas para as temperaturas entre $1000^{\circ} \mathrm{C} \mathrm{e}$ $1050^{\circ} \mathrm{C}$ são próximos entre si.

Tabela 15 - Valores das constantes cinéticas, $k$, calculadas a partir do modelo cinético da etapa de dissociação do radical $\mathrm{CH}_{3}$, representada pela reação (21).

\begin{tabular}{|c|c|c|c|}
\hline $\begin{array}{c}\text { Temperatura } \\
\left({ }^{\circ} \mathrm{C}\right)\end{array}$ & $\begin{array}{l}\text { Taxa de carburação } \\
\left(10^{-7} . \text { Mols C/s.g gRI) }\right.\end{array}$ & $\begin{array}{c}\text { Relação } \\
\mathrm{pCH}_{4} /\left(\mathrm{pH}_{2}\right)^{0,5} \\
\left(\mathrm{~atm}^{1 / 2}\right)\end{array}$ & $\begin{array}{c}\mathrm{k} \\
\left(\frac{10^{-5} \mathrm{mols}}{s . g_{D R I} \cdot a^{\prime} m^{1 / 2}}\right)\end{array}$ \\
\hline 900 & 0,69 & 0,07 & 0,10 \\
\hline 950 & 2,45 & 0,05 & 0,51 \\
\hline 1000 & 5,28 & 0,03 & 1,86 \\
\hline 1030 & 5,58 & 0,02 & 2,31 \\
\hline 1050 & 5,49 & 0,03 & 1,96 \\
\hline
\end{tabular}

Fonte: o autor. 
Aplicando a lei de Arrhenius às constantes cinéticas obtidas é possível calcular a energia de ativação da reação de decomposição do metano. A Figura 29 mostra o gráfico de Arrhenius construído a partir dos dados das constantes apresentados na Tabela 15.

O ajuste geral dos pontos a reta que compreende o intervalo de $900{ }^{\circ} \mathrm{C}$ a $1050{ }^{\circ} \mathrm{C}$ não foi razoável $\left(R^{2}=0,922\right)$. Os dados apresentaram comportamento linear até entre $900{ }^{\circ} \mathrm{C}$ e $1000{ }^{\circ} \mathrm{C}$, com $R^{2}$ próximo à unidade. Para esse intervalo, a energia de ativação calculada foi de $366 \mathrm{~kJ} / \mathrm{mol}$. Esse valor de energia de ativação é característico de um controle por reação química, concordando com a análise cinética de reações gás/sólido, realizada na Seção 5.2.3.1.

Entretanto, no intervalo entre $1000^{\circ} \mathrm{C}$ e $1050^{\circ} \mathrm{C}$, o valor de $R^{2}$ é muito baixo, indicando que os pontos experimentais não se adequaram ao modelo proposto por Grabke. ${ }^{33}$ A energia de ativação calculada para esse intervalo foi de $21,2 \mathrm{~kJ} / \mathrm{mol}$, característica de controles cinéticos por difusão, que não corresponde ao modelo cinético escolhido para cálculo das constantes cinéticas (k). Logo esses valores de $k$ e de energia de ativação não podem ser considerados

Figura 29 - Gráfico de Arrhenius obtido a partir das constantes cinéticas reportadas na Tabela 15.

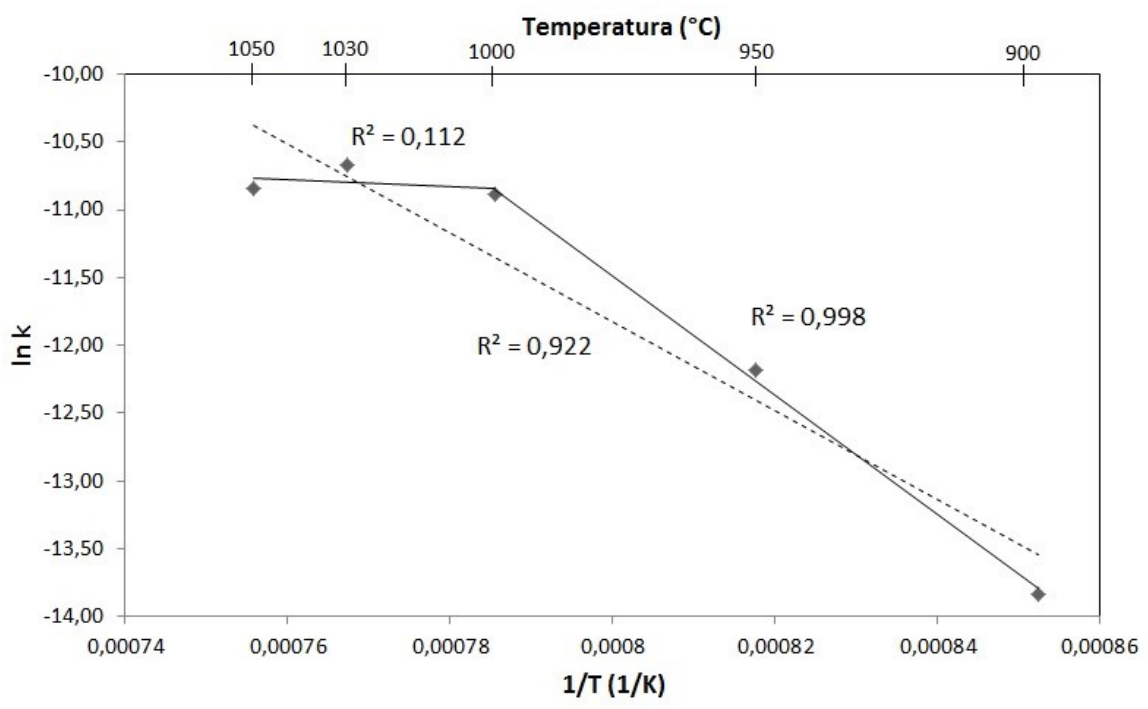


Fonte: o autor.

A avaliação cinética até este ponto mostrou que o controle cinético da carburação simultânea à reforma catalítica de metano, para os experimentos com temperaturas entre $900^{\circ} \mathrm{C}$ e $1000^{\circ} \mathrm{C}$, é o de reação química na superfície do ferro. O modelo de reação química em partículas esféricas e o modelo de dissociação do radical $\mathrm{CH}_{3}$ explicam satisfatoriamente o comportamento dos dados obtidos experimentalmente até $1000^{\circ} \mathrm{C}$. As constantes cinéticas resultantes se ajustaram bem à regressão de Arrhenius e a energia de ativação obtida concorda com controles por reação química.

Entretanto, os dados experimentais obtidos acima de $1000{ }^{\circ} \mathrm{C}$ não se adequaram aos modelos propostos. Uma das hipóteses levantadas para explicar o comportamento da carburação acima de $1000{ }^{\circ} \mathrm{C}$ é relacionada à sinterização dos poros do DRI pelo aumento de temperatura. Desta forma, a superfície do DRI disponível para interação com a mistura gasosa diminuiria, bem como haveria uma constrição dos caminhos de passagem dos reagentes e produtos gasosos, podendo influir sobre a cinética de carburação.

Para testar esta hipótese, escolheram-se aleatoriamente dez pelotas de DRI após cada ensaio de carburação, submetendo-as à caracterização de porosimetria de imagens. Essa técnica consiste em estimar o volume médio de um DRI, através de imagens tiradas de diferentes ângulos. O software do equipamento possui uma base de dados para densidades reais de pelotas e DRls em função de sua composição química. Após a definição do volume do DRI, juntamente com o valor da densidade real e da massa do DRI, calculou-se a porosidade do material.

A técnica de porosimetria por imagens tem como limitação o fato de definir o volume total de poros do DRI, e não apenas o volume de poros abertos, que são de fato os relevantes para o transporte de espécies gasosas. Entretanto, a avaliação do volume total de poros pode fornecer uma noção do grau de sinterização das amostras. Essa caracterização foi realizada com auxílio de uma câmera fotográfica digital da marca Fujinon, modelo SE, e o software de cálculo de porosidade da marca Automática Tecnologia S.A., versão 1.2. 
A Tabela 16 apresenta os valores de porosidade, dados em \% volumétrica, do DRI após os ensaios de carburação simultânea à reforma de metano.

Tabela 16 - Porosidade média do DRI após os ensaios de carburação simultânea à reforma de metano, calculada através da técnica de porosimetria de imagens.

\begin{tabular}{ccc}
\hline \multicolumn{2}{c}{ Ensaios } & Porosidade média (\%) \\
\hline Temperatura $\left({ }^{\circ} \mathbf{C}\right)$ & Tempo $(\mathbf{m i n})$ & 63,0 \\
\cline { 2 - 3 } 900 & 30 & 64,4 \\
\cline { 2 - 3 } & 60 & 65,3 \\
\cline { 2 - 3 } 950 & 90 & 64,9 \\
\cline { 2 - 3 } & 30 & 64,1 \\
\cline { 2 - 3 } 1000 & 60 & 64,5 \\
\hline \multirow{3}{*}{1050} & 90 & 65,8 \\
\hline \multirow{3}{*}{1050} & 30 & 65,1 \\
\hline & 60 & 65,2 \\
\hline & 90 & 64,4 \\
\hline & 30 & 64,6 \\
\hline & 60 & 64,3 \\
\hline
\end{tabular}

Fonte: o autor.

Nota-se que a porosidade do DRI após os ensaios não sofreu influência do tempo ou temperatura do ensaio. Desta forma, descartou-se a hipótese de influência da sinterização sobre a cinética de carburação. 


\subsection{Avaliação da presença de carbono no DRI}

Para avaliação da deposição de carbono no DRI, foi realizada uma caracterização microestrutural. A Figura 30 apresenta o perfil de difração de raios-x (DRX) do DRI após ensaio de carburação a $1000{ }^{\circ} \mathrm{C}$ e 60 minutos de duração. Os únicos picos identificados foram de $\mathrm{Fe}$ metálico. Esse perfil se repetiu para as pelotas ensaiadas a $900{ }^{\circ} \mathrm{C}$ e $950{ }^{\circ} \mathrm{C}$. Entretanto, esse resultado não era esperado, uma vez que o teor de carbono final do DRI a $100{ }^{\circ} \mathrm{C}$ e 60 minutos de duração $\left(\% \mathrm{C}_{\mathrm{DRI}}=1,88\right)$ é superior ao limite de saturação de carbono a $1000^{\circ} \mathrm{C}\left(\% \mathrm{C}_{\text {sat_ } 1000^{\circ} \mathrm{C}}=1,47\right)^{45} \mathrm{e}$, desta forma, seria esperada a formação de $\mathrm{Fe}_{3} \mathrm{C}$ ou grafita. Essas fases não foram detectadas no difratograma.

Figura 30 - Perfil de difração de raios-x obtido do DRI resultante do ensaio de carburação simultânea à reforma de metano a $1000{ }^{\circ} \mathrm{C}$ e 60 min de duração. $\% \mathrm{C}_{\mathrm{DRl}}=1,88$.

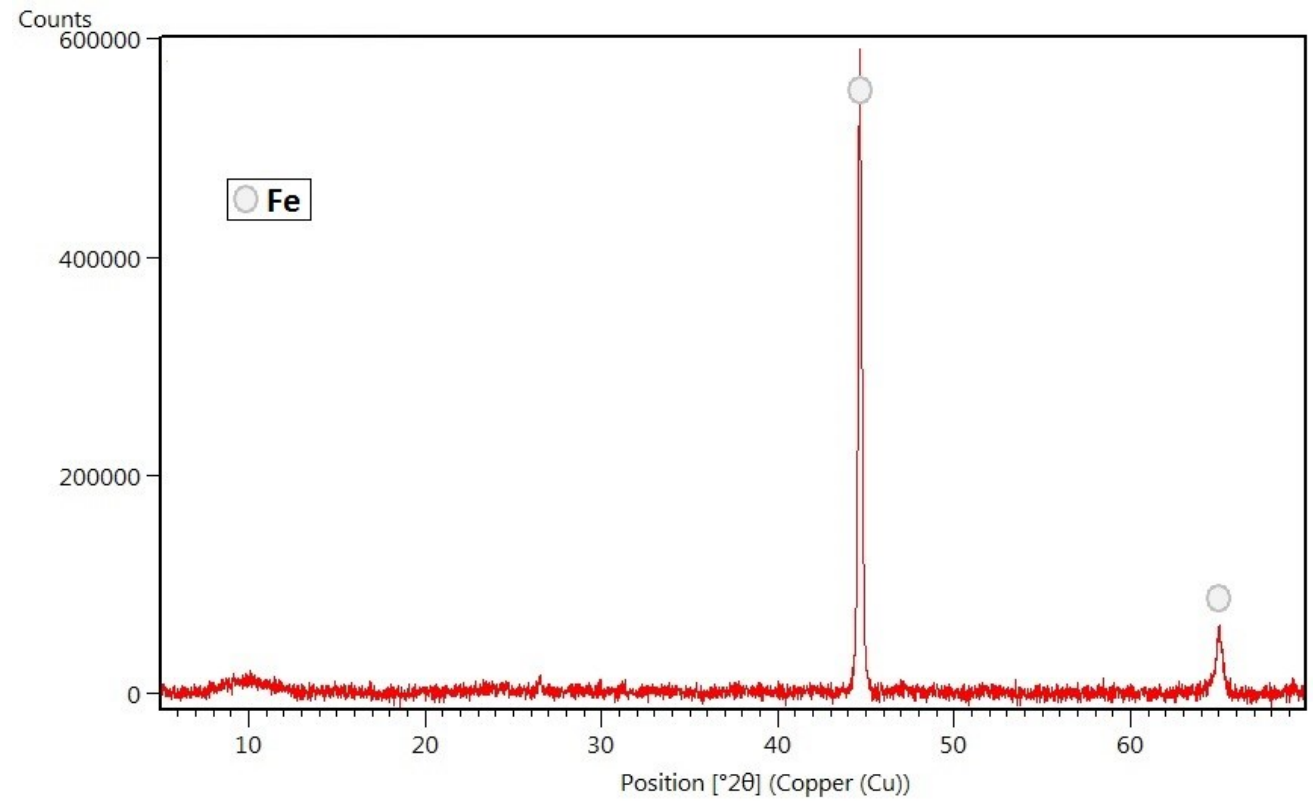

Fonte: o autor.

As Figuras 35 e 36 apresentam as micrografias de DRI's ensaiados a $900{ }^{\circ} \mathrm{C}$ e 30 minutos $\left(\% \mathrm{C}_{\mathrm{DRI}}=0,20\right)$ e $1000{ }^{\circ} \mathrm{C}$ e 60 minutos $\left(\% \mathrm{C}_{\mathrm{DRI}}=1,88\right)$, respectivamente. As amostras foram lixadas, polidas e atacadas com Nital. As micrografias revelam a matriz (regiões brancas), composta majoritariamente de ferrita, cercada por poros (regiões escuras). 
Figura 31 - Micrografia da seção transversal do DRI ensaiado a $900{ }^{\circ} \mathrm{C}$ por 30 minutos. Aumento de $500 x . \% C_{D R I}=0,20$. Ataque: nital.

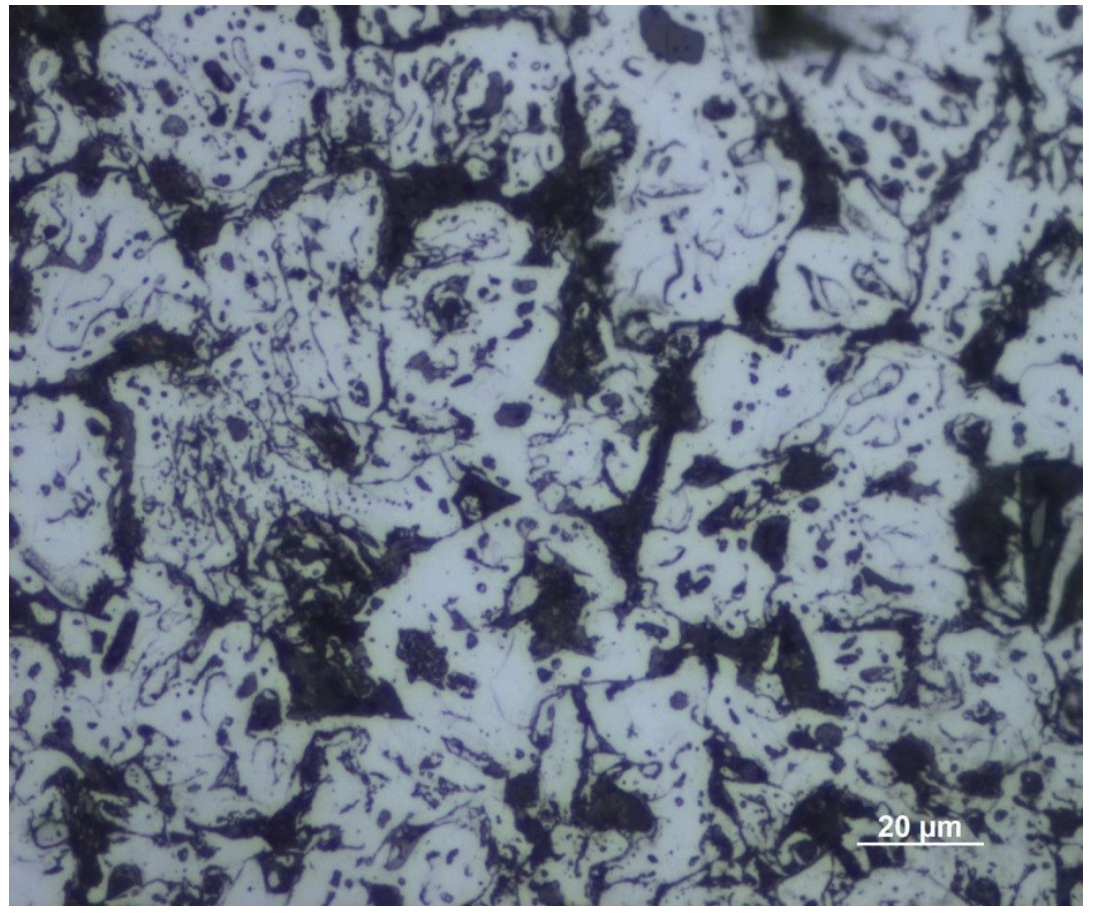

Fonte: o autor.

Figura 32 - Micrografia da seção transversal do DRI ensaiado a $1000{ }^{\circ} \mathrm{C}$ por 60 minutos. Aumento de $500 x . \% \mathrm{C}_{\mathrm{DRI}}=1,88$. Ataque: nital.

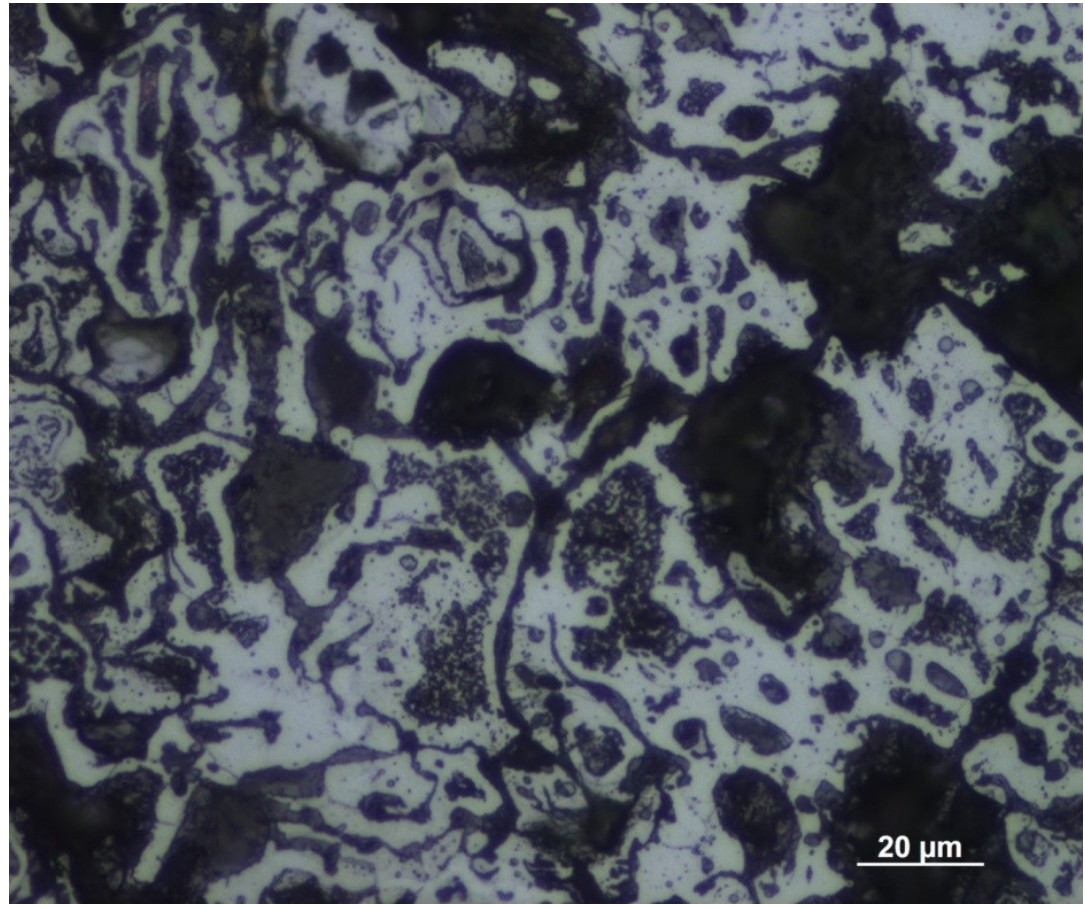

Fonte: o autor. 
Aparentemente, o carbono depositado na superfície foi dissolvido na matriz de ferro. Entretanto, após o resfriamento, precipitou-se na forma de lamelas de carbonetos $\left(\mathrm{Fe}_{3} \mathrm{C}\right)$, intercaladas com lamelas de ferrita, formando estruturas perlíticas observáveis em maiores aumentos, como exibido na Figura 33.

Figura 33 - Micrografia da seção transversal do DRI ensaiado a $900{ }^{\circ} \mathrm{C}$ por 30 minutos. Aumento de $1000 x . \% C_{D R I}=0,20$. Ataque: nital.

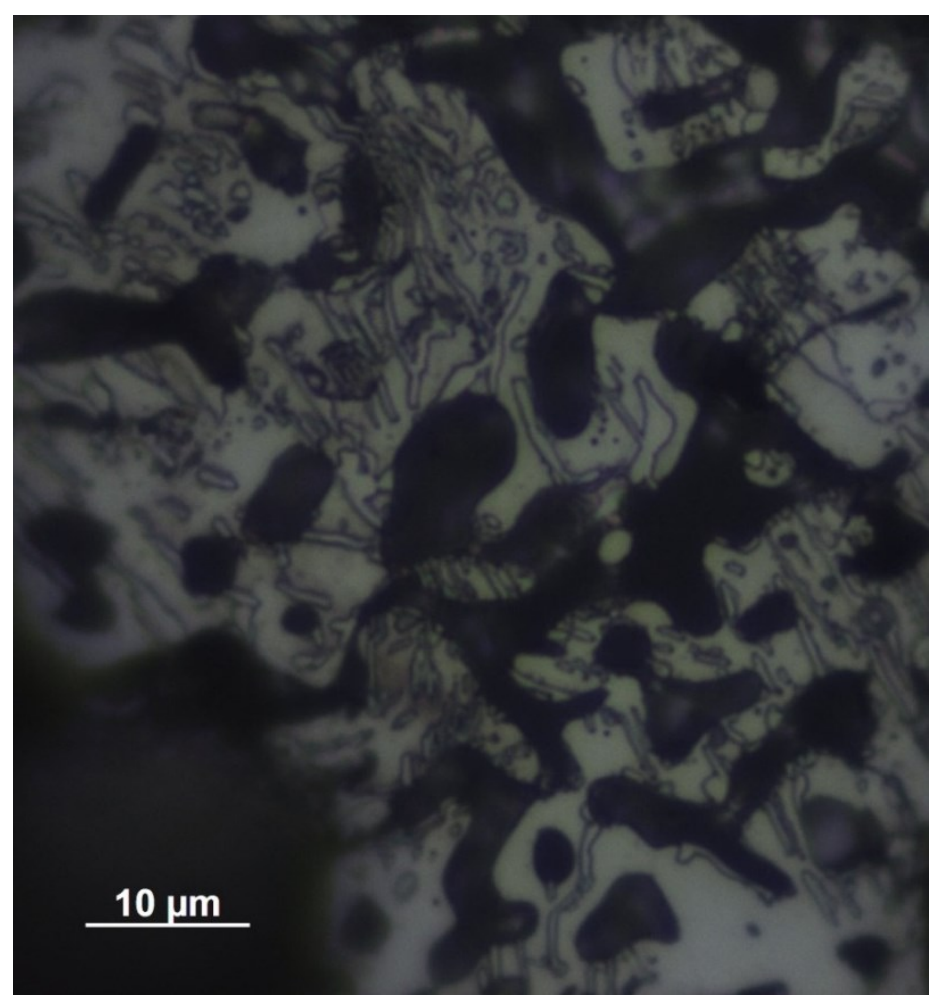

Fonte: o autor

A Figura 34 apresenta a imagem da microestrutura do DRI ensaiado a $950{ }^{\circ} \mathrm{C}$ e 60 minutos obtida em microscópio eletrônico de varredura, juntamente a dois perfis EDS (Espectrometria por Energia Dispersiva). As análises apontam que a estrutura clara com formato lamelar é a cementita, e a matriz acinzentada é composta majoritariamente por ferro. As estruturas de cores mais escuras são poros, ocupada pela baquelite durante o embutimento das amostras. 
Figura 34 - A) Microestrutura da seção transversal de ferro esponja após ensaios de carburação simultânea à reforma de metano a $950{ }^{\circ} \mathrm{C}$ e 60 minutos de duração. Aumento de 5000 vezes. Ataque: nital. B) Perfil EDS do ponto 1. C) Perfil EDS do ponto 2.
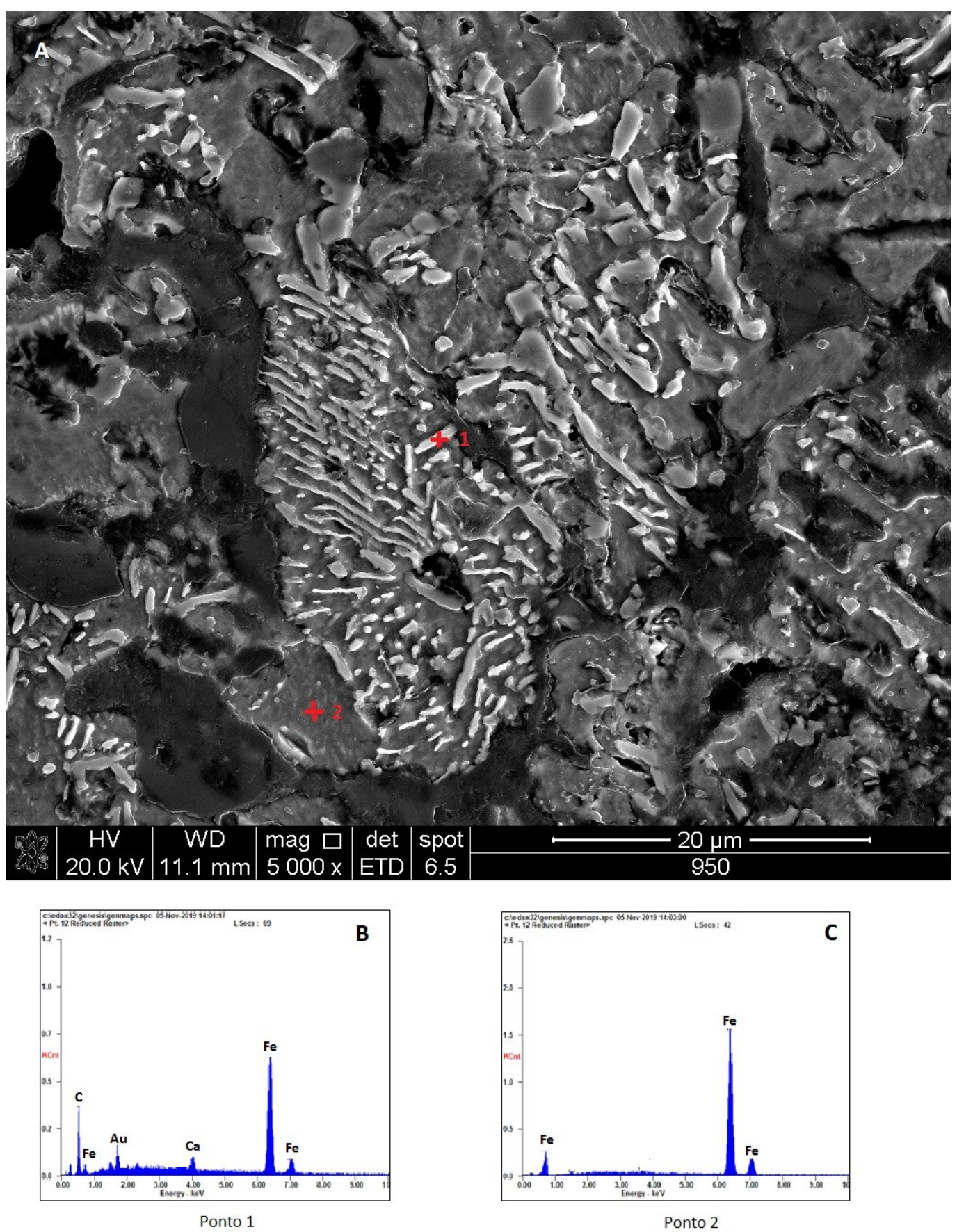

Fonte: o autor.

A Figura 35 apresenta o perfil de difração de raios-x (DRX) de pelotas de ferro esponja após ensaio de carburação a $1050^{\circ} \mathrm{C}$ e 60 minutos de duração. 
Esse perfil foi também obtido para os ensaios de carburação a $1000{ }^{\circ} \mathrm{C}$ e a $1050{ }^{\circ} \mathrm{C}$, com 90 minutos de duração.

Figura 35 - Perfil de difração de raios-x obtido do DRI resultante do ensaio de carburação simultânea à reforma de metano a $1050^{\circ} \mathrm{C}$ e 90 min de duração. $\% \mathrm{C}_{\mathrm{DRl}}=3,67$.

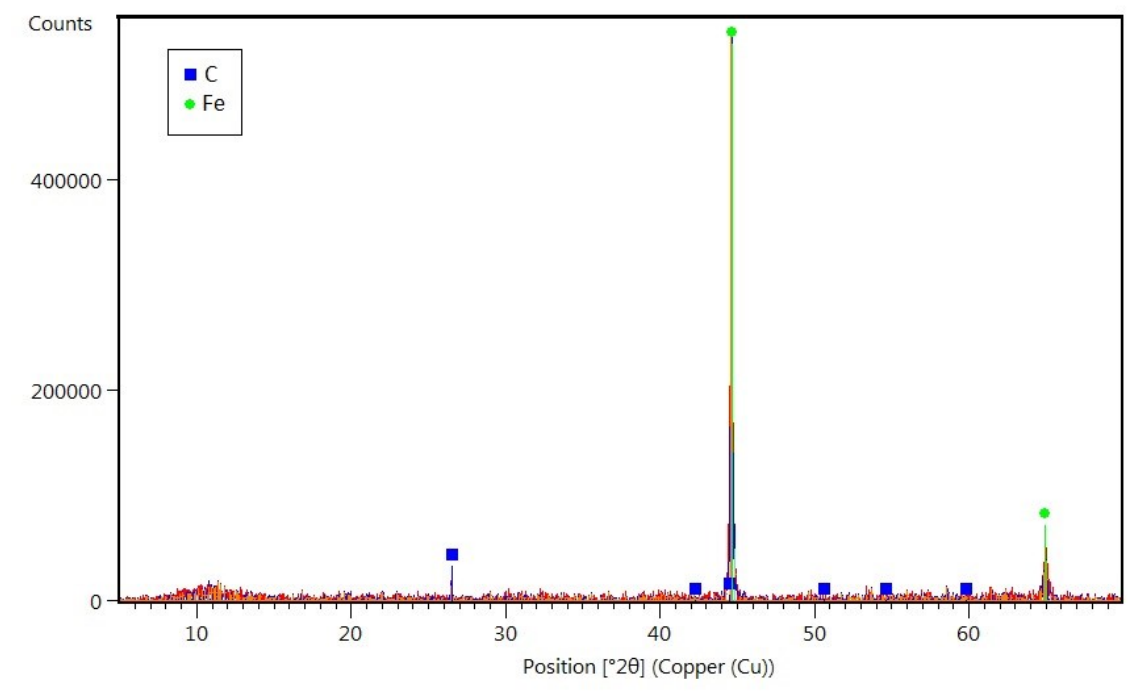

Fonte: o autor

A $1050{ }^{\circ} \mathrm{C}$, o limite de saturação de carbono da austenita é de $1,63 \% .{ }^{45}$ Assim, o carbono acima do limite de saturação pode ter precipitado na superfície do ferro como grafita. Entretanto, por se tratar de uma pequena quantidade, não foram observadas estruturas correspondentes à grafita na microestrutura do DRI ensaiado a $1050{ }^{\circ} \mathrm{C}$ por $90 \mathrm{~min}$, conforme exibido na Figura 36. Ademais, a grafita pode ter sido arrancada durante as etapas de preparo metalográfico das amostras. O que se nota é um aumento da quantidade de perlita e um refino de suas lamelas, quando comparada a micrografia apresentada na Figura 33. 
Figura 36 - Micrografia da seção transversal do DRI ensaiado a $1050{ }^{\circ} \mathrm{C}$ por 90 minutos. Aumento de $1000 x . \% C_{D R I}=3,67$. Ataque: nital.

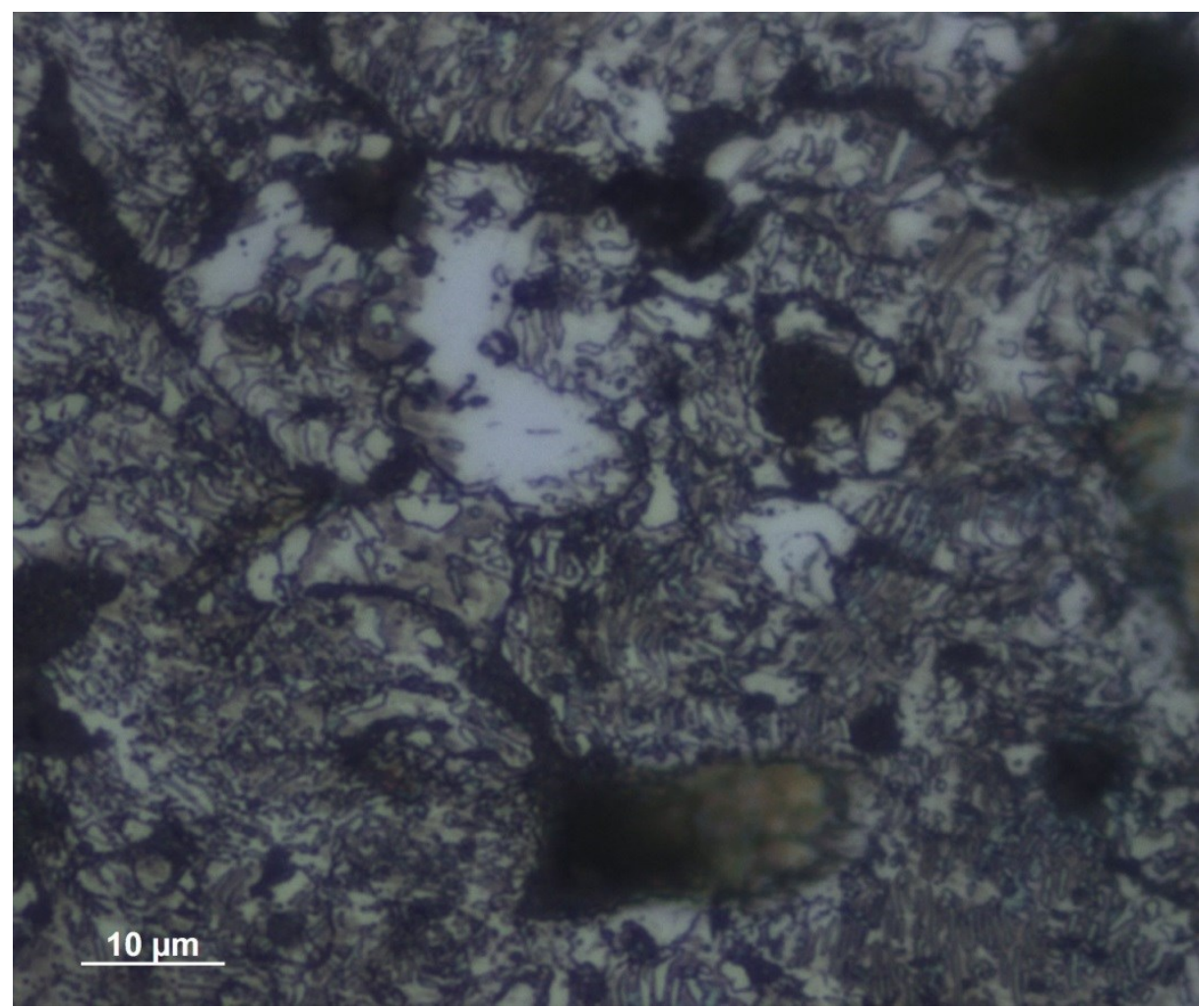

Fonte: o autor.

Uma hipótese levantada para explicar a mudança do comportamento da carburação próximo de $1000^{\circ} \mathrm{C}$ é a possível formação de cementita ou grafita. A partir de $1000{ }^{\circ} \mathrm{C}$, os DRls dos ensaios com duração de $60 \mathrm{~min}$ e $90 \mathrm{~min}$ apresentaram teor de carbono superior ao limite de saturação de carbono na austenita, que é de $1,47 \%$ a $1000^{\circ} \mathrm{C}, 1,57 \%$ a $1030^{\circ} \mathrm{C}$ e $1,63 \%$ a $1050{ }^{\circ} \mathrm{C} .{ }^{45}$

O coeficiente de difusão do carbono pela austenita em temperaturas próximas de $1000{ }^{\circ} \mathrm{C}$ é da ordem de $10^{-10}$ a $10^{-11} \mathrm{~m}^{2} / \mathrm{s}^{46,47}$, enquanto $\mathrm{O}$ coeficiente de difusão pela cementita é da ordem $10^{-12}$ a $10^{-14} \mathrm{~m}^{2} / \mathrm{s}^{48,49}$ e o coeficiente de autodifusão do carbono pela grafita é da ordem de $10^{-17}$ a $10^{-20}$ $\mathrm{m}^{2} / \mathrm{s} .{ }^{50}$ Assim, caso haja formação de cementita ou grafita, espera-se que a difusão do carbono por estas fases seja mais lenta, o que poderia afetar a cinética da carburação.

Contudo, pela análise microestrutural conduzida, conclui-se que o carbono depositado no DRI é dissolvido na matriz de ferro, precipitando-se 
preferencialmente como carboneto $\left(\mathrm{Fe}_{3} \mathrm{C}\right)$ durante o resfriamento. Não foi possível encontrar partículas de carbono aderidas aos contornos dos grãos da ferrita, mesmo nos casos em que o teor de carbono no ferro esponja superou o limite de solubilidade. 


\section{Conclusões}

Foi desenvolvida e testada uma metodologia para o estudo da carburação de pelotas de ferro esponja simultânea à reforma catalítica de metano por vapor de água, nas condições dos processos de redução. A partir dos resultados obtidos nas condições experimentais do presente trabalho, conclui-se que:

- A carburação, isto é, a quantidade de carbono depositada no DRI é maior conforme o aumento da temperatura, do tempo e da relação $\mathrm{CH}_{4} / \mathrm{H}_{2} \mathrm{O}$ na mistura gasosa;

- A reforma do metano é maior conforme o aumento da temperatura e independente do tempo dos ensaios. Observaram-se conversões do metano de até $80 \%$ do volume injetado da mistura de reação $\left(68 \% \mathrm{H}_{2}\right.$ $12 \% \mathrm{CH}_{4}-10 \% \mathrm{H}_{2} \mathrm{O}-10 \% \mathrm{Ar}$ ) em temperaturas de até $1050{ }^{\circ} \mathrm{C}$, sendo a maior parte para a reforma do metano. A carburação respondeu por, no máximo, uma conversão de metano de $8 \%$;

- No intervalo de temperatura de $900^{\circ} \mathrm{C}$ a $1000{ }^{\circ} \mathrm{C}$, o controle cinético da carburação do DRI se dá por reação química na superfície do ferro. A energia de ativação do processo de carburação nesse intervalo foi calculada em $366 \mathrm{~kJ} / \mathrm{mol}$, pelo modelo de carburação desenvolvido por Grabke $^{33}$, e em $280 \mathrm{~kJ} / \mathrm{mol}$ pelo modelo de reação química em partículas esféricas;

- $\quad \mathrm{Na}$ faixa de temperatura de $1000{ }^{\circ} \mathrm{C}$ a $1050{ }^{\circ} \mathrm{C}$ há uma mudança do mecanismo controlador da cinética de carburação do DRI. No entanto, não foi possível identificar o mecanismo controlador dessa cinética;

- A análise da microestrutura do DRI carburado mostrou que ocorre dissolução do carbono na matriz de ferro e formação de perlita durante o resfriamento. 


\section{Recomendações para continuidade do trabalho}

Para aqueles que desejam investigar a carburação de DRI quando utilizado como catalisador da reforma de metano, partindo do presente trabalho, sugerem-se as seguintes recomendações:

- Conduzir os experimentos em sistemas termogravimétricos, de forma a comparar a variação de massa do sistema com a variação da massa amostral e o percentual médio de carbono do DRI;

- Utilizar métodos de análise dos gases de saída que permitam a identificação do teor de todos os gases presentes, incluindo $\circ \mathrm{H}_{2}$, que não foi possível monitorar através do cromatógrafo gasoso. Análises via infravermelho (para $\mathrm{CO}, \mathrm{CO}_{2}$ e $\mathrm{CH}_{4}$ ) ou por condutividade térmica (para $\mathrm{H}_{2}$ ) são as mais indicadas, por terem um tempo de resposta mais rápido;

- Utilizar um aparato que possa medir a quantidade de vapor de água aprisionado no sistema de secagem do gás de saída;

- Se possível, conduzir os experimentos em um sistema que permita ser resfriado rapidamente, de forma a preservar a microestrutura formada em altas temperaturas. Dessa forma, será possível verificar como a deposição do carbono se procede durante a ocorrência dos fenômenos de interesse e, eventualmente, levantar hipóteses para explicar a cinética de carburação do DRI em temperaturas superiores a $1000{ }^{\circ} \mathrm{C}$;

- De forma a complementar o trabalho, realizar o estudo de carburação do DRI quando utilizado como catalisador da reação de reforma do metano por dióxido de carbono. 


\section{Referências bibliográficas}

1. VALE S.A. Formulário 20-F do exercício de 2018. Rio de Janeiro, 2019.

2. WORLD STEEL ASSOCIATION. Steel Statistical Yearbook. Brussels, 2018.

3. DUARTE, P.E.; BECERRA, J. Reducing greenhouse gas emissions with energiron non-selective carbon-free emissions scheme. Stahl un Eisen. vol. 131, pp. 85-94, 2011.

4. DUARTE, P.E.; TAVANO, A.; ZENDEJAS, E. Achieving carbon-free emissions via the ENERGIRON DR process. AISTECH - Iron and Steel Technology Conference Proceedings. pp. 165-173, 2010.

5. VAN HOOK, J.P. Methane-Steam Reforming. Catalysis Review - Science Engineering, vol. 21, pp. 1-51, 1980.

6. WANG, S.; LU, G.; MILLAR, G. Carbon dioxide reforming of methane to produce synthesis gas over metal-supported catalysts: State of the art. Energy and Fuels, vol. 10, pp. 896-904, 1996.

7. STEFFEN, R.; LÜNGEN. H.B. State of the art technology of direct and smelting reduction of iron ores. La Revue de Métallurgie, pp. 171-182, 2004.

8. KOLBEINSEN, L. Modelling of DRI Processes with Two Simultaneously Active Reducing Gases. Steel research international, vol. 81, n. 10, pp. 819-828, 2010.

9. EL-GEASSY, A.A. Gaseous reduction of $\mathrm{Fe}_{2} \mathrm{O}_{3}$ compacts at 600 to $1050^{\circ} \mathrm{C}$. Journal of Materials Science, vol. 21, n. 11, pp. 3889-3900, 1986.

10. ZERVAS, T.; MCMULLAN, J.T.; WILLIAMS, B.C. Solid-based direct reduction processes for iron. International Journal of Energy Research, Coleraine, vol. 20, p. 255-278, 1996.

11. MIDREX CORPORATION. World Direct Reduction Statistics. 2018. Disponível em: https://www.midrex.com/assets/user/news/Midrex_STATSbookprint_2018Fin al1.pdf. Acesso em 30092019.

12. ZERVAS, T.; MCMULLAN, J.T.; WILLIAMS, B.C. Gas-based direct reduction processes for iron. International Journal of Energy Research, Coleraine, vol. 20, p. 157-185, 1996. 
13. KURUNOV, I. The direct production of iron and alternatives to the blast furnace in iron metallurgy for the 21 st century. Metallurgist, vol. 54, pp. 335342, 2010.

14. PARISI, D.; LABORDE, M. Modeling of counter current moving bed gas-solid reactor used in direct reduction of iron ore. Chemical Engineering Journal, vol. 104, pp. 35-43, 2004.

15. KOPFLE, J.; HUNTER, R. Direct reduction's role in the world steel industry. Ironmaking and Steelmaking, vol. 35, pp. 254-259, 2008.

16. QUINTERO, R. HyL III - State of Art. Iron and Steel Engineer, vol. 59, n. 8, pp. 17-21, 1982.

17. FEINMAN, J. Direct Reduction and Smelting Processes. In: WAKELIN, D.H.; FRUEHAN, R.J. Making, Shaping and Treating of Steel: Ironmaking Volume, Pittsburgh, s.n., 1999, pp. 741-780.

18. EDSTRÖM, J.; VON SCHÉELE, J. Sponge iron and iron carbide: Competitive raw materials for high-quality steelmaking. Scandinavian Journal of Metallurgy, vol. 26, pp. 196-205, 1997.

19. HEINRICH, P.; KNOP, K.; MADLINGER, R. Status report and potentials for development of HYL-III direct reduction technology. Metallurgical plant and technology, vol. 13, pp. 1-9, 1990.

20. DUARTE, P.E. et al. Energiron direct reduction ironmaking - Economical, flexible, environmentally friendly. Steel Times International, vol. 34, pp. 2530, 2010.

21. CHATTERJEE, A. Sponge Iron Production by Direct Reduction of Iron Oxide, New Delhi: PHI Learning Private Limited, 2012.

22. JIANG, X.; WANG, L.; SHEN, F. Shaft furnace direct reduction technology --Midrex and Energiron. Advanced Materials Research, Vols. 2805-806, pp. 654-659, 2013.

23. DUARTE, P.E.; BECERRA, J. High-carbon DRI with energiron DR technology. Stahl un Eisen, vol. 135, pp. 153-160, 2015.

24. ROSENQVIST. T. Principles of Extractive Metallurgy, Trondheim: Tapir Academic Press, 2004.

25. KUBASCHEWSKI, O. Metallurgical Thermochemistry, New York: Pergamon Press, 1979. 
26. VIGNES, A. Extractive metallurgy, London: Wiley, 2011.

27. TURKDOGAN, E.T.; VINTERS, J. Gaseous Reduction of Iron Oxides: Part I. Reduction. Metallurgical Transactions, vol. 2, pp. 3175-3188, 1972.

28. TOWHIDI, N.; SZEKELY, J. Reduction kinetics of commercial low-silica hematite pellets with $\mathrm{CO}-\mathrm{H}_{2}$ mixtures over temperature range $600^{\circ}-1234^{\circ} \mathrm{C}$. Ironmaking and Steelmaking, vol. 6, pp. 237-249, 1981.

29. GASKELL, D.R. Introduction to the thermodynamics of materials, New York: Taylor \& Francis, 2008.

30. TURKDOGAN, E.T. Physical chemistry of high temperature technology, New York: Pergamon Press, 1980.

31. ZHANG, J.; OSTROVSKI, O. Cemntite Formation in $\mathrm{CH}_{4}-\mathrm{H}_{2}-\mathrm{Ar}$ Gas Mixture and Cementite Stability. ISIJ INternational, vol. 41, pp. 333-339, 2001.

32. ZALUDOVÁ, M. et al. Experimental study of Fe-C-O based system below $1000{ }^{\circ} \mathrm{C}$. Journal of Thermal Analysis and Calorimetry, vol. 111, pp. 1203-1210, 2013.

33. GRABKE, H.J. Evidence on the surface concentration of carbon on gamma iron from the kinetics of the carburization in $\mathrm{CH}_{4}-\mathrm{H}_{2}$. Metallurgical Transactions, vol. I, pp. 2972-2975, 1970.

34. GRABKE, H.J.; MÜLLER-LORENZ, E.M.; SCHENEIDER, A. Carburization and metal dusting on iron. ISIJ International, vol. 41, pp. S1 - S8, 2001.

35. GRABKE, H.J.; TAUBER, G. Kinetics of the Decarburization of alpha and gamma Iron in $\mathrm{H}_{2}-\mathrm{H}_{2} \mathrm{O}$ mixtures and of Carburization in $\mathrm{CO}-\mathrm{H}_{2}$ mixtures. Arch Eisenhuettenwes, vol. 46, n. 3, pp. 215-222, 1975.

36. TURKDOGAN, E.T.; VINTERS, J.V. Catalytic Effect of Iron on Decompostion of Carbon Monoxide: I. Carbon Deposition in $\mathrm{H}_{2}-\mathrm{CO}$ Mixtures. Metallurgical Transactions, vol. 5, pp. 11-19, 1974.

37. OLSON, R.G.; TURKDOGAN, E.T. Catalytic Effect of Iron on Decomposition of Carbon Monoxide: II. Effect of additions of $\mathrm{H}_{2}, \mathrm{H}_{2} \mathrm{O}, \mathrm{CO}, \mathrm{SO}_{2}$ e $\mathrm{H}_{2} \mathrm{~S}$. Metallurgical Transactions, vol. 5, pp. 21-26, 1974.

38. CHORKENDORFF, I.; NIEMANTSVERDRIET, J.W. Concepts of modern catalysis and kinetics, 2 ed., Weinheim : Wiley-VCH, 2007.

39. MÜNSTER, P.; GRABKE, H.J. Kinetics of the Steam Reforming of Methane on Iron as a Catalyst. Ber. Bunsenges. Phys. Chem. Berich: Gesell, 1980. 
40. MÜNSTER, P.; GRABKE, H.J. Kinetics of Steam Reforming of Methane with Iron, Nickel and Nickel-Ireon Alloys as Catalysts. Journal of Catalysis, vol. 72, pp. 279-287, 1981.

41. RIBEIRO, T.R.; FERREIRA NETO, J.B.; POÇO, J.G.; TAKANO, C.; KOLBEINSEN, L.; RINGDALEN, E. Reforma catalítica de metano para redução direta. Anais do $47^{\circ}$ Seminário de Redução de Minério de Ferro e Matérias-Primas, ABM Week, 02 a 06 outubro 2017.

42. VYAZOVKIN, S. et al. ICTAC Kinetics Committee recommendations for performing kinetic computations on thermal analysis data. Thermochimica Acta, vol 520, pp. 1-19, 2011.

43. KHAWAM, A.; FLANAGAN, D.R. Solid-State Kinetic Models: Basics and Mathematical Fundamentals. Journal of Physical Chemistry B, vol 110, pp. 17315 - 17328, 2006.

44. LEVENSPIEL, O. Chemical reaction engineering, New York: Wiley, 1999.

45. ELLIOT, J. Thermochemistry for steelmaking: thermodynamic and transport properties. Reading: Addison-Wesley, 1963.

46. VAN VLACK, L. Elements of materials and science engineering, Reading: Addison-Wesley, 1989.

47. PARRIS, D.; McLELLAN, R. The diffusivity of carbon in austenite. Acta Metallurgica, vol. 24, pp. 523-528, 1976.

48. EVTEEV, A. et al. Atomic Mechanism Diffusion of Carbon in Cementite. Defect and Diffusion Forum, vol. 277, pp. 101-106, 2008.

49. CERMAK, J.; KRAL, L. Carbon diffusion in carbon-supersaturated ferrite and austenite. Journal of Alloys and Compounds, vol. 586, pp. 129-135, 2014.

50. FEATES, F. The diffusion of carbon in single crystal graphite. Journal of Nuclear Materials, vol. 27, pp. 325-330, 1968. 
ANEXO A - RESULTADOS DOS ENSAIOS DE CARBURAÇÃO SIMULTÂNEA À REFORMA DE METANO 
Tabela A 1 - Dados do ensaios de carburação simultânea à reforma de metano a $900{ }^{\circ} \mathrm{C}$ e $30 \mathrm{~min}$.

\begin{tabular}{|c|c|c|c|c|c|c|c|c|c|c|}
\hline \multicolumn{3}{|c|}{ Identificação do ensaio } & \multicolumn{4}{|c|}{ Dados DRI } & & & & \\
\hline Ensaio & $\begin{array}{c}\text { Temperatura } \\
\left({ }^{\circ} \mathrm{C}\right)\end{array}$ & $\begin{array}{c}\text { Tempo } \\
\text { (min) }\end{array}$ & $\begin{array}{c}\text { Massa } \\
\text { inicial (g) }\end{array}$ & $\begin{array}{c}\text { Massa final } \\
\text { (g) }\end{array}$ & $\begin{array}{c}\text { C final } \\
\text { (\% massa) }\end{array}$ & $\begin{array}{l}\mathrm{m}_{\mathrm{DR}} / \text { Vazão } \\
\text { total } \\
\text { (g.min/NL) }\end{array}$ & & & & \\
\hline 14CF0900-30 & 900 & 30 & 70,17 & 69,88 & & 10,2 & & & & \\
\hline \multicolumn{11}{|c|}{ Dados gases } \\
\hline \multicolumn{4}{|c|}{ Vazões entrada (NL/min) } & \multirow{2}{*}{$\begin{array}{c}\text { Conversão } \mathrm{CH}_{4} \\
\text { média }\end{array}$} & \multicolumn{6}{|c|}{ Pressão parcial média (atm) } \\
\hline $\mathbf{H}_{2}$ & $\mathrm{CH}_{4}$ & $\mathrm{H}_{2} \mathrm{O}$ & Ar & & $\mathrm{CO}_{2}$ & $\mathrm{Ar}$ & CO & $\mathrm{CH}_{4}$ & $\mathrm{H}_{2}$ & $\mathrm{H}_{2} \mathrm{O}$ \\
\hline \multirow[t]{2}{*}{4,69} & 0,83 & 0,69 & 0,69 & 0,49 & $2,43 \mathrm{E}-03$ & 0,096 & 0,057 & 0,061 & 0,783 & $3,33 \mathrm{E}-02$ \\
\hline & \multicolumn{4}{|c|}{ \%vol. - gases de saída seco - cromatografia gasosa } & \multicolumn{6}{|c|}{ Vazões saída (NL/min) } \\
\hline Tempo (min) & $\mathrm{CO}_{2}$ & Ar & CO & $\mathrm{CH}_{4}$ & $\mathrm{CO} 2$ & $\mathrm{Ar}$ & CO & $\mathrm{CH}_{4}$ & $\mathrm{H}_{2}$ & $\mathrm{H}_{2} \mathrm{O}$ \\
\hline 3 & 0,28 & 9,64 & 4,80 & 6,64 & 0,020 & 0,69 & 0,34 & 0,47 & 5,65 & 0,33 \\
\hline 10 & 0,27 & 9,30 & 5,73 & 6,26 & 0,020 & 0,69 & 0,42 & 0,46 & 5,91 & 0,24 \\
\hline 17 & 0,24 & 9,27 & 5,68 & 6,06 & 0,018 & 0,69 & 0,42 & 0,45 & 5,93 & 0,25 \\
\hline 24 & 0,24 & 10,19 & 5,84 & 6,18 & 0,016 & 0,69 & 0,40 & 0,42 & 5,30 & 0,28 \\
\hline 30 & 0,24 & 10,19 & 5,84 & 6,18 & 0,016 & 0,69 & 0,40 & 0,42 & 5,30 & 0,28 \\
\hline
\end{tabular}


Tabela A 2 - Dados do ensaios de carburação simultânea à reforma de metano a $900{ }^{\circ} \mathrm{C}$ e 60 min.

\begin{tabular}{|c|c|c|c|c|c|c|c|c|c|c|}
\hline \multicolumn{3}{|c|}{ Identificação do ensaio } & \multicolumn{4}{|c|}{ Dados DRI } & & & & \\
\hline Ensaio & $\begin{array}{c}\text { Temperatura } \\
\left({ }^{\circ} \mathrm{C}\right)\end{array}$ & $\begin{array}{l}\text { Tempo } \\
\text { (min) }\end{array}$ & $\begin{array}{c}\text { Massa } \\
\text { inicial (g) }\end{array}$ & $\begin{array}{c}\text { Massa final } \\
\text { (g) }\end{array}$ & $\begin{array}{c}\text { C final } \\
\text { (\% massa) }\end{array}$ & $\begin{array}{c}\mathrm{m}_{\mathrm{DR} /} / \text { Vazão total } \\
\text { (g.min/NL) }\end{array}$ & & & & \\
\hline 15CF0900-60 & 900 & 60 & 72,30 & 71,5 & & 9,9 & & & & \\
\hline \multicolumn{11}{|c|}{ Dados gases } \\
\hline \multicolumn{4}{|c|}{ Vazões entrada (NL/min) } & Conversão & \multicolumn{6}{|c|}{ Pressão parcial média (atm) } \\
\hline $\mathbf{H}_{2}$ & $\mathrm{CH}_{4}$ & $\mathrm{H}_{2} \mathrm{O}$ & $\operatorname{Ar}$ & $\mathrm{CH}_{4}$ média & $\mathrm{CO}_{2}$ & $\mathrm{Ar}$ & CO & $\mathrm{CH}_{4}$ & $\mathrm{H}_{2}$ & $\mathrm{H}_{2} \mathrm{O}$ \\
\hline \multirow[t]{2}{*}{4,94} & 0,87 & 0,73 & 0,73 & 0,45 & $1,84 \mathrm{E}-03$ & 0,093 & 0,059 & 0,065 & 0,781 & $3,01 \mathrm{E}-02$ \\
\hline & \multicolumn{4}{|c|}{ \%vol. - gases de saída seco - cromatografia gasosa } & \multicolumn{6}{|c|}{ Vazões saída (NL/min) } \\
\hline Tempo (min) & $\mathrm{CO}_{2}$ & Ar & CO & $\mathrm{CH}_{4}$ & $\mathrm{CO}_{2}$ & $\mathrm{Ar}$ & CO & $\mathrm{CH}_{4}$ & $\mathbf{H}_{2}$ & $\mathrm{H}_{2} \mathrm{O}$ \\
\hline 4 & 0,20 & 9,57 & 5,07 & 6,86 & 0,015 & 0,73 & 0,38 & 0,52 & 6,01 & 0,33 \\
\hline 11 & 0,19 & 9,40 & 5,62 & 6,64 & 0,015 & 0,73 & 0,43 & 0,51 & 6,14 & 0,28 \\
\hline 18 & 0,20 & 9,35 & 5,83 & 6,62 & 0,015 & 0,73 & 0,45 & 0,51 & 6,19 & 0,26 \\
\hline 25 & 0,19 & 9,30 & 6,07 & 6,71 & 0,015 & 0,73 & 0,47 & 0,52 & 6,24 & 0,24 \\
\hline 32 & 0,20 & 9,57 & 6,17 & 6,77 & 0,015 & 0,73 & 0,47 & 0,51 & 6,03 & 0,24 \\
\hline 39 & 0,19 & 9,59 & 5,97 & 6,55 & 0,014 & 0,73 & 0,45 & 0,50 & 6,01 & 0,26 \\
\hline 46 & 0,19 & 9,56 & 6,11 & 6,56 & 0,014 & 0,73 & 0,46 & 0,50 & 6,04 & 0,25 \\
\hline 53 & 0,18 & 9,52 & 6,27 & 6,57 & 0,014 & 0,73 & 0,48 & 0,50 & 6,07 & 0,23 \\
\hline 60 & 0,17 & 9,58 & 6,09 & 6,46 & 0,013 & 0,73 & 0,46 & 0,49 & 6,02 & 0,25 \\
\hline
\end{tabular}


Tabela A 3 - Dados do ensaios de carburação simultânea à reforma de metano a $900{ }^{\circ} \mathrm{C}$ e 90 min.

\begin{tabular}{|c|c|c|c|c|c|c|c|c|c|c|}
\hline \multicolumn{3}{|c|}{ Identificação do ensaio } & \multicolumn{4}{|c|}{ Dados DRI } & & & & \\
\hline Ensaio & $\begin{array}{c}\text { Temperatura } \\
\left({ }^{\circ} \mathrm{C}\right) \\
\end{array}$ & $\begin{array}{c}\text { Tempo } \\
\text { (min) }\end{array}$ & $\begin{array}{c}\text { Massa } \\
\text { inicial (g) }\end{array}$ & $\begin{array}{l}\text { Massa final } \\
(\mathrm{g})\end{array}$ & $\begin{array}{c}\text { C final } \\
(\% \text { massa) }\end{array}$ & $\begin{array}{c}\mathrm{m}_{\mathrm{DRI}} / \text { Vazão total } \\
\text { (g.min/NL) }\end{array}$ & & & & \\
\hline 24CF0900-90 & 900 & 90 & 70,75 & 70,77 & & 9,6 & & & & \\
\hline \multicolumn{11}{|c|}{ Dados gases } \\
\hline \multicolumn{4}{|c|}{ Vazões entrada (NL/min) } & Conversão & \multicolumn{6}{|c|}{ Pressão parcial média (atm) } \\
\hline $\mathrm{H}_{2}$ & $\mathrm{CH}_{4}$ & $\mathrm{H}_{2} \mathrm{O}$ & Ar & $\mathrm{CH}_{4}$ média & $\mathrm{CO}_{2}$ & Ar & CO & $\mathrm{CH}_{4}$ & $\mathrm{H}_{2}$ & $\mathrm{H}_{2} \mathrm{O}$ \\
\hline \multirow[t]{2}{*}{4,99} & 0,88 & 0,73 & 0,73 & 0,49 & $1,99 \mathrm{E}-03$ & 0,095 & 0,070 & 0,060 & 0,774 & $2,09 \mathrm{E}-02$ \\
\hline & \multicolumn{4}{|c|}{ \%vol. - gases de saída seco - cromatografia gasosa } & \multicolumn{6}{|c|}{ Vazões saída (NL/min) } \\
\hline Tempo (min) & $\mathrm{CO}_{2}$ & $\mathrm{Ar}$ & CO & $\mathrm{CH}_{4}$ & $\mathrm{CO}_{2}$ & $\mathrm{Ar}$ & CO & $\mathrm{CH}_{4}$ & $\mathrm{H}_{2}$ & $\mathrm{H}_{2} \mathrm{O}$ \\
\hline 3 & 0,22 & 10,04 & 5,94 & 6,27 & 0,016 & 0,73 & 0,43 & 0,46 & 5,75 & 0,28 \\
\hline 10 & 0,22 & 9,85 & 6,76 & 6,41 & 0,017 & 0,73 & 0,50 & 0,48 & 5,90 & 0,21 \\
\hline 17 & 0,21 & 9,86 & 6,73 & 6,31 & 0,016 & 0,73 & 0,50 & 0,47 & 5,90 & 0,22 \\
\hline 24 & 0,19 & 9,87 & 6,70 & 6,22 & 0,014 & 0,73 & 0,50 & 0,46 & 5,89 & 0,22 \\
\hline 31 & 0,19 & 9,81 & 6,90 & 6,23 & 0,014 & 0,73 & 0,52 & 0,47 & 5,93 & 0,20 \\
\hline 38 & 0,20 & 9,79 & 7,03 & 6,06 & 0,015 & 0,73 & 0,53 & 0,45 & 5,95 & 0,19 \\
\hline 45 & 0,20 & 9,78 & 7,14 & 6,11 & 0,015 & 0,73 & 0,54 & 0,46 & 5,97 & 0,18 \\
\hline 52 & 0,20 & 9,76 & 7,22 & 6,08 & 0,015 & 0,73 & 0,54 & 0,46 & 5,98 & 0,18 \\
\hline 59 & 0,20 & 9,77 & 7,22 & 6,04 & 0,015 & 0,73 & 0,54 & 0,45 & 5,98 & 0,18 \\
\hline 66 & 0,21 & 9,71 & 7,46 & 6,08 & 0,016 & 0,73 & 0,56 & 0,46 & 6,02 & 0,15 \\
\hline 73 & 0,22 & 9,72 & 7,51 & 6,09 & 0,016 & 0,73 & 0,57 & 0,46 & 6,02 & 0,15 \\
\hline 80 & 0,22 & 9,71 & 7,50 & 6,13 & 0,016 & 0,73 & 0,57 & 0,46 & 6,03 & 0,15 \\
\hline 87 & 0,20 & 9,73 & 7,38 & 5,89 & 0,015 & 0,73 & 0,56 & 0,44 & 6,01 & 0,16 \\
\hline 90 & 0,20 & 9,73 & 7,38 & 5,89 & 0,015 & 0,73 & 0,56 & 0,44 & 6,01 & 0,16 \\
\hline
\end{tabular}


Tabela A 4 - Dados do ensaios de carburação simultânea à reforma de metano a $950{ }^{\circ} \mathrm{C}$ e $30 \mathrm{~min}$.

\begin{tabular}{|c|c|c|c|c|c|c|c|c|c|c|}
\hline \multicolumn{3}{|c|}{ Identificação do ensaio } & \multicolumn{4}{|c|}{ Dados DRI } & & & & \\
\hline Ensaio & $\begin{array}{c}\text { Temperatura } \\
\left({ }^{\circ} \mathrm{C}\right)\end{array}$ & $\begin{array}{c}\text { Tempo } \\
\text { (min) }\end{array}$ & $\begin{array}{c}\text { Massa } \\
\text { inicial (g) }\end{array}$ & Massa final (g) & $\begin{array}{l}\text { C final } \\
\text { (\% massa) }\end{array}$ & $\begin{array}{c}\mathrm{m}_{\mathrm{DRI}} / \mathrm{Vazão} \\
\text { total (g.min/NL) }\end{array}$ & & & & \\
\hline 20CF0950-30 & 950 & 30 & 74,64 & 74,08 & & 10,2 & & & & \\
\hline \multicolumn{11}{|c|}{ Dados gases } \\
\hline \multicolumn{4}{|c|}{ Vazões entrada (NL/min) } & \multirow{2}{*}{$\begin{array}{c}\text { Conversão } \mathrm{CH}_{4} \\
\text { média }\end{array}$} & \multicolumn{6}{|c|}{ Pressão parcial média (atm) } \\
\hline $\mathbf{H}_{2}$ & $\mathrm{CH}_{4}$ & $\mathrm{H}_{2} \mathrm{O}$ & Ar & & $\mathrm{CO}_{2}$ & $\mathrm{Ar}$ & CO & $\mathrm{CH}_{4}$ & $\mathrm{H}_{2}$ & $\mathrm{H}_{2} \mathrm{O}$ \\
\hline \multirow[t]{2}{*}{4,97} & 0,88 & 0,73 & 0,73 & 0,66 & $1,17 \mathrm{E}-03$ & 0,090 & 0,082 & 0,039 & 0,788 & $7,01 \mathrm{E}-03$ \\
\hline & \multicolumn{4}{|c|}{ \%vol. - gases de saída seco - cromatografia gasosa } & \multicolumn{6}{|c|}{ Vazões saída (NL/min) } \\
\hline Tempo (min) & $\mathrm{CO}_{2}$ & $\mathrm{Ar}$ & $\mathrm{CO}$ & $\mathrm{CH}_{4}$ & $\mathrm{CO}_{2}$ & $\mathrm{Ar}$ & CO & $\mathrm{CH}_{4}$ & $\mathrm{H}_{2}$ & $\mathrm{H}_{2} \mathrm{O}$ \\
\hline 3 & 0,19 & 9,07 & 7,81 & 4,21 & 0,015 & 0,73 & 0,63 & 0,34 & 6,51 & 0,09 \\
\hline 10 & 0,13 & 8,90 & 8,54 & 4,02 & 0,011 & 0,73 & 0,70 & 0,33 & 6,67 & 0,02 \\
\hline 17 & 0,13 & 9,31 & 8,64 & 4,06 & 0,011 & 0,73 & 0,68 & 0,32 & 6,35 & 0,04 \\
\hline 24 & 0,11 & 9,43 & 8,09 & 3,89 & 0,008 & 0,73 & 0,63 & 0,30 & 6,23 & 0,10 \\
\hline 30 & 0,11 & 9,43 & 8,09 & 3,89 & 0,008 & 0,73 & 0,63 & 0,30 & 6,23 & 0,10 \\
\hline
\end{tabular}


Tabela A 5 - Dados do ensaios de carburação simultânea à reforma de metano a $950^{\circ} \mathrm{C}$ e $60 \mathrm{~min}$.

\begin{tabular}{|c|c|c|c|c|c|c|c|c|c|c|}
\hline \multicolumn{3}{|c|}{ Identificação do ensaio } & \multicolumn{4}{|c|}{ Dados DRI } & & & & \\
\hline Ensaio & $\begin{array}{c}\text { Temperatura } \\
\left({ }^{\circ} \mathrm{C}\right) \\
\end{array}$ & $\begin{array}{c}\text { Tempo } \\
\text { (min) }\end{array}$ & $\begin{array}{c}\text { Massa } \\
\text { inicial (g) }\end{array}$ & $\begin{array}{l}\text { Massa final } \\
\text { (g) }\end{array}$ & $\begin{array}{c}\text { C final } \\
(\% \text { massa) }\end{array}$ & $\begin{array}{c}\mathrm{m}_{\mathrm{DR} /} / \text { Vazão total } \\
\text { (g.min/NL) }\end{array}$ & & & & \\
\hline 25CF0950-60 & 950 & 60 & 72,96 & 73,03 & & 10,3 & & & & \\
\hline \multicolumn{11}{|c|}{ Dados gases } \\
\hline \multicolumn{4}{|c|}{ Vazões entrada (NL/min) } & Conversão & \multicolumn{6}{|c|}{ Pressão parcial média (atm) } \\
\hline $\mathbf{H}_{2}$ & $\mathrm{CH}_{4}$ & $\mathrm{H}_{2} \mathrm{O}$ & Ar & $\mathrm{CH}_{4}$ média & $\mathrm{CO}_{2}$ & Ar & CO & $\mathrm{CH}_{4}$ & $\mathrm{H}_{2}$ & $\mathrm{H}_{2} \mathrm{O}$ \\
\hline \multirow[t]{2}{*}{4,82} & 0,85 & 0,71 & 0,71 & 0,62 & 1,59E-03 & 0,087 & 0,081 & 0,044 & 0,787 & $4,72 \mathrm{E}-03$ \\
\hline & \multicolumn{4}{|c|}{ \%vol. - gases de saída seco - cromatografia gasosa } & \multicolumn{6}{|c|}{ Vazões saída (NL/min) } \\
\hline Tempo (min) & $\mathrm{CO}_{2}$ & Ar & CO & $\mathrm{CH}_{4}$ & $\mathrm{CO}_{2}$ & $\mathrm{Ar}$ & CO & $\mathrm{CH}_{4}$ & $\mathbf{H}_{2}$ & $\mathrm{H}_{2} \mathrm{O}$ \\
\hline 0 & 0,17 & 9,12 & 7,68 & 4,57 & 0,013 & 0,71 & 0,60 & 0,36 & 6,26 & 0,10 \\
\hline 7 & 0,17 & 9,02 & 8,07 & 4,58 & 0,014 & 0,71 & 0,63 & 0,36 & 6,35 & 0,06 \\
\hline 14 & 0,17 & 9,00 & 8,24 & 4,57 & 0,013 & 0,71 & 0,65 & 0,36 & 6,38 & 0,05 \\
\hline 21 & 0,17 & 8,92 & 8,46 & 4,55 & 0,014 & 0,71 & 0,67 & 0,36 & 6,45 & 0,02 \\
\hline 28 & 0,16 & 8,97 & 8,31 & 4,54 & 0,012 & 0,71 & 0,66 & 0,36 & 6,40 & 0,04 \\
\hline 35 & 0,16 & 8,95 & 8,35 & 4,50 & 0,012 & 0,71 & 0,66 & 0,36 & 6,42 & 0,03 \\
\hline 42 & 0,15 & 8,96 & 8,33 & 4,49 & 0,012 & 0,71 & 0,66 & 0,36 & 6,41 & 0,04 \\
\hline
\end{tabular}


Tabela A 6 - Dados do ensaios de carburação simultânea à reforma de metano a $950^{\circ} \mathrm{C}$ e 90 min.

\begin{tabular}{|c|c|c|c|c|c|c|c|c|c|c|}
\hline \multicolumn{3}{|c|}{$\begin{array}{l}\text { Identificação do ensaio } \\
\text { Temperatura Tempo }\end{array}$} & $\begin{array}{c}\text { Massa } \\
\text { inicial (g) }\end{array}$ & $\begin{array}{r}\text { Dad } \\
\text { Massa final (g) }\end{array}$ & $\begin{array}{l}\text { S DRI } \\
\text { C final } \\
\text { (\% massa) }\end{array}$ & $\begin{array}{c}\mathrm{m}_{\mathrm{DRI}} / \text { Vazão total } \\
\text { (g.min/NL) }\end{array}$ & & & & \\
\hline 26CF0950-90 & 950 & 90 & 70,30 & 70,32 & & 9,9 & & & & \\
\hline \multicolumn{11}{|c|}{ Dados gases } \\
\hline \multicolumn{4}{|c|}{ Vazões entrada (NL/min) } & \multirow{2}{*}{$\begin{array}{l}\text { Conversão } \mathrm{CH}_{4} \\
\text { média }\end{array}$} & \multicolumn{6}{|c|}{ Pressão parcial média (atm) } \\
\hline $\mathrm{H}_{2}$ & $\mathrm{CH}_{4}$ & $\mathrm{H}_{2} \mathrm{O}$ & $\mathrm{Ar}$ & & $\mathrm{CO}_{2}$ & Ar & CO & $\mathrm{CH}_{4}$ & $\mathrm{H}_{2}$ & $\mathrm{H}_{2} \mathrm{O}$ \\
\hline \multirow[t]{2}{*}{4,84} & 0,85 & 0,71 & 0,71 & 0,66 & $1,14 \mathrm{E}-03$ & 0,089 & 0,091 & 0,037 & 0,782 & 0,00 \\
\hline & \multicolumn{4}{|c|}{ \%vol. - gases de saída seco - cromatografia gasosa } & \multicolumn{6}{|c|}{ Vazões saída (NL/min) } \\
\hline Tempo (min) & $\mathrm{CO}_{2}$ & Ar & CO & $\mathrm{CH}_{4}$ & $\mathrm{CO}_{2}$ & $\mathrm{Ar}$ & CO & $\mathrm{CH}_{4}$ & $\mathbf{H}_{2}$ & $\mathrm{H}_{2} \mathrm{O}$ \\
\hline 3 & 0,16 & 8,58 & 8,88 & 4,01 & 0,013 & 0,71 & 0,74 & 0,33 & 6,78 & 0,00 \\
\hline 10 & 0,14 & 8,49 & 9,38 & 4,05 & 0,012 & 0,71 & 0,79 & 0,34 & 6,87 & 0,00 \\
\hline 17 & 0,12 & 8,55 & 9,18 & 3,91 & 0,010 & 0,71 & 0,76 & 0,33 & 6,81 & 0,00 \\
\hline 24 & 0,12 & 8,46 & 9,47 & 3,91 & 0,010 & 0,71 & 0,80 & 0,33 & 6,91 & 0,00 \\
\hline 31 & 0,13 & 9,46 & 9,56 & 3,89 & 0,010 & 0,71 & 0,72 & 0,29 & 6,11 & 0,00 \\
\hline 38 & 0,11 & 9,58 & 9,22 & 3,82 & 0,008 & 0,71 & 0,69 & 0,28 & 6,01 & 0,02 \\
\hline 45 & 0,12 & 9,51 & 9,38 & 3,83 & 0,009 & 0,71 & 0,70 & 0,29 & 6,06 & 0,00 \\
\hline 52 & 0,12 & 9,54 & 9,29 & 3,77 & 0,009 & 0,71 & 0,69 & 0,28 & 6,03 & 0,01 \\
\hline 59 & 0,11 & 9,43 & 9,76 & 3,85 & 0,009 & 0,71 & 0,74 & 0,29 & 6,13 & 0,00 \\
\hline 66 & 0,10 & 9,58 & 9,17 & 3,78 & 0,008 & 0,71 & 0,68 & 0,28 & 6,00 & 0,02 \\
\hline 73 & 0,11 & 9,53 & 9,34 & 3,76 & 0,008 & 0,71 & 0,70 & 0,28 & 6,04 & 0,01 \\
\hline 80 & 0,11 & 9,53 & 9,35 & 3,72 & 0,008 & 0,71 & 0,70 & 0,28 & 6,04 & 0,00 \\
\hline 87 & 0,11 & 9,49 & 9,61 & 3,75 & 0,009 & 0,71 & 0,72 & 0,28 & 6,09 & 0,00 \\
\hline 90 & 0,11 & 9,49 & 9,61 & 3,75 & 0,009 & 0,71 & 0,72 & 0,28 & 6,09 & 0,00 \\
\hline
\end{tabular}


Tabela A 7 - Dados do ensaios de carburação simultânea à reforma de metano a $1000{ }^{\circ} \mathrm{C}$ e 30 min.

\begin{tabular}{|c|c|c|c|c|c|c|c|c|c|c|}
\hline \multicolumn{3}{|c|}{\begin{tabular}{l}
\multicolumn{3}{c}{ Identificação do ensaio } \\
\\
Temperatura \\
$\begin{array}{lcc}\text { Tempo } \\
\text { Ensaio } & \left({ }^{\circ} \mathrm{C}\right) & (\mathrm{min})\end{array}$
\end{tabular}} & $\begin{array}{c}\text { Massa } \\
\text { inicial (g) }\end{array}$ & Massa final (g) & $\begin{array}{l}\text { DRI } \\
\text { C final } \\
\text { (\% massa) }\end{array}$ & $\begin{array}{c}\mathrm{m}_{\mathrm{DR}} / \text { Vazão total } \\
\text { (g.min/NL) }\end{array}$ & & & & \\
\hline 23CF1000-30 & 1000 & 30 & 73,16 & 72,78 & & 9,9 & & & & \\
\hline \multicolumn{11}{|c|}{ Dados gases } \\
\hline \multicolumn{4}{|c|}{ Vazões entrada (NL/min) } & \multirow{2}{*}{$\begin{array}{c}\text { Conversão } \mathrm{CH}_{4} \\
\text { média }\end{array}$} & \multicolumn{6}{|c|}{ Pressão parcial média (atm) } \\
\hline $\mathbf{H}_{2}$ & $\mathrm{CH}_{4}$ & $\mathrm{H}_{2} \mathrm{O}$ & Ar & & $\mathrm{CO}_{2}$ & Ar & CO & $\mathrm{CH}_{4}$ & $\mathrm{H}_{2}$ & $\mathrm{H}_{2} \mathrm{O}$ \\
\hline \multirow[t]{2}{*}{5,00} & 0,88 & 0,74 & 0,74 & 0,74 & $1,05 \mathrm{E}-03$ & 0,082 & 0,092 & 0,025 & 0,800 & 0,00 \\
\hline & \multicolumn{4}{|c|}{ \%vol. - gases de saída seco - cromatografia gasosa } & \multicolumn{6}{|c|}{ Vazões saída (NL/min) } \\
\hline Tempo (min) & $\mathrm{CO}_{2}$ & Ar & CO & $\mathrm{CH}_{4}$ & $\mathrm{CO}_{2}$ & $\mathrm{Ar}$ & $\mathrm{CO}$ & $\mathrm{CH}_{4}$ & $\mathbf{H}_{\mathbf{2}}$ & $\mathrm{H}_{2} \mathrm{O}$ \\
\hline 3 & 0,16 & 8,66 & 8,61 & 2,74 & 0,013 & 0,74 & 0,73 & 0,23 & 6,92 & 0,00 \\
\hline 10 & 0,12 & 8,51 & 9,19 & 2,57 & 0,010 & 0,74 & 0,79 & 0,22 & 7,08 & 0,00 \\
\hline 17 & 0,11 & 8,46 & 9,39 & 2,60 & 0,010 & 0,74 & 0,82 & 0,23 & 7,13 & 0,00 \\
\hline 24 & 0,10 & 8,44 & 9,49 & 2,61 & 0,009 & 0,74 & 0,83 & 0,23 & 7,16 & 0,00 \\
\hline 30 & 0,10 & 8,44 & 9,49 & 2,61 & 0,009 & 0,74 & 0,83 & 0,23 & 7,16 & 0,00 \\
\hline
\end{tabular}


Tabela A 8 - Dados do ensaios de carburação simultânea à reforma de metano a $1000{ }^{\circ} \mathrm{C}$ e 60 min.

\begin{tabular}{|c|c|c|c|c|c|c|c|c|c|c|}
\hline \multicolumn{3}{|c|}{ Identificação do ensaio } & \multicolumn{4}{|c|}{ Dados DRI } & & & & \\
\hline Ensaio & $\begin{array}{c}\text { Temperatura } \\
\left({ }^{\circ} \mathrm{C}\right)\end{array}$ & $\begin{array}{l}\text { Tempo } \\
\text { (min) }\end{array}$ & $\begin{array}{c}\text { Massa } \\
\text { inicial (g) }\end{array}$ & $\begin{array}{l}\text { Massa final } \\
\text { (g) }\end{array}$ & $\begin{array}{c}\text { C final } \\
(\% \text { massa })\end{array}$ & $\begin{array}{c}\text { m }_{\text {DRI/Vazão total }} / \text { (g.min/NL) } \\
\text { (g.mon }\end{array}$ & & & & \\
\hline 22CF1000-60 & 1000 & 60 & 70,55 & 71,06 & & 9,8 & & & & \\
\hline \multicolumn{11}{|c|}{ Dados gases } \\
\hline \multicolumn{4}{|c|}{ Vazões entrada (NL/min) } & \multirow{2}{*}{$\begin{array}{c}\text { Conversão } \mathrm{CH}_{4} \\
\text { média }\end{array}$} & \multicolumn{6}{|c|}{ Pressão parcial média (atm) } \\
\hline $\mathbf{H}_{2}$ & $\mathrm{CH}_{4}$ & $\mathrm{H}_{2} \mathrm{O}$ & $\operatorname{Ar}$ & & $\mathrm{CO}_{2}$ & $\mathrm{Ar}$ & CO & $\mathrm{CH}_{4}$ & $\mathrm{H}_{2}$ & $\mathrm{H}_{2} \mathrm{O}$ \\
\hline \multirow[t]{2}{*}{4,89} & 0,86 & 0,72 & 0,72 & 0,75 & $8,05 \mathrm{E}-04$ & 0,087 & 0,089 & 0,027 & 0,796 & 0,00 \\
\hline & \multicolumn{4}{|c|}{ \%vol. - gases de saída seco - cromatografia gasosa } & \multicolumn{6}{|c|}{ Vazões saída (NL/min) } \\
\hline Tempo (min) & $\mathrm{CO}_{2}$ & $\mathrm{Ar}$ & CO & $\mathrm{CH}_{4}$ & $\mathrm{CO}_{2}$ & $\mathrm{Ar}$ & CO & $\mathrm{CH}_{4}$ & $\mathrm{H}_{2}$ & $\mathrm{H}_{2} \mathrm{O}$ \\
\hline 4 & 0,12 & 9,03 & 8,66 & 2,74 & 0,010 & 0,72 & 0,69 & 0,22 & 6,45 & 0,02 \\
\hline 11 & 0,10 & 8,90 & 9,14 & 2,79 & 0,008 & 0,72 & 0,74 & 0,23 & 6,58 & 0,00 \\
\hline 18 & 0,08 & 8,96 & 8,95 & 2,72 & 0,007 & 0,72 & 0,72 & 0,22 & 6,53 & 0,00 \\
\hline 25 & 0,08 & 8,94 & 8,93 & 2,74 & 0,006 & 0,72 & 0,72 & 0,22 & 6,54 & 0,00 \\
\hline 32 & 0,08 & 8,92 & 9,00 & 2,79 & 0,006 & 0,72 & 0,73 & 0,23 & 6,56 & 0,00 \\
\hline 39 & 0,08 & 8,93 & 9,01 & 2,81 & 0,006 & 0,72 & 0,73 & 0,23 & 6,55 & 0,00 \\
\hline 46 & 0,08 & 8,94 & 9,01 & 2,75 & 0,006 & 0,72 & 0,73 & 0,22 & 6,55 & 0,00 \\
\hline 53 & 0,08 & 8,84 & 9,37 & 2,88 & 0,007 & 0,72 & 0,76 & 0,23 & 6,64 & 0,00 \\
\hline 60 & 0,08 & 8,84 & 9,37 & 2,88 & 0,007 & 0,72 & 0,76 & 0,23 & 6,64 & 0,00 \\
\hline
\end{tabular}


Tabela A 9 - Dados do ensaios de carburação simultânea à reforma de metano a $1000{ }^{\circ} \mathrm{C}$ e 90 min.

\begin{tabular}{|c|c|c|c|c|c|c|c|c|c|c|}
\hline \multicolumn{3}{|c|}{ Identificação do ensaio } & \multicolumn{4}{|c|}{ Dados DRI } & & & & \\
\hline Ensaio & $\begin{array}{c}\text { Temperatura } \\
\left({ }^{\circ} \mathrm{C}\right) \\
\end{array}$ & $\begin{array}{l}\text { Tempo } \\
\text { (min) }\end{array}$ & $\begin{array}{c}\text { Massa } \\
\text { inicial (g) }\end{array}$ & $\begin{array}{c}\text { Massa final } \\
\text { (g) }\end{array}$ & $\begin{array}{c}\text { C final } \\
\text { (\% massa) }\end{array}$ & $\begin{array}{c}\mathrm{m}_{\mathrm{DRI} /} / \text { Vazão total } \\
\text { (g.min/NL) }\end{array}$ & & & & \\
\hline 21CF1000-90 & 1000 & 90 & 72,45 & 73,02 & & 10,1 & & & & \\
\hline \multicolumn{11}{|c|}{ Dados gases } \\
\hline \multicolumn{4}{|c|}{ Vazões entrada (NL/min) } & Conversão & \multicolumn{6}{|c|}{ Pressão parcial média (atm) } \\
\hline $\mathrm{H}_{2}$ & $\mathrm{CH}_{4}$ & $\mathrm{H}_{2} \mathrm{O}$ & $\mathrm{Ar}$ & $\mathrm{CH}_{4}$ média & $\mathrm{CO}_{2}$ & Ar & CO & $\mathrm{CH}_{4}$ & $\mathrm{H}_{2}$ & $\mathrm{H}_{2} \mathrm{O}$ \\
\hline \multirow[t]{2}{*}{4,86} & 0,86 & 0,71 & 0,71 & 0,80 & $5,81 \mathrm{E}-04$ & 0,069 & 0,090 & 0,024 & 0,818 & 0,00 \\
\hline & \multicolumn{4}{|c|}{ \%vol. - gases de saída seco - cromatografia gasosa } & \multicolumn{6}{|c|}{ Vazões saída (NL/min) } \\
\hline Tempo (min) & $\mathrm{CO}_{2}$ & $\mathrm{Ar}$ & CO & $\mathrm{CH}_{4}$ & $\mathrm{CO}_{2}$ & $\mathrm{Ar}$ & CO & $\mathrm{CH}_{4}$ & $\mathrm{H}_{2}$ & $\mathrm{H}_{2} \mathrm{O}$ \\
\hline 2 & 0,15 & 7,28 & 8,68 & 2,45 & 0,014 & 0,71 & 0,85 & 0,24 & 8,18 & 0,00 \\
\hline 9 & 0,07 & 7,13 & 9,09 & 2,15 & 0,007 & 0,71 & 0,91 & 0,22 & 8,36 & 0,00 \\
\hline 16 & 0,05 & 7,14 & 9,02 & 2,17 & 0,005 & 0,71 & 0,90 & 0,22 & 8,36 & 0,00 \\
\hline 23 & 0,05 & 7,09 & 9,17 & 2,27 & 0,005 & 0,71 & 0,92 & 0,23 & 8,42 & 0,00 \\
\hline 30 & 0,05 & 7,00 & 9,52 & 2,39 & 0,006 & 0,71 & 0,97 & 0,24 & 8,55 & 0,00 \\
\hline 37 & 0,05 & 7,07 & 9,32 & 2,47 & 0,006 & 0,71 & 0,94 & 0,25 & 8,45 & 0,00 \\
\hline 44 & 0,06 & 7,07 & 9,29 & 2,53 & 0,006 & 0,71 & 0,94 & 0,26 & 8,45 & 0,00 \\
\hline 51 & 0,06 & 7,03 & 9,45 & 2,54 & 0,006 & 0,71 & 0,96 & 0,26 & 8,51 & 0,00 \\
\hline 58 & 0,06 & 7,11 & 9,10 & 2,52 & 0,006 & 0,71 & 0,91 & 0,25 & 8,39 & 0,00 \\
\hline 65 & 0,06 & 7,09 & 9,25 & 2,52 & 0,006 & 0,71 & 0,93 & 0,25 & 8,42 & 0,00 \\
\hline 72 & 0,06 & 7,16 & 8,93 & 2,47 & 0,006 & 0,71 & 0,89 & 0,25 & 8,32 & 0,00 \\
\hline 79 & 0,06 & 6,76 & 9,21 & 2,48 & 0,006 & 0,71 & 0,97 & 0,26 & 8,87 & 0,00 \\
\hline 86 & 0,06 & 6,80 & 8,97 & 2,43 & 0,006 & 0,71 & 0,94 & 0,26 & 8,80 & 0,00 \\
\hline 90 & 0,06 & 6,80 & 8,97 & 2,43 & 0,006 & 0,71 & 0,94 & 0,26 & 8,80 & 0,00 \\
\hline
\end{tabular}


Tabela A 10 - Dados do ensaios de carburação simultânea à reforma de metano a $1030{ }^{\circ} \mathrm{C}$ e 60 min.

\begin{tabular}{|c|c|c|c|c|c|c|c|c|c|c|}
\hline \multicolumn{3}{|c|}{ Identificação do ensaio } & \multicolumn{4}{|c|}{ Dados DRI } & & & & \\
\hline Ensaio & $\begin{array}{c}\text { Temperatura } \\
\left({ }^{\circ} \mathrm{C}\right) \\
\end{array}$ & $\begin{array}{c}\text { Tempo } \\
\text { (min) }\end{array}$ & $\begin{array}{c}\text { Massa } \\
\text { inicial (g) }\end{array}$ & $\begin{array}{c}\text { Massa final } \\
\text { (g) }\end{array}$ & $\begin{array}{c}\text { C final } \\
\text { (\% massa) }\end{array}$ & $\begin{array}{c}\mathrm{m}_{\mathrm{DRI}} / \text { Vazão total } \\
\text { (g.min/NL) }\end{array}$ & & & & \\
\hline 29CF1030-60 & 1030 & 60 & 69,70 & 69,79 & & 9,9 & & & & \\
\hline \multicolumn{11}{|c|}{ Dados gases } \\
\hline \multicolumn{4}{|c|}{ Vazões entrada (NL/min) } & Conversão & \multicolumn{6}{|c|}{ Pressão parcial média (atm) } \\
\hline $\mathbf{H}_{2}$ & $\mathrm{CH}_{4}$ & $\mathrm{H}_{2} \mathrm{O}$ & Ar & $\mathrm{CH}_{4}$ média & $\mathrm{CO}_{2}$ & $\mathrm{Ar}$ & CO & $\mathrm{CH}_{4}$ & $\mathrm{H}_{2}$ & $\mathrm{H}_{2} \mathrm{O}$ \\
\hline \multirow[t]{2}{*}{4,76} & 0,84 & 0,70 & 0,70 & 0,79 & 7,87E-04 & 0,086 & 0,088 & 0,024 & 0,802 & 0,00 \\
\hline & \multicolumn{4}{|c|}{ \%vol. - gases de saída seco - cromatografia gasosa } & \multicolumn{6}{|c|}{ Vazões saída (NL/min) } \\
\hline Tempo (min) & $\mathrm{CO}_{2}$ & $\mathrm{Ar}$ & CO & $\mathrm{CH}_{4}$ & $\mathrm{CO}_{2}$ & $\mathrm{Ar}$ & CO & $\mathrm{CH}_{4}$ & $\mathbf{H}_{2}$ & $\mathrm{H}_{2} \mathrm{O}$ \\
\hline 3 & 0,11 & 8,82 & 8,80 & 2,42 & 0,009 & 0,70 & 0,70 & 0,19 & 6,47 & 0,00 \\
\hline 10 & 0,08 & 8,66 & 9,22 & 2,29 & 0,007 & 0,70 & 0,75 & 0,19 & 6,61 & 0,00 \\
\hline 17 & 0,08 & 8,62 & 9,22 & 2,25 & 0,006 & 0,70 & 0,75 & 0,18 & 6,65 & 0,00 \\
\hline 24 & 0,08 & 8,85 & 8,39 & 2,26 & 0,006 & 0,70 & 0,66 & 0,18 & 6,42 & 0,03 \\
\hline 31 & 0,08 & 8,63 & 9,22 & 2,42 & 0,006 & 0,70 & 0,75 & 0,20 & 6,63 & 0,00 \\
\hline 38 & 0,09 & 8,63 & 9,27 & 2,45 & 0,007 & 0,70 & 0,75 & 0,20 & 6,64 & 0,00 \\
\hline 45 & 0,08 & 8,77 & 8,73 & 2,42 & 0,006 & 0,70 & 0,70 & 0,19 & 6,50 & 0,00 \\
\hline 52 & 0,08 & 8,69 & 9,02 & 2,48 & 0,007 & 0,70 & 0,73 & 0,20 & 6,57 & 0,00 \\
\hline 59 & 0,08 & 8,72 & 8,93 & 2,47 & 0,007 & 0,70 & 0,72 & 0,20 & 6,55 & 0,00 \\
\hline 60 & 0,08 & 8,72 & 8,93 & 2,47 & 0,007 & 0,70 & 0,72 & 0,20 & 6,55 & 0,00 \\
\hline
\end{tabular}


Tabela A 11 - Dados do ensaios de carburação simultânea à reforma de metano a $1030{ }^{\circ} \mathrm{C}$ e 90 min.

\begin{tabular}{|c|c|c|c|c|c|c|c|c|c|c|}
\hline \multicolumn{3}{|c|}{ Identificação do ensaio } & \multicolumn{4}{|c|}{ Dados DRI } & & & & \\
\hline Ensaio & $\begin{array}{c}\text { Temperatura } \\
\left({ }^{\circ} \mathrm{C}\right) \\
\end{array}$ & $\begin{array}{l}\text { Tempo } \\
\text { (min) }\end{array}$ & $\begin{array}{c}\text { Massa } \\
\text { inicial (g) }\end{array}$ & $\begin{array}{c}\text { Massa final } \\
\text { (g) }\end{array}$ & $\begin{array}{c}\text { C final } \\
\text { (\% massa) }\end{array}$ & $\begin{array}{c}\mathrm{m}_{\mathrm{DR} /} / \text { Vazão total } \\
\text { (g.min/NL) }\end{array}$ & & & & \\
\hline 28CF1030-90 & 1030 & 90 & 66,87 & 68,96 & & 9,7 & & & & \\
\hline \multicolumn{11}{|c|}{ Dados gases } \\
\hline \multicolumn{4}{|c|}{ Vazões entrada (NL/min) } & Conversão & \multicolumn{6}{|c|}{ Pressão parcial média (atm) } \\
\hline $\mathrm{H}_{2}$ & $\mathrm{CH}_{4}$ & $\mathrm{H}_{2} \mathrm{O}$ & $\mathrm{Ar}$ & $\mathrm{CH}_{4}$ média & $\mathrm{CO}_{2}$ & Ar & CO & $\mathrm{CH}_{4}$ & $\mathrm{H}_{2}$ & $\mathrm{H}_{2} \mathrm{O}$ \\
\hline \multirow[t]{2}{*}{4,70} & 0,83 & 0,69 & 0,69 & 0,81 & $5,82 \mathrm{E}-04$ & 0,081 & 0,091 & 0,025 & 0,802 & 0,00 \\
\hline & \multicolumn{4}{|c|}{ \%vol. - gases de saída seco - cromatografia gasosa } & \multicolumn{6}{|c|}{ Vazões saída (NL/min) } \\
\hline Tempo (min) & $\mathrm{CO}_{2}$ & $\mathrm{Ar}$ & CO & $\mathrm{CH}_{4}$ & $\mathrm{CO}_{2}$ & $\mathrm{Ar}$ & CO & $\mathrm{CH}_{4}$ & $\mathbf{H}_{2}$ & $\mathrm{H}_{2} \mathrm{O}$ \\
\hline 5 & 0,10 & 8,32 & 8,87 & 1,78 & 0,008 & 0,69 & 0,74 & 0,15 & 6,80 & 0,00 \\
\hline 12 & 0,08 & 8,23 & 9,29 & 1,88 & 0,007 & 0,69 & 0,78 & 0,16 & 6,89 & 0,00 \\
\hline 19 & 0,08 & 8,21 & 9,37 & 1,97 & 0,006 & 0,69 & 0,79 & 0,17 & 6,92 & 0,00 \\
\hline 26 & 0,07 & 8,31 & 8,95 & 1,97 & 0,006 & 0,69 & 0,74 & 0,16 & 6,81 & 0,00 \\
\hline 33 & 0,06 & 8,26 & 9,20 & 2,05 & 0,005 & 0,69 & 0,77 & 0,17 & 6,86 & 0,00 \\
\hline 40 & 0,06 & 8,23 & 9,33 & 2,07 & 0,005 & 0,69 & 0,78 & 0,17 & 6,90 & 0,00 \\
\hline 47 & 0,05 & 8,24 & 9,25 & 2,05 & 0,005 & 0,69 & 0,78 & 0,17 & 6,88 & 0,00 \\
\hline 54 & 0,06 & 8,17 & 9,57 & 2,07 & 0,005 & 0,69 & 0,81 & 0,18 & 6,96 & 0,00 \\
\hline 61 & 0,05 & 8,22 & 9,32 & 2,04 & 0,004 & 0,69 & 0,78 & 0,17 & 6,91 & 0,00 \\
\hline 68 & 0,06 & 8,23 & 9,27 & 2,04 & 0,005 & 0,69 & 0,78 & 0,17 & 6,89 & 0,00 \\
\hline 75 & 0,05 & 8,20 & 9,50 & 2,03 & 0,004 & 0,69 & 0,80 & 0,17 & 6,93 & 0,00 \\
\hline 82 & 0,05 & 8,30 & 9,09 & 2,00 & 0,004 & 0,69 & 0,76 & 0,17 & 6,83 & 0,00 \\
\hline 89 & 0,05 & 8,24 & 9,30 & 2,00 & 0,004 & 0,69 & 0,78 & 0,17 & 6,89 & 0,00 \\
\hline 90 & 0,05 & 8,24 & 9,30 & 2,00 & 0,004 & 0,69 & 0,78 & 0,17 & 6,89 & 0,00 \\
\hline
\end{tabular}


Tabela A 12 - Dados do ensaios de carburação simultânea à reforma de metano a $1050{ }^{\circ} \mathrm{C}$ e 30 min.

\begin{tabular}{|c|c|c|c|c|c|c|c|c|c|c|}
\hline \multicolumn{3}{|c|}{ Identificação do ensaio } & \multicolumn{4}{|c|}{ Dados DRI } & & & & \\
\hline Ensaio & \multicolumn{2}{|c|}{$\begin{array}{cc}\text { Icaçao do ensalo } \\
\text { Temperatura } & \text { Tempo } \\
\left({ }^{\circ} \mathrm{C}\right) & \text { (min) }\end{array}$} & $\begin{array}{c}\text { Massa } \\
\text { inicial (g) }\end{array}$ & \multirow{2}{*}{$\begin{array}{l}\text { Massa final } \\
\text { (g) }\end{array}$} & $\begin{array}{l}\text { C final } \\
\text { (\% massa) }\end{array}$ & $\begin{array}{c}\mathrm{m}_{\mathrm{DRI}} / \text { Vazão total } \\
\text { (g.min/NL) }\end{array}$ & & & & \\
\hline 13CF1050-30 & 1050 & 30 & 74,81 & & & 10,0 & & & & \\
\hline \multicolumn{11}{|c|}{ Dados gases } \\
\hline \multicolumn{4}{|c|}{ Vazões entrada (NL/min) } & \multirow{2}{*}{$\begin{array}{c}\text { Conversão } \mathrm{CH}_{4} \\
\text { média }\end{array}$} & \multicolumn{6}{|c|}{ Pressão parcial média (atm) } \\
\hline $\mathrm{H}_{2}$ & $\mathrm{CH}_{4}$ & $\mathrm{H}_{2} \mathrm{O}$ & Ar & & $\mathrm{CO}_{2}$ & Ar & CO & $\mathrm{CH}_{4}$ & $\mathbf{H}_{2}$ & $\mathrm{H}_{2} \mathrm{O}$ \\
\hline \multirow[t]{2}{*}{5,10} & 0,90 & 0,75 & 0,75 & 0,80 & $4,87 \mathrm{E}-04$ & 0,086 & 0,078 & 0,022 & 0,813 & 7,27E-03 \\
\hline & \multicolumn{4}{|c|}{ \%vol. - gases de saída seco - cromatografia gasosa } & \multicolumn{6}{|c|}{ Vazões saída (NL/min) } \\
\hline Tempo (min) & $\mathrm{CO}_{2}$ & $\mathrm{Ar}$ & $\mathrm{CO}$ & $\mathrm{CH}_{4}$ & $\mathrm{CO}_{2}$ & $\mathrm{Ar}$ & CO & $\mathrm{CH}_{4}$ & $\mathrm{H}_{2}$ & $\mathrm{H}_{2} \mathrm{O}$ \\
\hline 3 & 0,11 & 8,75 & 7,74 & 2,15 & 0,010 & 0,75 & 0,66 & 0,18 & 6,95 & 0,08 \\
\hline 10 & 0,06 & 8,57 & 8,02 & 2,05 & 0,005 & 0,75 & 0,70 & 0,18 & 7,13 & 0,04 \\
\hline 17 & 0,05 & 8,64 & 7,66 & 2,17 & 0,004 & 0,75 & 0,67 & 0,19 & 7,05 & 0,08 \\
\hline 24 & 0,05 & 8,59 & 7,76 & 2,33 & 0,004 & 0,75 & 0,68 & 0,20 & 7,10 & 0,07 \\
\hline 30 & 0,05 & 8,59 & 7,76 & 2,33 & 0,004 & 0,75 & 0,68 & 0,20 & 7,10 & 0,07 \\
\hline
\end{tabular}


Tabela A 13 - Dados do ensaios de carburação simultânea à reforma de metano a $1050{ }^{\circ} \mathrm{C}$ e 60 min.

\begin{tabular}{|c|c|c|c|c|c|c|c|c|c|c|}
\hline \multicolumn{3}{|c|}{ Identificação do ensaio } & \multicolumn{4}{|c|}{ Dados DRI } & & & & \\
\hline Ensaio & $\begin{array}{c}\text { Temperatura } \\
\left({ }^{\circ} \mathrm{C}\right) \\
\end{array}$ & $\begin{array}{c}\text { Tempo } \\
\text { (min) }\end{array}$ & $\begin{array}{c}\text { Massa } \\
\text { inicial (g) }\end{array}$ & $\begin{array}{c}\text { Massa final } \\
\text { (g) }\end{array}$ & $\begin{array}{c}\text { C final } \\
(\% \text { massa) }\end{array}$ & $\begin{array}{c}\mathrm{m}_{\mathrm{DRI}} / \text { Vazão total } \\
\text { (g.min/NL) }\end{array}$ & & & & \\
\hline 12CF1050-60 & 1050 & 60 & 72,11 & 72,62 & & 9,9 & & & & \\
\hline \multicolumn{11}{|c|}{ Dados gases } \\
\hline \multicolumn{4}{|c|}{ Vazões entrada (NL/min) } & Conversão & \multicolumn{6}{|c|}{ Pressão parcial média (atm) } \\
\hline $\mathbf{H}_{2}$ & $\mathrm{CH}_{4}$ & $\mathrm{H}_{2} \mathrm{O}$ & Ar & $\mathrm{CH}_{4}$ média & $\mathrm{CO}_{2}$ & Ar & CO & $\mathrm{CH}_{4}$ & $\mathrm{H}_{2}$ & $\mathrm{H}_{2} \mathrm{O}$ \\
\hline \multirow[t]{2}{*}{4,93} & 0,87 & 0,73 & 0,73 & 0,77 & $6,47 \mathrm{E}-04$ & 0,090 & 0,080 & 0,026 & 0,803 & $8,45 \mathrm{E}-03$ \\
\hline & \multicolumn{4}{|c|}{ \%vol. - gases de saída seco - cromatografia gasosa } & \multicolumn{6}{|c|}{ Vazões saída (NL/min) } \\
\hline Tempo (min) & $\mathrm{CO}_{2}$ & $\mathrm{Ar}$ & CO & $\mathrm{CH}_{4}$ & $\mathrm{CO}_{2}$ & $\mathrm{Ar}$ & Co & $\mathrm{CH}_{4}$ & $\mathrm{H}_{2}$ & $\mathrm{H}_{2} \mathrm{O}$ \\
\hline 4 & 0,09 & 8,44 & 8,20 & 2,51 & 0,008 & 0,73 & 0,70 & 0,22 & 7,01 & 0,01 \\
\hline 11 & 0,07 & 9,13 & 7,77 & 2,50 & 0,006 & 0,73 & 0,62 & 0,20 & 6,40 & 0,10 \\
\hline 18 & 0,06 & 9,09 & 7,88 & 2,58 & 0,005 & 0,73 & 0,63 & 0,21 & 6,44 & 0,09 \\
\hline 25 & 0,06 & 9,01 & 8,23 & 2,68 & 0,005 & 0,73 & 0,66 & 0,22 & 6,52 & 0,06 \\
\hline 32 & 0,07 & 9,04 & 8,18 & 2,73 & 0,005 & 0,73 & 0,66 & 0,22 & 6,49 & 0,06 \\
\hline 39 & 0,06 & 9,09 & 7,97 & 2,70 & 0,005 & 0,73 & 0,64 & 0,22 & 6,44 & 0,08 \\
\hline 46 & 0,06 & 9,07 & 8,05 & 2,70 & 0,005 & 0,73 & 0,64 & 0,22 & 6,46 & 0,08 \\
\hline 53 & 0,07 & 9,04 & 8,24 & 2,70 & 0,005 & 0,73 & 0,66 & 0,22 & 6,49 & 0,06 \\
\hline 60 & 0,07 & 9,04 & 8,24 & 2,70 & 0,005 & 0,73 & 0,66 & 0,22 & 6,49 & 0,06 \\
\hline
\end{tabular}


Tabela A 14 - Dados do ensaios de carburação simultânea à reforma de metano a $1050{ }^{\circ} \mathrm{C}$ e 90 min.

\begin{tabular}{|c|c|c|c|c|c|c|c|c|c|c|}
\hline \multicolumn{3}{|c|}{ Identificação do ensaio } & \multicolumn{4}{|c|}{ Dados DRI } & & & & \\
\hline Ensaio & $\begin{array}{c}\text { Temperatura } \\
\left({ }^{\circ} \mathrm{C}\right)\end{array}$ & $\begin{array}{c}\text { Tempo } \\
\text { (min) }\end{array}$ & $\begin{array}{c}\text { Massa } \\
\text { inicial (g) }\end{array}$ & $\begin{array}{l}\text { Massa final } \\
\text { (g) }\end{array}$ & $\begin{array}{c}\text { C final } \\
\text { (\% massa) }\end{array}$ & $\begin{array}{c}\mathrm{m}_{\mathrm{DRR} /} / \text { Vazão total } \\
\text { (g.min/NL) }\end{array}$ & & & & \\
\hline 09CF1050-90 & 1050 & 90 & 73,00 & 74,71 & & 10,1 & & & & \\
\hline \multicolumn{11}{|c|}{ Dados gases } \\
\hline \multicolumn{4}{|c|}{ Vazões entrada (NL/min) } & \multirow{2}{*}{$\begin{array}{c}\text { Conversão } \mathrm{CH}_{4} \\
\text { média }\end{array}$} & \multicolumn{6}{|c|}{ Pressão parcial média (atm) } \\
\hline $\mathrm{H}_{2}$ & $\mathrm{CH}_{4}$ & $\mathrm{H}_{2} \mathrm{O}$ & $\mathrm{Ar}$ & & $\mathrm{CO}_{2}$ & Ar & CO & $\mathrm{CH}_{4}$ & $\mathrm{H}_{2}$ & $\mathrm{H}_{2} \mathrm{O}$ \\
\hline \multirow[t]{2}{*}{4,90} & 0,86 & 0,72 & 0,72 & 0,81 & $6,75 \mathrm{E}-04$ & 0,082 & 0,078 & 0,027 & 0,812 & 2,92E-03 \\
\hline & \multicolumn{4}{|c|}{ \%vol. - gases de saída seco - cromatografia gasosa } & \multicolumn{6}{|c|}{ Vazões saída (NL/min) } \\
\hline Tempo (min) & $\mathrm{CO}_{2}$ & $\mathrm{Ar}$ & CO & $\mathrm{CH}_{4}$ & $\mathrm{CO}_{2}$ & $\mathrm{Ar}$ & CO & $\mathrm{CH}_{4}$ & $\mathrm{H}_{2}$ & $\mathrm{H}_{2} \mathrm{O}$ \\
\hline 3 & 0,02 & 8,78 & 6,76 & 2,61 & 0,002 & 0,72 & 0,55 & 0,21 & 6,62 & 0,16 \\
\hline 10 & 0,04 & 8,72 & 7,58 & 2,65 & 0,004 & 0,72 & 0,63 & 0,22 & 6,69 & 0,09 \\
\hline 17 & 0,05 & 8,74 & 7,59 & 2,72 & 0,004 & 0,72 & 0,63 & 0,22 & 6,68 & 0,09 \\
\hline 24 & 0,06 & 8,11 & 8,08 & 2,77 & 0,005 & 0,72 & 0,72 & 0,25 & 7,27 & 0,00 \\
\hline 31 & 0,07 & 8,15 & 7,85 & 2,73 & 0,006 & 0,72 & 0,69 & 0,24 & 7,23 & 0,02 \\
\hline 38 & 0,06 & 8,25 & 7,52 & 2,66 & 0,005 & 0,72 & 0,66 & 0,23 & 7,12 & 0,06 \\
\hline 45 & 0,06 & 8,19 & 7,78 & 2,71 & 0,006 & 0,72 & 0,68 & 0,24 & 7,19 & 0,03 \\
\hline 52 & 0,07 & 8,17 & 7,87 & 2,66 & 0,006 & 0,72 & 0,69 & 0,23 & 7,21 & 0,02 \\
\hline 59 & 0,07 & 8,10 & 8,02 & 2,68 & 0,006 & 0,72 & 0,71 & 0,24 & 7,28 & 0,00 \\
\hline 66 & 0,08 & 8,10 & 8,09 & 2,81 & 0,007 & 0,72 & 0,72 & 0,25 & 7,29 & 0,00 \\
\hline 73 & 0,07 & 8,24 & 7,48 & 2,70 & 0,006 & 0,72 & 0,65 & 0,24 & 7,13 & 0,06 \\
\hline 80 & 0,08 & 8,17 & 7,93 & 2,75 & 0,007 & 0,72 & 0,70 & 0,24 & 7,22 & 0,01 \\
\hline 87 & 0,09 & 8,07 & 8,29 & 2,79 & 0,008 & 0,72 & 0,74 & 0,25 & 7,32 & 0,00 \\
\hline 90 & 0,09 & 8,07 & 8,29 & 2,79 & 0,008 & 0,72 & 0,74 & 0,25 & 7,32 & 0,00 \\
\hline
\end{tabular}

